\title{
A Methodology for Probabilistic Performance-Based Seismic Risk Assessment of Bridge Inventories
}

\author{
A thesis submitted to \\ the Faculty of Graduate Studies and Research \\ in Partial Fulfillment of the requirements for the degree \\ Masters of Applied Science
}

by

Charlotte L. Waller

Department of Civil and Environmental Engineering

Carleton University

Ottawa-Carleton Institute for Civil and Environmental Engineering

November 2010

Copyright $(\mathcal{C} 2010$, Charlotte L. Waller 
Library and Archives

Canada

Published Heritage Branch

395 Wellington Street Ottawa ON K1A ON4

Canada
Bibliotheque et

Archives Canada

Direction du

Patrimoine de l'édition

395, rue Wellington

Ottawa ON K1A ON4

Canada
Your file Votre référence

ISBN: 978-0-494-79557-6

Ourfile Notre référence

ISBN: 978-0-494-79557-6
NOTICE:

The author has granted a nonexclusive license allowing Library and Archives Canada to reproduce, publish, archive, preserve, conserve, communicate to the public by telecommunication or on the Internet, loan, distribute and sell theses worldwide, for commercial or noncommercial purposes, in microform, paper, electronic and/or any other formats.

The author retains copyright ownership and moral rights in this thesis. Neither the thesis nor substantial extracts from it may be printed or otherwise reproduced without the author's permission.
AVIS:

L'auteur a accordé une licence non exclusive permettant à la Bibliothèque et Archives Canada de reproduire, publier, archiver, sauvegarder, conserver, transmettre au public par télécommunication ou par l'Internet, prêter, distribuer et vendre des thèses partout dans le monde, à des fins commerciales ou autres, sur support microforme, papier, électronique et/ou autres formats.

L'auteur conserve la propriété du droit d'auteur et des droits moraux qui protège cette thèse. $\mathrm{Ni}$ la thèse ni des extraits substantiels de celle-ci ne doivent être imprimés ou autrement reproduits sans son autorisation.
In compliance with the Canadian Privacy Act some supporting forms may have been removed from this thesis.

While these forms may be included in the document page count, their removal does not represent any loss of content from the thesis.
Conformément à la loi canadienne sur la protection de la vie privée, quelques formulaires secondaires ont été enlevés de cette thèse.

Bien que ces formulaires aient inclus dans la pagination, il n'y aura aucun contenu manquant. 


\begin{abstract}
Over the past several decades, many structural lessons have been learned from disastrous seismic events resulting in major advances in the understanding of seismic response behaviour and performance of bridges. Over the years, these advances and improved design methods have been implemented in numerous revisions of bridge design standards. From damage observations and analysis, various deficiencies, in terms of seismic performance, have been identified in bridges designed based on specifications from bridge design standards from different time periods. Knowing there are seismic deficiencies in our existing aging infrastructure, it is important to have a methodology to evaluate and quantify the seismic risk and vulnerability of the existing bridge systems. In current state-ofpractice, individual bridges of high priority are selected for detailed examination and review of their structural integrity. However, due to the large number of bridges involved and the limitation of resources available, there is a need to prioritize what bridges undergo complete structural reviews and possible rehabilitations. This is done through physical site inspections and assessments by computer structural analysis. Although this approach gives detailed information on the risk of individual bridges, it does not give high level assessment information on the risk and vulnerability of the entire bridge infrastructure from a system perspective. Probabilistic performance-based seismic risk assessment methodologies can be used to identify the probable performance of selected bridges. The probabilistic framework involves four interim steps of site hazard analysis, structural response analysis, damage analysis and loss analysis. It requires the
\end{abstract}


evaluation of the seismic hazard at a bridge site, the analysis of the bridge responses to ground motion excitations compatible with the seismic hazard, the probability of damage associated with the calculated responses by using fragility curves, and the evaluation of losses resulting from expected damage levels. In this study, the probabilistic performance-based seismic risk assessment methodology has been adapted and further developed to formulate a new evaluation approach suitable for quick assessment of large bridge inventories in a city, regional or national network. The new quick assessment approach does not require detailed non-linear time history analysis of all evaluated bridges. Nonlinear time-history analysis of selected representative bridges has been carried out to calibrate the quick assessment methodology. Fragility relationships relating potential or probability of damage to easily identified or determined structural performance characteristic parameters of evaluated bridges are developed.

In collaboration with the City of Ottawa, a pilot study of seismic risk assessment of a sample inventory of bridges has been conducted by using the new quick assessment methodology. From the assessment results, an order or priority list of bridges can be established. The system perspective information and assessment results would help with better decision making on resource allocation for more efficient and effective bridge infrastructure maintenance and management. 


\section{Acknowledgement}

I would also like to thank my friends and loved ones for their support and encouragement during my research as well as my advisor Dr. David T. Lau for his support and direction. Special thanks go out to Dr. Jack Zhao and Ms. Carina Duclos at the City of Ottawa for providing me with the necessary sample bridge inventory information, and to Dr. John Adams of the Geological Survey of Canada for providing the seismic hazard information of Ottawa needed for achieving the objectives of this research. I would also like to acknowledge the financial support making this research possible provided by the Canadian Seismic Research Network and the NSERC Strategic Network Grant Program. 
1. Introduction

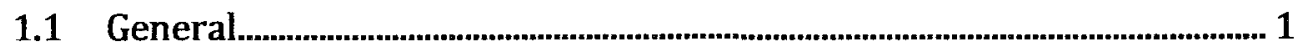

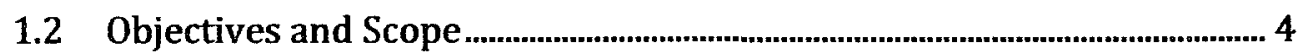

2. Seismic Probabilistic Performance-Based Risk Assessment Methodology

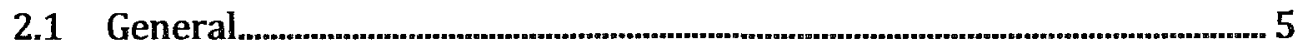

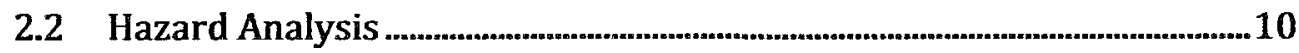

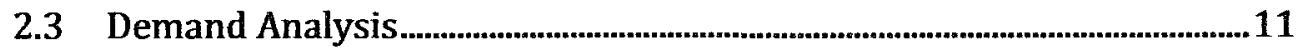

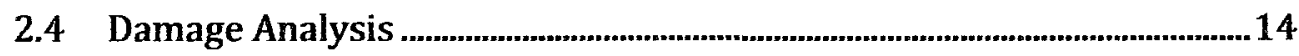

2.4.1 Interim Damage Models...............................................................15

2.4.1.1 Experimentally Developed Fragility Curves.............. 18

2.4.1.2 Damage Curves Developed from In-Field

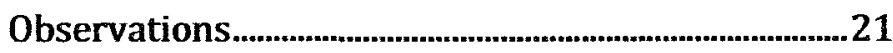

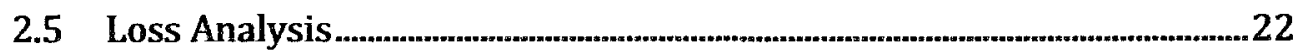

3. Seismic Probabilistic Performance-Based Assessment of Canadian Bridges

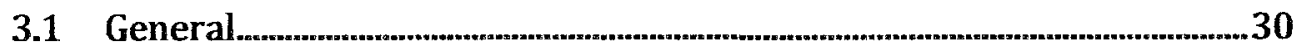

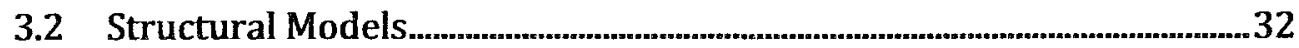

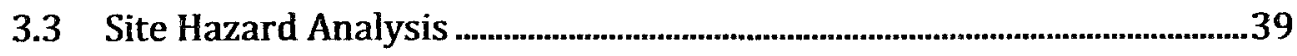

3.3.1 Assessment of Site Seismic Hazard ..................................................39

3.3.2 Simulated Ground Motions......................................................................41 
3.3.3 Scale Ground Models ...................................................................................43

3.3.4 Hazard Curve .....................................................................................................44

3.4 Demand Analysis .........................................................................................................4

3.5 Probabilistic Damage Evaluation .............................................................................46

3.6 Discussion …....................................................................................................................

4. Performance-Based Seismic Risk Evaluation of Sample Bridge Inventory

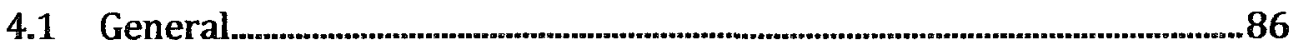

4.2 Sample Inventory

4.3 Seismic Risk Assessment of Sample Bridge Inventory ................................91

4.3.1 Fragility Relationship Based on Pier Longitudinal

Reinforcement Ratio...................................................................................93

4.3.2 Fragility Relationship Based on Span over Pier Height Ratio..96

\subsubsection{Fragility Relationship Based on Pier Transverse}

Reinforcement Ratio .................................................................................98

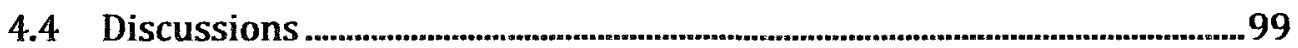

5. Summary and Recommendations

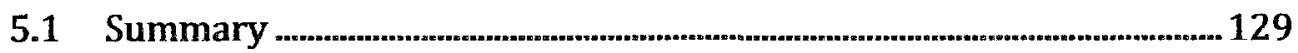

5.2 Recommendations..............................................................................................

References ….................................................................................................. 134 


\section{LIST OF TABLES}

Table 2.1: Damage states and ductility capacities for bridge columns .25

Table 3.1: General characteristics of Blair Bridge .50

Table 3.2: General characteristics of Nicholas Bridge .51

Table 3.3: Properties of hollow core deck section for Blair Bridge .52

Table 3.4: Properties of hollow core deck section for Nicholas Bridge. .53

Table 4.1: Sample Bridge Inventory General Properties. 102

Table 4.2: Probability of Spalling and Longitudinal Bar Buckling for Low, Moderate and Extreme Earthquake Events for the Evaluated Bridges 103

Table 4.3: Estimated Probabilities of Spalling and Longitudinal Bar Buckling based on Effective Longitudinal Reinforcement Ratios 104

Table 4.4: Estimated Probabilities of Spalling and Longitudinal Bar Buckling based on Effective Span over Pier Height Ratios. 105

Table 4.5: Estimated Probabilities of Spalling and Longitudinal Bar Buckling based on Effective Transverse Reinforcement Ratios 106

Table 4.6: Summary of Projected Performance Probabilities for Sample Inventory 107 
Table 4.7: Priority List of Bridge Inventory to Improve Life Safety 108

Table 4.8: Priority List of Bridge Inventory to Minimize Repair Costs 109 


\section{LIST OF FIGURES}

Figure 2.1: General fragility curve for concrete cover spalling for rectangular-

reinforced columns

Figure 2.2: Fragility curve for concrete cover spalling for spiral-reinforced concrete columns .27

Figure 2.3: Fragility curve for longitudinal bar buckling for rectangularreinforced concrete columns 28

Figure 2.4: Fragility curve for longitudinal bar buckling for spiral-reinforced concrete columns .29

Figure 3.1: Blair Road Bridge elevation and profile .54

Figure 3.2: Blair Road Bridge deck and typical column cross-section .55

Figure 3.3: Nicholas Street Bridge elevation and profile .56

Figure 3.4: Nicholas Street Bridge deck and typical column cross-section 57

Figure 3.5: First modal shapes for Blair Bridge modeled scenarios. .58

Figure 3.6: First modal shape for Nicholas Street Bridge .59

Figure 3.7: Uniform hazard response spectra for Ottawa, Ontario (Site Class

C) for $50 \%, 10 \%$ and $2 \%$ in 50 -years probability of exceedance 60 
Figure 3.8: Response spectrum for SIMQKE generated ground motions compared to Ottawa $2 \%$ in 50 -years UHS

Figure 3.9: Response spectrum for SIMQKE generated ground motions compared to Ottawa $10 \%$ in 50 -years UHS .62

Figure 3.10: Response spectrum for SIMQKE generated ground motions compared to Ottawa $50 \%$ in 50 -years UHS

Figure 3.11: Simulated ground motions for $2 \%$ in 50 -years probability of exceedance for the Ottawa region .64

Figure 3.12: Simulated ground motions for $10 \%$ in 50 -years probability of exceedance for the Ottawa region

Figure 3.13: Simulated ground motions for $50 \%$ in 50 -years probability of exceedance for the Ottawa region .66

Figure 3.14: Scaled response spectrum from Val-des-Bois Earthquake ground motions compared to Ottawa $2 \%$ in 50 -years UHS

Figure 3.15: Scaled Val-des-Bois Earthquake ground motion RE01 scaled to match the Ottawa $2 \%$ in 50 -years UHS .68

Figure 3.16: Scaled Val-des-Bois Earthquake ground motion RE01 scaled to match the Ottawa $10 \%$ in 50 -years UHS .69 
Figure 3.17: Scaled Val-des-Bois Earthquake ground motion RE01 scaled to match the Ottawa $50 \%$ in 50 -years UHS

Figure 3.18: Scaled Val-des-Bois Earthquake ground motion RE02 scaled to match the Ottawa $2 \%$ in 50 -years UHS .71

Figure 3.19: Scaled Val-des-Bois Earthquake ground motion RE02 scaled to match the Ottawa $10 \%$ in 50 -years UHS .72

Figure 3.20: Scaled Val-des-Bois Earthquake ground motion RE02 scaled to match the Ottawa $50 \%$ in 50 -years UHS .73

Figure 3.21: Blair Bridge hazard curves. 74

Figure 3.22: Nicholas Bridge hazard curve .75

Figure 3.23: Blair Bridge demand curves .76

Figure 3.24: Nicholas Bridge demand curve .77

Figure 3.25: Probable drift ratio of the Blair Bridge under low, moderate and high probable events. .78

Figure 3.26: Probable drift ratio of the Nicholas Bridge under low, moderate and high probable events 79

Figure 3.27: Mean annual frequency of exceeding a given drift ratio for Blair Bridge 80 
Figure 3.28: Mean annual frequency of exceeding a given drift ratio for Nicholas Bridge .81

Figure 3.29: Damage fragility curve based on material and structural properties of the typical Blair Bridge pier

Figure 3.30: Damage fragility curve based on material and structural properties of the typical Nicholas Bridge pier .83

Figure 3.31: Probability of concrete spalling or longitudinal bar buckling given a level of seismic event for Blair Bridge

Figure 3.32: Probability of concrete spalling or longitudinal bar buckling given a level of seismic event for Nicholas Bridge. .85

Figure 4.1: Effective tributary apan length supported by Pier 2 of the Blair Road Bridge. 110

Figure 4.2: Relationship between $\rho_{\mathrm{L}}^{*}$ and probability of spalling for a low seismic event $(50 \% / 50$ years $)$

Figure 4.3: Relationship between $\rho_{\mathrm{L}}{ }^{*}$ and probability of spalling for a moderate seismic event $(10 \% / 50$ years $)$ 112

Figure 4.4: Relationship between $\rho_{\mathrm{L}}{ }^{*}$ and probability of spalling for an extreme seismic event $(2 \% / 50$ years $)$ 
Figure 4.5: Relationship between $\rho_{\mathrm{L}}{ }^{*}$ and probability of longitudinal bar buckling for a low seismic event $(50 \% / 50$ years)

Figure 4.6: Relationship between $\rho_{\mathrm{L}}{ }^{*}$ and probability of longitudinal bar buckling for a moderate seismic event $(10 \% / 50$ years $)$

Figure 4.7: Relationship between $\rho_{\mathrm{L}}{ }^{*}$ and probability of longitudinal bar buckling for an extreme seismic event ( $2 \% / 50$ years) 116

Figure 4.8: Relationship between $\operatorname{Span} / L^{*}$ and probability of spalling for a low seismic event $(50 \% / 50$ years $)$

Figure 4.9: Relationship between $\operatorname{Span} / \mathrm{L}^{*}$ and probability of spalling for a moderate seismic event $(10 \% / 50$ years $)$ 118

Figure 4.10: Relationship between Span $/ L^{*}$ and probability of spalling for an extreme seismic event ( $2 \% / 50$ years)

Figure 4.11: Relationship between Span $/ \mathrm{L}^{*}$ and probability of longitudinal bar buckling for a low seismic event (50\%/50 years) 120

Figure 4.12: Relationship between Span $/ \mathrm{L}^{*}$ and probability of longitudinal bar buckling for a moderate seismic event ( $10 \% / 50$ years)

Figure 4.13: Relationship between $\operatorname{Span} / \mathrm{L}^{*}$ and probability of longitudinal bar buckling for an extreme seismic event ( $2 \% / 50$ years) 
Figure 4.14: Relationship between $\rho_{s}^{*}$ and probability of spalling for a low seismic event $(50 \% / 50$ years $)$

Figure 4.15: Relationship between $\rho_{\mathrm{S}}{ }^{*}$ and probability of spalling for a moderate seismic event $(10 \% / 50$ years $)$

Figure 4.16: Relationship between $\rho_{\mathrm{s}}{ }^{*}$ and probability of spalling for an extreme seismic event $(2 \% / 50$ years $)$

Figure 4.17: Relationship between $\rho_{\mathrm{s}}{ }^{*}$ and probability of longitudinal bar buckling for a low seismic event $(50 \% / 50$ years) 126

Figure 4.18: Relationship between $\rho_{\mathrm{S}}{ }^{*}$ and probability of longitudinal bar buckling for a moderate seismic event ( $10 \% / 50$ years) 127

Figure 4.19: Relationship between $\rho_{\mathrm{s}}^{*}$ and probability of longitudinal bar buckling for an extreme seismic event (2\%/50 years) 128 


\section{Nomenclature}

$\mathrm{A}_{\mathrm{g}} \quad$ Gross area of concrete cross-section

$A_{n} \quad$ Amplitude

$A_{v, g} \quad$ Gross shear area

$A_{v, e f f} \quad$ Effective shear area

CCDF Complimentary Cumulative Distribution Function

$d_{b} \quad$ Nominal bar diameter of longitudinal reinforcement

$d v^{L S} \quad$ Decision variable limit state

D Column diameter or depth

DM Damage Measures

$\widehat{\mathrm{DM}} \quad$ Median Damage Measures

DV Decision Variables

E Modulus of elasticity

EDP Engineering Demand Parameter

EDP $\quad$ Median Engineering Demand Parameter

$\mathbf{f}_{c} \quad$ Compressive stress of concrete

$f_{\text {ye }} \quad$ Effective yield stress

$f(Y) \quad$ Probability density function of variable $Y$

$G(X) \quad$ Cumulative distribution function of intermediate variable X

$G(\omega) \quad$ Stationary power spectral density function

$I_{g} \quad$ Gross moment of inertia

IM Intensity Measures 
$I(t) \quad$ Envelope function

$J_{\text {eff }} \quad$ Effective torsional constant

$J_{g} \quad$ Gross torsional constant

L Distance from the point of fixity to the point of inflection

$L_{P} \quad$ Plastic hinge length

M Earthquake magnitude

$M_{y i} \quad$ Ideal yield moment

P Axial load

PDF Probability Density Function

PGA Peak Ground Acceleration

PGV Peak Ground Velocity

$\mathrm{R}$ Distance from earthquake

$\mathrm{S}_{\mathrm{a}}\left[\mathrm{T}_{1}\right] \quad$ First-mode pseudo-spectral acceleration

Span/L Span over pier height ratio

Span $/ L^{*} \quad$ Effective span over pier height ratio

$\mathrm{z}(\mathrm{t}) \quad$ Simulated motion

$\Delta_{\text {bb_act }} \quad$ Actual displacement at the initiation of longitudinal bar buckling

$\Delta_{\text {bb calc }} \quad$ Estimated displacement at initiation of longitudinal bar buckling

$\Delta_{\text {damage calc }}$ Estimated displacement at the initiation of damage

$\Delta_{\text {demand }} \quad$ Displacement demand

$\Delta_{\text {spall_act } \quad \text { Actual displacement at initiation of concrete spalling }}$

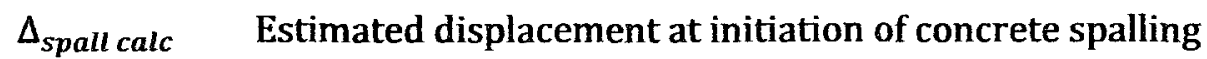

$\lambda \quad$ Mean rate 


$\begin{array}{ll}\rho_{L} & \text { Longitudinal reinforcement ratio } \\ \rho_{L}{ }^{*} & \text { Effective longitudinal reinforcement ratio } \\ \rho_{s} & \text { Volumetric transverse reinforcement ratio } \\ \rho_{S}^{*} & \text { Effective volumetric transverse reinforcement ratio } \\ \sigma & \text { Dispersion } \\ \Phi_{y i} & \text { Ideal yield curvature } \\ \varphi_{n} & \text { Phase angle }\end{array}$




\section{Chapter 1 \\ Introduction}

\subsection{General}

In Canada and other parts of the world, it is recognized that there are seismic deficiencies in existing aging bridge infrastructure. To help improve public safety and emergency preparedness, it is important to have a methodology to evaluate and quantify the seismic risk and vulnerability of the existing bridge systems. Due to the large number of bridges in existing infrastructure inventories and the limitation of resources available, there is a need to prioritize which bridges should be selected to undergo structural assessments by detailed analysis and possible rehabilitations.

In current practice, seismic risk of bridges is determined through detailed seismic performance evaluations carried out by structural engineers. These evaluations are 
time consuming and expensive. The outcome of these evaluations is typically presented in the form of a ratio of demand over capacity of various structural components. The components identified as vulnerable are those with a demand over capacity ratio greater than one. A limitation in this approach is that while it identifies the components likely to fail, it does not identify how extensive the failure will be. For example, for a pier deemed vulnerable, failure could be in the form of severe concrete spalling, longitudinal bar buckling or longitudinal bar fracture. If more details of the damage potential of individual structural members are known such as, the probability of a particular damage state of an individual structural component, more accurate assessment results can be obtained which lead to more reliable priority ordering of deficient bridges based on risk consideration. On this basis, resources can then be better allocated in the mitigation of the seismic risk of bridges.

The limitations to the existing risk assessment process has led to the development of performance-based design (PBD), or review, which is, as the name suggests, designing to meet specific performance objectives, such as preventing or limiting the amount of spalling of concrete under a rare loading event. Performance-based earthquake engineering (PBEE) is a subset of performance-based design in which the performance objectives specified are related to seismic events. Performancebased earthquake engineering involves the prediction of damage states and calculation of the probability of reaching a given damage state under particular seismic events (Berry and Eberhard, 2003). 
The PBEE design methodology is more extensive and comprehensive than the typical prescriptive approaches currently found in most design codes. The PBEE methodology includes four standard phases. The first is seismic hazard analysis of the site where the structure is located or is to be built. The second phase is determination of the structural response of the structure to the seismic hazard through structural analysis by a numerical model of the structure. The third phase is the damage analysis stage in which the probability of a damage level occurring is assessed for the loading level of concern. The final stage is the loss analysis in which the probability of direct and indirect economic losses due to damage and disruption to operation is assessed (Mackie et al., 2008).

A practical limitation of the current evaluation practice is that the current seismic risk assessment approach requires every bridge to be evaluated separately in details in order to identify its vulnerability. To quantify the risk and vulnerability of the bridges in the inventory stock of a city, a region or a national network, the current approach requires tremendous amount of resources. There are not enough resources available for this to be realistic. Most bridges in a region's bridge inventory can be grouped into categories based on particular shared characteristics. It can be expected that bridges that have certain characteristics in common will perform in a similar manner under particular earthquake loading. Theoretically, performing performance-based assessments on a representative group of bridges would provide the necessary information needed to develop structural performance relationships which can be used to estimate the performance of other bridges in the system based on shared characteristics to give a system perspective on the overall 
risk and vulnerability of bridges in an inventory or network. This system perspective assessment results could be used to help with better decision making on resource allocation for bridge infrastructure maintenance and management.

\subsection{Objectives and Scope}

The objectives of this thesis are to adapt and apply a PBEE risk assessment approach to Canadian bridges, and to develop a process by which these evaluations could be used to calibrate a seismic risk evaluation methodology for assessing the vulnerability of a bridge inventory. No similar work has been performed before in terms of developing a methodology for estimating the vulnerability of an entire inventory rather than just a single structure.

This thesis is composed of five chapters. Following the Introduction in Chapter 1, Chapter 2 identifies and describes the stages of a general PBEE methodology. Chapter 3 describes the application of a PBEE methodology to two representative Ottawa bridges. Chapter 4 discusses the development and calibration of a new quick evaluation methodology for probabilistic seismic risk assessment of bridge inventories, and its application to the assessment of the vulnerability of bridges in a sample inventory of bridges in the City of Ottawa. Chapter 5 provides a summary and recommendations for future work. 


\section{Chapter 2 \\ Seismic Probabilistic Performance Based Risk Assessment Methodology}

\subsection{General}

In earthquake engineering, performance-based design methodologies have been developed by several research groups of which their applications have mainly focused on the design or assessment of buildings. Recently the Pacific Earthquake Engineering Research Center (PEER), in California, has initiated to develop a probabilistic performance-based approach for the design and assessment of bridges. The goal of the PEER methodology is to realize a full probabilistic design and evaluation of earthquake resistance of bridge structures and systems by decoupling the problem into smaller and more clearly defined steps (hazard analysis, demand analysis, damage analysis and loss analysis) (Mackie and Stojadinovic, 2005).

The PEER approach utilizes the total probability theorem to de-aggregate the PBEE problem into several interim probabilistic models. The first of these models is the 
seismic hazard model for which the probable seismic hazard intensity measures (IMs) of the site are evaluated. The most common forms of IMs for a seismic probabilistic analysis are: peak ground acceleration (PGA), peak ground velocity (PGV), and first-mode pseudo-spectral acceleration $\left(\mathrm{S}_{\mathrm{a}}\left(\mathrm{T}_{1}\right)\right.$ ) (Mackie et al., 2008).

Following the hazard model a demand model is developed which correlate IMs and engineering demand parameters (EDPs) which represent the structure's response to a particular loading and typically come in the form of displacement, drift ratio, strain, curvature, moment, and residual deformation (Mackie et al., 2008).

The last two stages in the performance-based framework are the damage and loss analysis models. The damage model gives an indication of the level of damage that can be expected in the structure as related to the structural response that is determined from the demand model. The damage model relates EDPs to damage measures (DMs) which are typically observable damage states of structural components, such as concrete spalling and reinforcement bar buckling. Alternatively, DMs may include the loss of live-load or gravity-load-carrying capacity. In the loss analysis phase, the damage models are used to evaluate the loss in performance, evaluated in terms of decision variables (DVs). Typical DVs include repair cost, downtime, repair time, and loss of life. (Mackie et al., 2008)

Each of the above mentioned models can be mathematically represented by distribution functions. Equations $2-1$ to $2-3$, developed from the total probability theory, represent the complementary cumulative distribution functions (CCDFs) for 
these interim stages. These CCDFs are used to calculate the total probability that a variable (EDP, DM or DV) exceeds a particular level. In Equations 2-1 to 2-3, $G(X)$ represents the CCDF of intermediate variable X (DV, DM, or EDP); $G(X \mid Y)$ represents the CCDF of $X$ conditioned on intermediate variable $Y$ (DM, EDP, or IM); and $f(Y)$ is the probability density function (PDF) of variable Y. The corresponding PDF of each interim model is simply the derivative of the CCDF. For example, the PDF for EDP is $f(E D P)=\left|\frac{d G(E D P)}{d E D P}\right|$ (Mackie et al., 2008).

$$
\begin{aligned}
& G(E D P)=\int_{0}^{\infty} G(E D P \mid I M) f(I M) d I M \\
& G(D M)=\int_{0}^{\infty} G(D M \mid E D P) f(E D P) d E D P \\
& G(D V)=\int_{0}^{\infty} G(D V \mid D M) f(D M) d D M
\end{aligned}
$$

To summarize the overall mathematical process, Equation 2-3 can be expanded to Equation 2-4 which represents the total probability that a DV will be exceeded.

$$
\begin{aligned}
& G(D V) \\
& =\iiint_{0}^{\infty} G(D V \mid D M)\left|\frac{d G(D M \mid E D P)}{d D M}\right|\left|\frac{d G(E D P \mid I M)}{d E D P}\right| f(I M) d I M d E D P d D M
\end{aligned}
$$

In the above equations, it is assumed that $I M$ is a random variable that represents the value of the intensity of the impending earthquake. It is also common to introduce a probabilistic occurrence model to describe the probability of occurrence of earthquakes of varying intensity. This leads to the expression of the outcome of the PBEE methodology in the form of mean annual frequency of exceedance as 
shown in Equation 2-5. In this report the mean rate is represented by variable $\lambda$. The mean rate as a function of $I M$, namely $\lambda(I M)$, is interpreted as a seismic hazard curve, which is determined, e.g., by probabilistic seismic hazard analysis. Notably, $\lambda(I M)$ is interpreted as a cumulative distribution function that is differentiated with respect to $I M$ before replacing $f(I M)$ in Equation 2-4.

$$
\begin{aligned}
& \lambda_{D V}\left(d v^{L S}\right) \\
& =\iiint_{0}^{\infty} G(D V \mid D M)|d G(D M \mid E D P)||d G(E D P \mid I M)||d \lambda(\mid \mathrm{M})|
\end{aligned}
$$

The outcome of this methodology can also be defined as the conditional probability of exceeding a single (scalar) decision limit state $\left(d v^{L S}\right)$ given an earthquake intensity value $i m$ as shown in Equation 2-6.

$$
\begin{aligned}
& P\left(D V>d v^{L S} \mid I M=i m\right) \\
& \quad=\iint G(D V \mid D M) \mid d G(D M|E D P||d G(E D P \mid I M)|
\end{aligned}
$$

Solutions of the above form of equations can be obtained by numerical integration or Monte Carlo simulation. However, closed form solutions have been developed (Mackie et al. (2008); Jalayer et al. (2003)] which greatly increase the utility of the PEER methodology. The median decision fragility curve (complementary CDF) for an arbitrary DV limit state $\left(d v^{L S}\right)$ is given by Equation 2-7. This closed-form formulation has numerous assumptions, but is the most readily implementable in extensive loss simulations by computers. The numerical integration formulation is 
more general but requires more input parameters for each of the intermediate models and is more computationally demanding. In the closed form simplified solutions, the following assumptions are made: (1) the conditional distribution of intermediate variable $\mathrm{X}$ given an intermediate variable $\mathrm{Y}$ can be modeled by the lognormal distribution, and (2) the conditional dispersion of an intermediate variable $\mathrm{X}$ given an intermediate variable $\mathrm{Y}$ is constant (homoskedastic) over the range of Y considered (Mackie et al., 2008). The closed form solution facilitates the generation of required decision fragility curves. The closed form fragility relationship is shown in Equation 2-7. The details of the coefficients A, b, C, d, E and f in Equation 2-7, which are parameters used in the seismic hazard, damage and loss models, are presented in later sections in this Chapter.

$$
\begin{aligned}
& P\left(D V>d v^{L S} \mid I M=i m\right) \\
& =1-\Phi\left[\frac{\ln \left(d v^{L S}\right)-(E+f C+f A d+F d b \ln (i m))}{\sqrt{D^{2} f^{2} \sigma_{E D P \mid I M}^{2}+f^{2} \sigma_{D M \mid E D P}^{2}+\sigma_{D V \mid D M}^{2}}}\right]
\end{aligned}
$$

where $\Phi()$ : standard normal distribution function

$\sigma_{E D P \mid I M}:$ standard deviation of the EDPs

$\sigma_{D M \mid E D P}:$ standard deviation of the DMs

$\sigma_{D V \mid D M}:$ standard deviation of the DVs

Medina (2002) observed that the closed-form solution developed by Jalayer and Cornell (2003) was reasonably close to the results obtained by numerical 
integration. However, the results indicated a strong sensitivity to the estimated standard deviation that is assumed to be constant with respect to the intensity level (one of the assumptions underlying the closed-form solution).

\subsection{Hazard Analysis}

As discussed earlier, the first step in the performance-based seismic bridge design framework is developing a hazard model for the bridge site. This model identifies the frequency at which seismic events of varying intensity are expected to occur. It is important to select a representative IM for the site's seismic risks that minimizes uncertainty in the probability analysis. Various sources have identified the first mode $5 \%$ damped elastic spectral acceleration of the structure $\left(\mathrm{Sa}\left(\mathrm{T}_{1}\right)\right)$, the Peak Ground Acceleration (PGA) and the Peak Ground Velocity (PGV) as being acceptable IMs for a probabilistic performance-based evaluation (Mackie et al., 2008).

Various studies have shown that the seismic hazard curve can be approximated as a linear function on a $\log$-log scale. As recommended in some of these studies (Sewell et al., 1991; Kennedy et al., 1994; Cornell, 1996), the median hazard curve generated is assumed to have a power-law form with two unknown parameters ( $k$ and $k_{0}$ ) in the range of the ground motions investigated as shown in Equation 2-8. Using a least-squares fit in log space the unknown parameters in Equation 2-8 can be determined numerically. 


$$
\lambda_{\mathrm{IM}}=k_{0}[\mathrm{IM}]^{-k}
$$

To generate the probabilistic hazard model, it is necessary to consider a range of hazard events with different probability of occurrence for the calibration of the hazard model. Typically, it is desirable to look at events with a low, moderate and extreme probability of occurrence, which can be taken as corresponding to seismic events with probability of occurrence of $50 \%, 10 \%$ and $2 \%$ in 50 -years, respectively Kunnath (2007).

Representative ground motions are then obtained for the site that fit in the respective IM range. Several factors should be considered in the selection of the suite of site-specific ground motions. The site-specific ground motions, whether from previous earthquake recorded ground motion records or artificially simulated ground motions should have ground shaking characteristics compatible with seismic events that can be expected to occur from relevant sources based on consideration of magnitude (M), distance (R), local soil type characteristics, and faulting mechanisms of the area (Atkinson et al., 1998).

\subsection{Demand Analysis}

Following the seismic hazard analysis of the bridge site, it is then necessary to relate the seismic hazard to structural response of the bridge in the form of a demand 
model. The objective of the demand model is to describe the probable effect of sitespecific ground motions on a structure in terms of engineering demand parameters (EDPs). A relation between IMs and EDPs can be derived using the response data for each of the ground motions in the selected site-specific ground motion suite. Nonlinear time-history dynamic analysis of a suitable numerical model of the bridge is required to minimize epistemic uncertainty by providing the best estimate of structural response to the site-specific ground motions. (Mackie et al., 2008)

There are a variety of EDPs that can be used for developing a demand model some of which include: drift ratio, displacement ductility, plastic rotation, compressive strain and pier rotation (Berry and Eberhard, 2003). In the study by Mackie and Stojadinovic (2005) on the different EDPs considered, an efficient and practical demand model is determined to be the relationship between $S_{a}\left[T_{1}\right)$ and drift ratio.

Similar to the seismic hazard model and following the study by Kunnath (2007), the distribution of EDPs conditioned on IMs is assumed to have a lognormal distribution and the best fit line through the data in log space can be expressed in the form shown in Equation 2-9. The two unknown coefficients ( $a$ and b) and the unknown dispersion can be computed by least-squares regression (Mackie et al., 2008). Based of this relation, which is referred to as the interim demand model, the probability of occurrence for the representative EDP of the bridge for a given intensity level can be written in the form shown in Equation 2-10. 


$$
\begin{gathered}
\widehat{E D P}=a(I M)^{b} \\
P(E D P>e d p \mid I M=i m)=1-\Phi\left[\frac{\ln (E D P)-\mu_{\ln (E D P \mid I M)}}{\sigma_{\ln (E D P \mid I M)}}\right] \\
\text { where } \mu_{\ln (E D P \mid I M)}: \text { mean of the natural log of the EDP } \\
\qquad \begin{array}{c}
\sigma_{\ln (E D P \mid I M)}: \text { standard deviation of the natural log of the } \\
\text { EDPs }
\end{array}
\end{gathered}
$$

The demand model can also be modeled as a mean annual frequency (MAF) curve similar to the seismic hazard curve discussed in Section 2.2 as the relation shown in Equation 2-11. This integral can be evaluated numerically (using the demand data) or based on the data fit expression given in Equation 2-9, a closed form equation can be developed as reported by Kunnath (2007). The resulting closed-form demand hazard curve is shown in Equation 2-12. The closed form equation facilitates easy generation of the demand hazard curve.

$$
\begin{aligned}
& \lambda(\mathrm{EDP})=\int_{0}^{\infty} P(E D P \mid I M)|d \lambda(\mathrm{IM})| \\
& \lambda(\mathrm{EDP})=k_{0}\left[\left(\frac{E D P}{a}\right)^{\frac{1}{b}}\right]^{-k} \exp \left(\frac{k^{2}}{2 b^{2}} \sigma_{\ln (E D P \mid I M)}^{2}\right)
\end{aligned}
$$

The dispersion term $\sigma_{\ln (E D P \mid I M)}$ in Equation 2-12 represents the aleatoric uncertainty associated with the demand model. Typical values for $\sigma_{\operatorname{In}(E D P \mid I M)}$ range from 0.25-0.35 for efficient demand models (Mackie et al., 2008). 


\subsection{Damage Analysis}

As part of a performance-based analysis, it is important to relate the response predicted by analytical demand models to physical descriptions of damage. Demand simulations performed using simplified structural models by linear elastic finite element analysis are usually unable to completely capture complex natural phenomena such as global and local buckling, cracking, rebar buckling, and the onset of collapse. Therefore, in seismic risk assessment of bridges, it is necessary to employ nonlinear analysis and consider the actual capacity of bridge components and/or the complete bridge system in comparison with the expected levels of demand (Mackie et al., 2005). The development of this relation, known as the damage analysis phase in performance based assessment framework, is discussed here.

In the damage analysis phase, the structural responses corresponding to different hazard levels are related to the probable damage induced. To accomplish this task, first a relationship between the probability of different damage events occurring, such as spalling of concrete or longitudinal bar buckling, under different structural response levels needs to be established (interim damage model). This is accomplished through incorporating observed, experimental, and analytical estimates of damage into a performance-based formulation. Once this relationship is obtained, it can be combined with the demand model developed in Section 2.3 to 
form the damage model to obtain the probability of damage given an earthquake event.

\subsubsection{Interim Damage Models}

In order to identify the probable damage induced at different levels of seismic activity for a given bridge, it is necessary to first develop a relationship between structural response and level of damage. This relationship can be obtained through experiments, analytical investigations or infield observations. Over the past decade, various forms of each of these techniques have been used to develop interim damage fragility curves. The objectives of these interim damage models are to describe the probable damage state of a structure, described in terms of damage measures (DMs), under a given level of structural response, also called engineering demand parameter (EDP). Damage measures are usually discrete, rather than continuous quantities, as defined by the onset of certain damage states (Mackie et al., 2008). Depending on the relationship used, examples of damage states of reinforced concrete columns include cracking, spalling, longitudinal bar buckling and transverse reinforcement fracture, or the less definite of almost no damage, minor, moderate, or major damage or collapse. In the case of continuous damage measures, such as loss of lateral load carrying capacity, the median relationship 
between EDP and DM (Equation 2-13) and the associated dispersion $\left(\sigma_{D M \mid E D P}\right)$ completely define the damage model.

$$
\widehat{\mathrm{DM}}=c(E D P)^{d}
$$

If the damage states are assumed to be continuous, that is, there is a continuous progression of physical damage in the structure, then, all intermediate points between the discretely observed damage states can be used in the fragility analysis. Due to the discrete nature of most DMs it is often difficult to formulate a damage model in terms of a median DM value conditioned on EDP, as in the case of continuous DM because the cumulative distribution function describing the observed discrete DMs is a step function rather than a continuous function. In this study, it is assumed that damage models can be cast in a continuous form. This simplification is applicable to the discrete DM case when the coefficients of variation (c.o.v.) for each of the discrete damage states are approximately equal. In this case, the regression constants in Equation 2-13 are assumed to be $c=1, d=1$, and $\sigma_{D M \mid E D P}=$ c.o.v. Such an approximation is consistent with the assumption that damage limit states can be defined at discrete (median) levels of demand. However, it increases the overall uncertainty by the uncertainty from the damage model (Mackie et al., 2008). The resulting probability of occurrence of damage measures is shown in Equation 2-14. 
Similarly, it is possible to obtain a closed-form expression for the mean annual frequency of exceeding different damage measure (DM) values by integrating the damage model (Equation 2-13) with the derivative of the demand hazard (Equation 2-12). The hazard curve describing the mean annual frequency of exceeding a damage level is shown in Equation 2-15 (Mackie et al., 2008)

$$
P(D M>d m \mid I M=i m)=1-\Phi\left[\frac{\ln (d m)-(C+d A+d b \ln (i m))}{\sqrt{d^{2} \sigma_{E D P \mid M}^{2}+\sigma_{D M \mid E D P}^{2}}}\right]
$$

where $A=\ln (a)$

$C=\ln (c)$

$$
\lambda_{D M}(d m)=k_{0}\left[\frac{1}{a}\left(\frac{d m}{c}\right)^{\frac{1}{d}}\right] \frac{k}{b} \exp \left(\frac{k^{2}}{2 b^{2} d^{2}}\left(d^{2} \sigma_{E D P \mid M}^{2}+\sigma_{D M \mid E D P}^{2}\right)\right)
$$

Obviously, every bridge has unique structural characteristics and so ideally the performance of each bridge should be represented by a unique damage model. However; it is not economically realistic to carry out individual investigations or tests for every bridge or component under investigation. As stated in the study by Shinozuka et al., (2007) it is envisioned that a class of bridges of similar configuration, materials, and size will have correspondingly similar failure mechanism that apply to other bridge structures of the same classification. Databases of collected experimental results (Berry et al., 2004) on similar type of test specimens are often used to develop such descriptive equations that involve geometric and material properties of the specimen. Consequently, there are several 
damage models for reinforced concrete columns (Berry and Eberhard, 2003; Panagiotakos and Fardis, 2001). The shortcoming of the database approach is the lack of test data involving different materials and structural components, subassemblies, and structures encountered in practice to give a comprehensive set and variation in the database (Mackie et al., 2008).

Similar to the experimental approach, damage curves have also been developed from observed damage after major earthquakes. One such approach has been developed by the Multidisciplinary Centre for Earthquake Engineering Research (MCEER). This approach is described in details by Shinozuka et al., (2007).

\subsubsection{Experimentally Developed Fragility Curves}

One approach to developing a relationship between damage and structural response is to perform scaled experiments to develop a mathematical relationship. In the past several decades, many experimental studies have been carried out around the world to better understand the behavior of reinforced concrete columns of different structural configurations. Studies by PEER have assembled over 400 of these tests in a seismic performance database (SPD). This database contains experiment results from tests performed at research institutes from the United States, Canada, Japan and New Zealand (Berry et al., 2004). The purpose of this database is to provide 
researchers with the data needed to evaluate and develop seismic performance models (Berry et al., 2004).

Various mathematical relations have been developed based on the information provided by this database. One relationship is described in the study by Berry and Eberhard (2003) in which they develop estimates for the response at which different damage levels (concrete spalling or longitudinal bar buckling) will occur based on different structural characteristics. These equations combine plastic-hinge analysis with approximations for the column yield displacement, plastic curvature, buckling strain, and plastic hinge length to develop relationships between column damage and commonly used engineering demand parameters (plastic rotation, drift ratio, and displacement ductility). Equation 2-16 shows the relationship developed for drift ratio at the initiation of concrete spalling for both rectangular and spiral reinforced columns. Equation 2-17 shows a similar relation developed for estimating the drift ratio at the initiation of longitudinal bar buckling where the constant $k_{e b b}$ is 50 for rectangular-reinforced columns and 150 for spiralreinforced columns.

$$
\begin{aligned}
& \frac{\Delta_{\text {spall calc }}}{L}(\%)=1.6\left(1-\frac{P}{A_{g} f_{c}^{\prime}}\right)\left(1+\frac{L}{10 D}\right) \\
& \frac{\Delta_{b b \text { calc }}}{L}(\%)=3.25\left(1+k_{e b b} \rho_{\text {eff }} \frac{d_{b}}{D}\right)\left(1-\frac{P}{A_{g} f_{c}^{\prime}}\right)\left(1+\frac{L}{10 D}\right)
\end{aligned}
$$


In the study by Berry and Eberhard (2003) the above estimated values at which damage is expected to occur is compared to the actual damage occurrence demand of a large group of columns in the SPD. It is found that the coefficient of variation (COV) for the ratio of actual demand over estimated demand at the longitudinal bar buckling damage level $\left(\frac{\Delta_{b b_{a} a c t}}{\Delta_{b b_{-} \text {calc }}}\right)$ is $26 \%$ for rectangular columns and $25 \%$ for spiral reinforced columns. For the concrete spalling damage level the COV for the actual to estimated ratio $\left(\frac{\Delta_{\text {spall_act }}}{\Delta_{\text {spall_calc }}}\right)$ is $43 \%$ for rectangular columns and $35 \%$ for spiral reinforced columns. Some of the scatter in the value of actual versus estimated demand likely arises from the influence of repeated deformation cycling (Kunnath et al. 1997) and the fact that the identification of damage states is subjective and may vary among observers (Kunnath, 2007).

Equations 2-16 and 2-17 can be combined with observations of actual deformation at different damage states to develop general fragility curves that can be easily converted to fragility curves for specific columns (Berry and Eberhard, 2003). These curves are shown in Figures 2.1 to 2.4. These curves provide the probability of damage occurring given the ratio of actual demand to the demand at which damage is estimated to occur $\left(\Delta_{\text {demand }} / \Delta_{\text {damage calc }}\right)$, based on Equation 2-16 or 2-17.

Assuming the database is representative of the general population of rectangularand spiral-reinforced columns, Figures 2.1 to 2.4 can be used to evaluate individual columns and/or develop the fragility curves for these columns. To evaluate specific 
columns, the displacement demand, $\Delta_{\text {demand }}$, is estimated based on structural analysis of the full structure. The estimated displacement at spalling or longitudinal bar buckling ( $\Delta_{\text {spall calc }}$ or $\Delta_{b b \text { calc }}$ ) is then calculated using Equation 2-16 or 2-17, based on the known column properties. The ratio $\Delta_{\text {demand }} / \Delta_{\text {damage calc }}$ is then compared to the appropriate fragility curve shown in Figures 2.1 to 2.4 to evaluate the probability that the column will experience concrete spalling or longitudinal bar buckling at or before the expected displacement demand (Kunnath, 2007). To convert these fragility curves to specific curves for a particular column the horizontal axis $\left(\Delta_{\text {demand }} / \Delta_{\text {damage calc }}\right)$ is multiplied by the calculated drift ratio at the damage state of interest ( $\Delta_{\text {damage calc }} / L$ ) giving the probability that a failure state will occur under varying drift ratio levels.

\subsubsection{Damage Curves Developed from Infield Observations}

Alternative to experimental data, fragility curves have been developed from information of actual damage observed during earthquakes. This approach has both advantages and disadvantages to the experimental approach. One major advantage is the fact that the entire bridge structure is subjected to the influence and effect of the ground motion rather than just only a part of the bridge, namely a pier applied with the seismic loads to simulate the expected conditions. A major disadvantage 
would be that the situation is uncontrolled unlike in the case of a test conducted in a controlled laboratory environment.

In a study by Shinozuka et al. (2003), damage observations of Caltrans bridges, as documented after the 1994 Northridge earthquake, are utilized to develop empirical fragility curves. A sample of bridges are divided into four levels of sub-sets (ie. number of spans, soil conditions, and bridge skew). Differing from the damage states used in the study by Berry and Eberhard (2003), the damage levels are documented as 'almost no' damage, 'minor', 'moderate' or 'major' damage or 'collapse'. These damage states are described in Table 2.1. The drift limits included in the table are obtained from the study by Dutta and Mander (1998) which are typical values used to assess a bridge's damage risk in analytical studies. In another study by Shinozuka et al. (2007), analytical assessment results are compared with the empirical curves developed earlier (Shinozuka et al., 2003). It is determined that the analytical results are significantly more conservative than the empirical curve results and therefore need to be calibrated to better match empirical curves.

\subsection{Loss Analysis}

The final component of a PBEE assessment is the loss analysis stage. This stage is where, based on the preceding models, the probable losses are evaluated in terms of decision variables (DVs). Typical DVs include: repair cost, downtime, repair time, 
and loss of life. (Mackie et al., 2008) The objective of loss analysis is to provide information on impact or consequence of potential earthquake damage which are of immediate concerns to emergency managers, recovery planners, and structural engineers after an earthquake. Some of the key concerns are what is the safe load a damaged bridge can support, what are the repair cost of the damages, and the duration of interruption to service. Today answers to these questions are based on experience and engineering judgement rather than quantitative analyses and engineering evaluations. After an earthquake, quick decisions for timely emergency response are necessary. It is important to have a probability framework relating the decision variables to hazard intensity measures (Mackie and Stojadinovic, 2005).

Bridge decision variables can be separated into two classes: functional DVs and repair DVs. Functional DVs describe the post-earthquake operational state of the bridge such as required lane closures, reduction in traffic volume, or complete bridge closure. The repair DVs include time and cost of bridge repair and restoration.

Following the same relationships discussed in the earlier sections, an interim loss model, relating DV to $\mathrm{DM}$, can be developed in the form shown in Equation 2-18 where $\widehat{\mathrm{DV}}$ represents the median DV. Once this interim model is developed, it can be combined with the hazard, demand and damage models to determine the probability relation between DV and IM as shown in Equation 2-19. 


$$
\widehat{\mathrm{DV}}=e D M^{f}
$$

$$
P(D V \mid I M)=1-\Phi\left[\frac{\ln \left(d v^{L S}\right)-(E+f C+f d A+f d b \ln (i m))}{\sqrt{d f^{2} \sigma_{E D P \mid I M}^{2}+f^{2} \sigma_{D M \mid E D P}^{2}+\sigma_{D V \mid D M}^{2}}}\right]
$$

where $A=\ln (a)$

$$
\begin{aligned}
& C=\ln (c) \\
& E=\ln (e)
\end{aligned}
$$


Table 2.1: Damage states and ductility capacities for bridge columns (Shinozuka et al., 2007)

\begin{tabular}{|l|l|l|}
\hline Damage State & Description & Drift Limit $\left(\frac{\Delta}{L}\right)$ \\
\hline Almost No & First yield & Yield $(0.005)$ \\
\hline Minor & Cracking spalling & 0.01 \\
\hline Moderate & Loss of anchorage & 0.025 \\
\hline Major & Incipient column collapse & 0.05 \\
\hline Complete & Column collapse & 0.075 \\
\hline
\end{tabular}




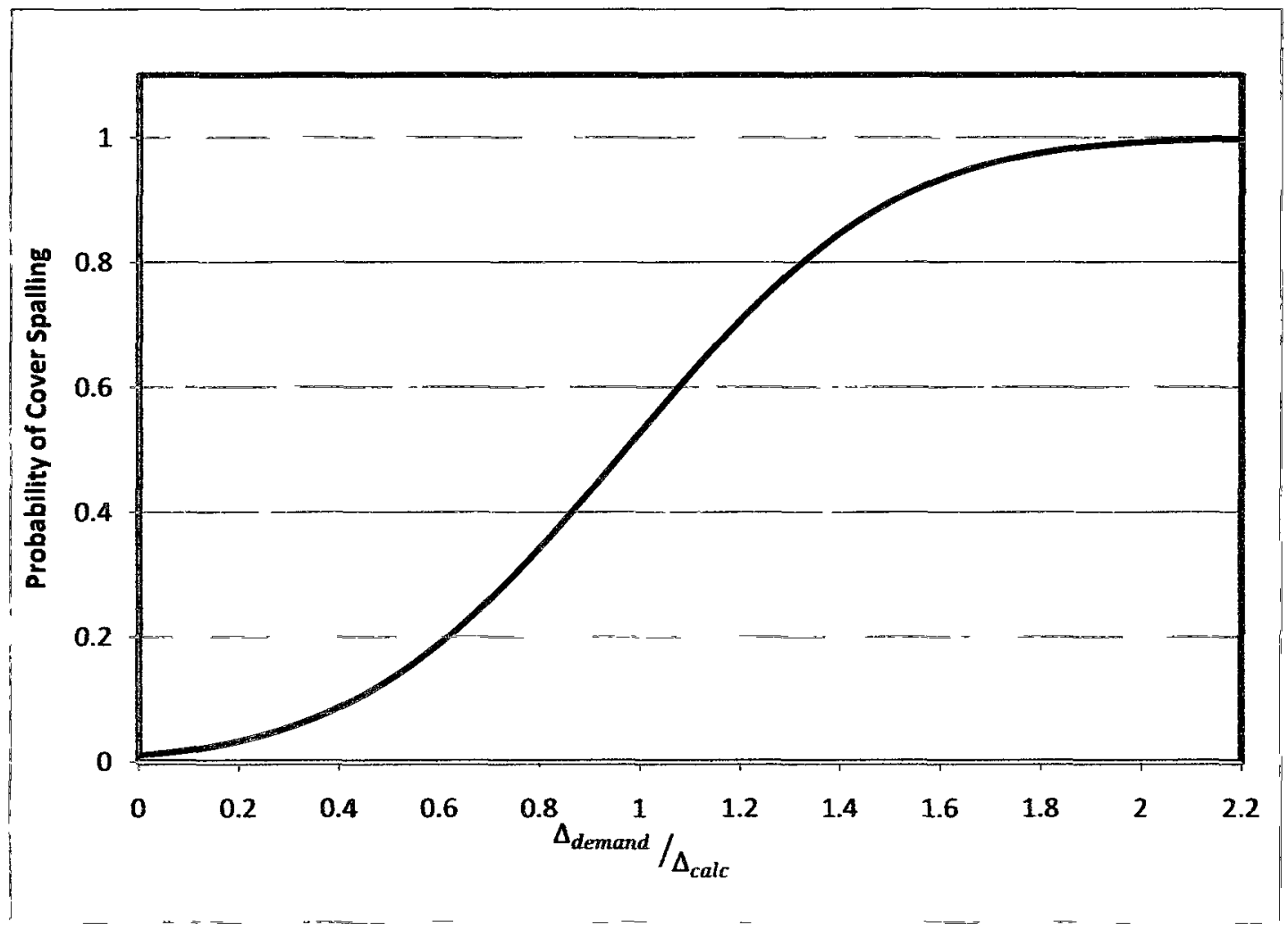

Figure 2.1: General fragility curve for concrete cover spalling for rectangular reinforced columns 


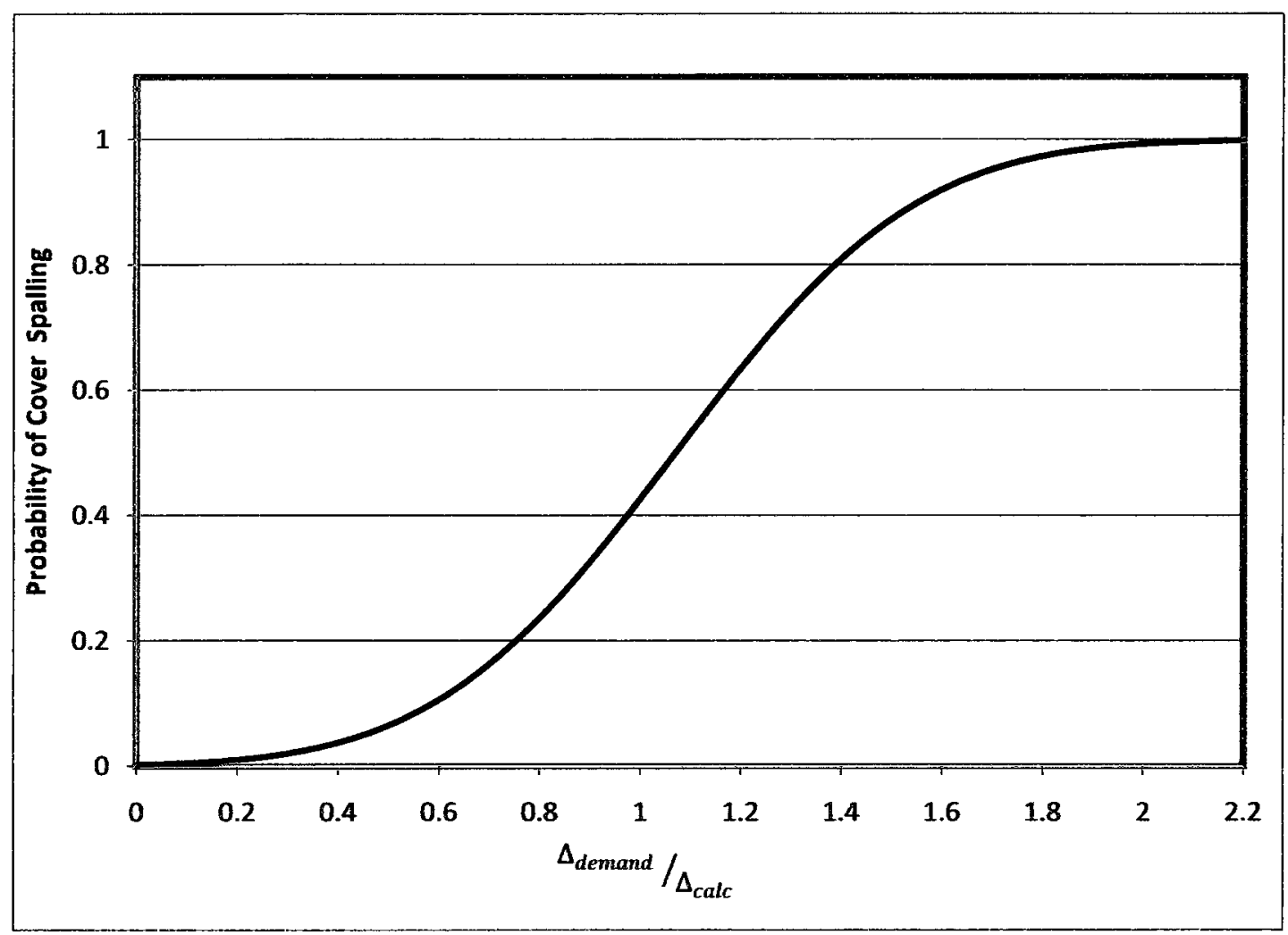

Figure 2.2: General fragility curve for concrete cover spalling for spiral reinforced concrete columns 


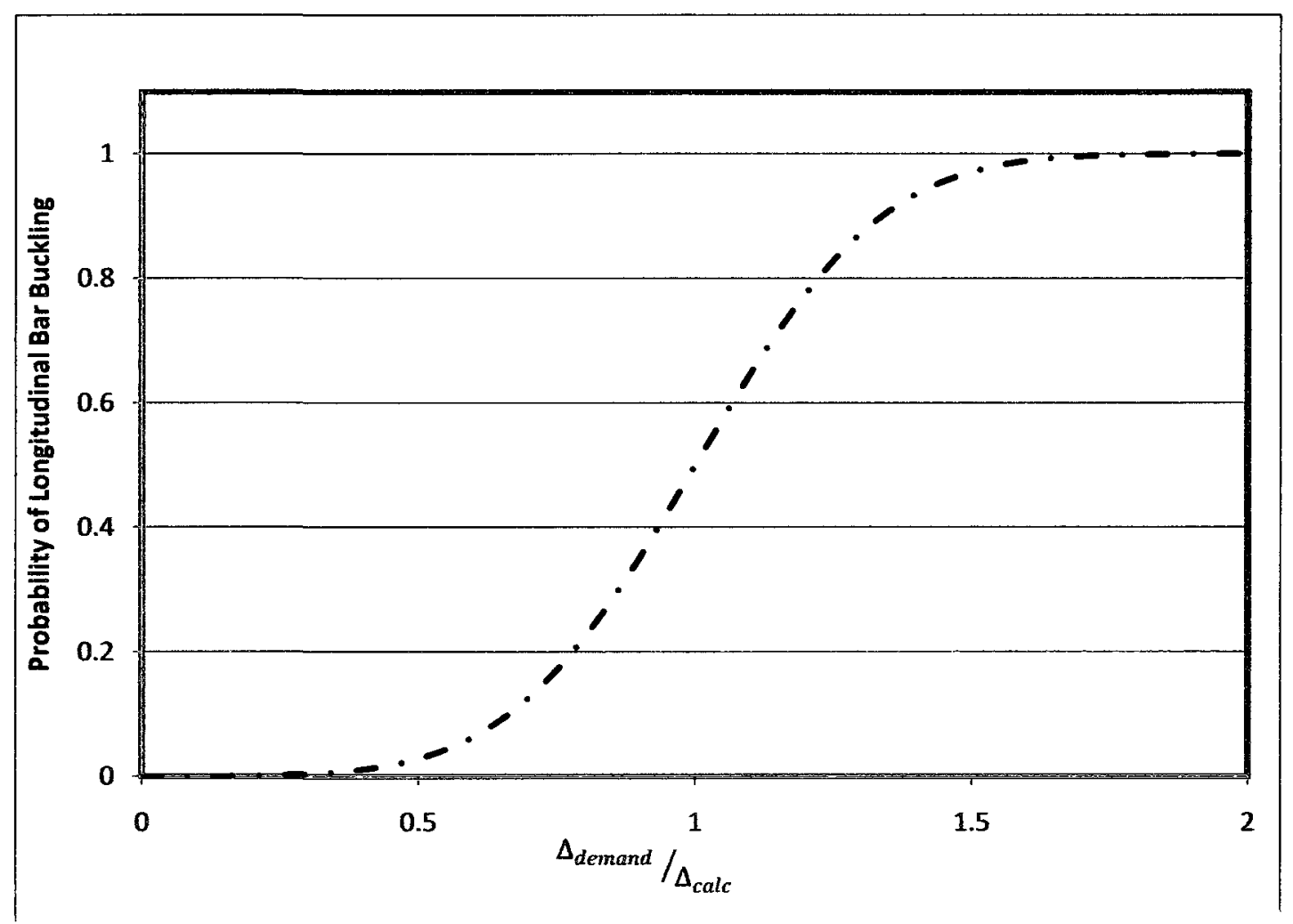

Figure 2.3: General fragility curve for longitudinal bar buckling for rectangular reinforced concrete columns 


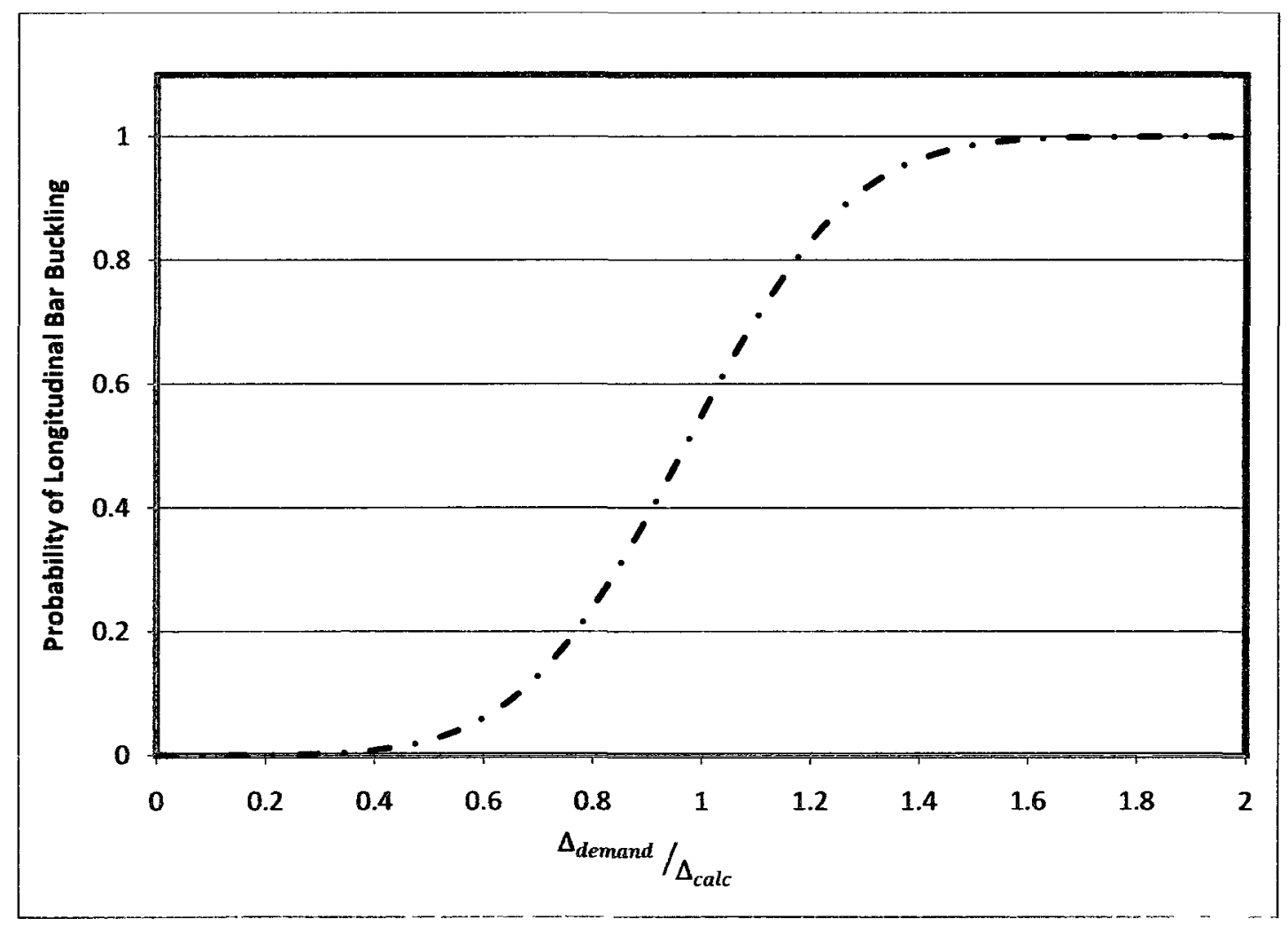

Figure 2.4: General fragility curve for longitudinal bar buckling for spiral reinforced concrete columns 
Chapter 3

Seismic Probabilistic Performance-Based
Assessment of Canadian Bridges

\subsection{General}

Bridges that share similar characteristics and structural properties, such as degree of skew, span length, continuity, reinforcement ratio, and other structural configurations and design details, can be expected to respond similarly during seismic events and have similar vulnerability to earthquake damage. Bridges constructed during a particular period of time typically have similar design details and thus similar structural properties because their design and construction are based on similar design codes and standards. In this chapter, the performance based assessment methodology as discussed in Chapter 2 is applied to evaluate the seismic vulnerability of representative Canadian bridges. Two bridges with representative 
characteristics from a sample inventory of bridges in the Ottawa region have been selected for assessment to illustrate the concept and steps in the performance based assessment methodology.

The first selected bridge is a continuous 4-span bridge with a prestressed hollow core deck. The bridge was constructed in 1969 on Blair Road crossing over Highway 417 in Ottawa. The bridge is straight in alignment and has three column bents, each made up of four identical reinforced concrete columns. The first and third bents support the deck's vertical load through expansion bearings which allow movement in both translational directions and rotation in the longitudinal direction. Bent 2 is connected to the deck through a fixed connection. The support conditions at both abutments allow longitudinally and rotationally movement in the longitudinal direction but are fixed in all other directions. Table 3.1 lists the general properties of the bridge and Figures 3.1 and 3.2 show the bridge profile and cross-section, respectively.

The second selected bridge is a continuous 3-span bridge with a prestressed hollow core deck similar to the first bridge. The bridge profile and cross-sections can be seen in Figures 3.3 and 3.4. The bridge was constructed in 1981 on Nicholas Street crossing over the Southeast Transitway in Ottawa. As with the Blair Road Bridge, this bridge is straight in alignment. It has two piers with identical reinforcement properties connected to the deck through fixed joints while the supporting 
conditions at the abutments allow translational and rotational movement in the longitudinal direction. Table 3.2 lists the general properties of the bridge.

\subsection{Structural Models}

Three-dimensional (3D) nonlinear spine models of the two sample bridges have been developed using the structural analysis program SAP2000 (version 14.0) to investigate nonlinear responses of the bridge systems resulting from inelastic behavior of individual bridge components due to damage suffered during severe seismic events. In order to be able to accurately capture the earthquake load resistance and deformation capacities of the analyzed bridges, the non-linear stressstrain behavior of the concrete material of each bridge have been modeled by stressstrain models for unconfined and confined concrete developed by Mander et al. (1984).

The bridge deck behavior has been modeled by equivalent beams in spine models of the bridge superstructure. The bridge superstructures are divided into multiple segments modeled by equivalent beams located at the centre of gravity of the deck cross section along its longitudinal direction. In the present study, the modeling recommendations for bridges by ATC-32 (1996) are followed which recommend that the superstructure, cap beam and column bents be discretized into a minimum of five elements. Refinement of the discretization of the bridge models has been 
investigated by increasing the number of discretized elements of which no improvement to the accuracy of the analysis results is observed.

As experiences from earthquake studies of bridges have shown, during strong shaking of major seismic events the nonlinear behavior of bridge systems are concentrated on the bridge bents where plastic hinges are formed at the column ends and/or at splice locations of longitudinal reinforcement. The bridge deck is often found to remain elastic throughout the duration of the event. Consequently, the bridge deck superstructures in the present study are assumed to remain within the linear elastic range of behavior and are modeled by linear elastic beam elements in the spine models. The properties of each bridge deck section are presented in Table 3.3 and 3.4. Additional dead loads of $48 \mathrm{kN} / \mathrm{m}$ and $40 \mathrm{kN} / \mathrm{m}$ are applied to the Blair Road Bridge and Nicholas Street Bridge models respectively to account for the asphalt, barrier and railing loads. No effective property modifiers were applied to the superstructures due to the fact that the decks are prestressed concrete and will not experience cracking.

The piers are modeled as discretized line elements of which the total height is taken from the centroid of the footing element to the centroid of the superstructure. The top and bottom of each pier height are assigned a weightless segment with an end offset with a rigid zone factor of 1.0 to account for the high stiffness from the top of the pier to the centroid of the superstructure and from the bottom of the pier to the 
centre of the footing. The boundary condition at the base of each bent is modeled as fixed. Figures 3.1 to 3.4 show schematics and cross sections of the bridges modeled.

For the Blair Bridge, the first and third column bents support the deck's vertical load through expansion bearings and allow movement in both translational directions and ratation in the longitudinal direction. Bent two is connected to the deck through a fixed connection and is modeled as such. The bridge's abutment supports are modeled using rollers in the longitudinal direction and fixed supports in the transverse direction. These modeling assumptions are based on information shown on the structural drawings. A separate model has also been created to investigate the scenario in which the bearings are assumed to have deteriorated and no longer permit free translational movement.

For the Nicholas Bridge, both columns are connected to the deck through a fixed connection and are modeled as such. The bridge's abutment supports are modeled using rollers in the longitudinal direction and fixed supports in the transverse direction as per the structural drawings.

It is important to consider effective section properties in modeling the elastic behavior of concrete member segments to properly reflect the cracked state behaviour of the concrete pier during seismic responses. These effective properties are used in anticipation of the development of cracking in reinforced concrete columns due to gravity and wind loads. Under repeated cycles of wind pressure or seismic loading, the inflection point in column bents oscillates with respect to its 
original location. To account for this behavior, effective properties are used for the entire length of the member (Aviram et al., 2008). Property modifiers are applied to the moment of inertia, the shear area and torsional moment of inertia of the member. The effective moment of inertia can be determined from the sectional moment-curvature analysis as shown in Equation 3-1, where $M_{y i}$ and $\Phi_{y i}$ represent the ideal yield moment and curvature for a bilinear moment-curvature approximation. A reduction in effective moment of inertia to between $35 \%$ to $60 \%$ of the gross section is typical. The effective moment of inertia for the columns in the Blair Bridge is determined to be $0.36 \mathrm{I}_{\mathrm{g}}$, and $0.40 \mathrm{Ig}$ for the Nicholas Bridge. The effective shear area is employed to reflect the increased shear deformations in flexurally cracked members. According to the California Department of Transportation's Seismic Design Criteria (SDC) (2006) can be estimated by Equation $3-2$. The torsional moment of inertia is reduced to approximately $20 \%$ of that of the gross section, as shown in Equation 3-3.

$$
\begin{aligned}
& I_{e f f}=\frac{M_{y i}}{\mathrm{E} \Phi_{\mathrm{yi}}} \\
& A_{v, e f f}=0.8 A_{v, g} \\
& J_{\text {eff }}=0.2 J_{g}
\end{aligned}
$$

Due to the fact that for the expansion bearing case of the Blair Road Bridge, bents 1 and 3 are fixed at the based and support the deck by bearings which allow rotation, these piers are modeled as ideal cantilevers (SDC 2006) and therefore a potential plastic hinge may occur only at the base of the pier when it is subjected to a seismic 
demand that exceeds its elastic limit from a severe earthquake event. For bent 2 and in the case where all the bents have fixed bearing conditions, the columns are fixed at both the top and bottom such that plastic hinges may potentially occur at both ends of the column at the connections. To model these hinge locations, column segments based on the calculated hinge length have been assigned to the top and bottom of the columns for bent 2 and at the column base of bents 1 and 3 for the expansion bearing condition case. For the fixed bearing case, all piers are assigned hinges at the top and bottom. The plastic hinge zones are assigned inelastic properties while the rest of the pier segments are modeled by elastic elements. According to Priestley (1996), a reasonable estimate for the plastic hinge length when the hinge forms against supporting member, is given by Equation 3-4 where $\mathrm{L}$ is the distance from the point of fixity to the point of inflection, $d_{b}$ is the diameter of the longitudinal reinforcement, and $\mathrm{f}_{\mathrm{ye}}$ is the effective yield stress. For a column with fixed-pinned boundary conditions, the potential plastic hinge zone is expected to occur at the bottom of the column. For the case of fixed-fixed boundary conditions, plastic hinges are expected to form at both the top and bottom of each column.

$$
\begin{aligned}
& L_{P}=0.08 L+0.022 f_{y e} d_{b} \geq 0.044 f_{y e} d_{b} \\
& f_{y e} \text { in MPa }
\end{aligned}
$$

For the Nicholas Bridge, the columns are fixed at both the top and base. Therefore, plastic hinges may potentially occur at both ends of the column connections. 
Equation 3-4 has been applied to calculate the required hinge length for each of the Nicholas Street Bridge piers.

The plastic moment capacity of the plastic hinge zone of a bridge pier is calculated by moment-curvature analysis based on expected material properties. The moment-curvature analysis derives the relationship between curvature and moment for a cross section subjected to monotonic loading based on the principles of strain compatibility and equilibrium. To model the inelastic hinge elements the fibre P-M-M hinge option in SAP2000 is employed. This model enables the evaluation of the column behavior under combined loading actions of applied curvature and axial strain. The model can represent the loss of stiffness caused by concrete cracking, yielding of reinforcing steel due to flexural yielding, and the effects of strain hardening. It can capture the effects of strength degradation and stiffness softening after yielding in the behavior of concrete members. In the present study, the pinching effect due to bond slip in the hysteric behavior of concrete members is not considered. Due to the fact that both the nonlinear fiber model and the elastic column have finite stiffnesses, the resultant column stiffness is a series combination of the stiffness of the two components which may be overly flexible compared to the actual behavior of the column resulting in a first mode vibration period greater than the corresponding period of an elastic column. As a result of this extra flexibility, property modifiers have been applied to the gross area, shear area and gross inertia of the column in the plastic hinge zones to achieve the target elastic period. Aviram et al. (2008) suggests the use of a uniform factor in the order 
of 1.0 to 3.0 of which the correct value can be determined iteratively. In the present study, a factor of 2 is applied for the case of the Blair Bridge and 1.15 for the Nicholas Bridge which are determined by iteratively adjusting the above mentioned property modifiers until the plastic hinge model's first mode period matched that of the elastic model .

This investigation is focused on presenting the overall probabilistic PBEE methodology to illustrate the concept of the framework. Some simplifications and assumptions are made in the modeling and analysis here. It is assumed that the soil conditions are Class C based on the NBCC (2005) and no other soil-structure interaction affects are taken into account in the model. Soil-structure interaction can have a significant effect on the seismic response of bridges. It may introduce flexibility and energy dissipation into the system compared with the assumption of a rigid or pinned support in modeling the foundation support condition of bridge piers in the structural model.

Modal analyses of the models have been carried out to determine the fundamental periods of the model bridges and to ensure at least 90 percent mass participation in the dynamic analysis. In all the bridge models, forty modes have been investigated which account for approximately $99 \%$ mass participation in the longitudinal directions as well as in the transverse direction. The fundament periods of the model bridges have been determined to be $1.7 \mathrm{~s}, 0.92 \mathrm{~s}$ and $0.60 \mathrm{~s}$ for the expansion 
bearing Blair Bridge case, fixed bearing Blair Bridge case, and the Nicholas Bridge respectively. First vibration mode shapes are shown in Figures 3.5 and 3.6.

\subsection{Site Hazard Analysis}

As, discussed in Chapter 2, the first stage in a performance-based seismic risk analysis is identifying the seismic hazard of the site. In this section, hazard analysis for the sites of the sample bridges is briefly discussed, which includes identifying the seismicity of the site and developing a probabilistic description of the seismic hazard of the sites. Three seismic hazard levels are considered in the bridge assessment analysis. These represent the low, moderate and extreme seismic events for the Ottawa area with $50 \%, 10 \%$ and $2 \%$ in 50 -years probability of exceedance, respectively. Based on these hazard levels time history records have been simulated to be used in the demand analysis stage.

\subsubsection{Assessment of Site Seismic Hazard}

A key step in the hazard analysis stage is identifying how the seismic hazard of a site should be evaluated or quantified. Past research has shown that the first-mode spectral acceleration $\left(S a\left(T_{1}\right)\right.$ ) is an efficient choice of intensity measure (IM) for

most structures in a performance-based analysis. This does not however imply that 
$\mathrm{Sa}\left(\mathrm{T}_{1}\right)$ would lead to a demand model with the lowest possible dispersion for a given structure (Mackie et al., 2008). Other forms of IM that are commonly used to represent seismic hazard are peak ground acceleration (PGA) and peak ground velocity (PGV). For this research $\mathrm{Sa}\left(\mathrm{T}_{1}\right)$ is used since spectral acceleration is what response spectra in design codes use .

In the probabilistic seismic analysis here, seismic events of $50 \%, 10 \%$ and $2 \%$ in 50 years probability of exceedance which are representative of low, moderate and extreme seismic events for the area have been selected to be used as input motions in the demand analyses of the example bridges.

Seismic hazards in Canada are provided by the Geological Survey of Canada (GSC) in the form of $5 \%$ damped uniform hazard response spectra (UHS) of firm ground conditions. The UHS curves for the three hazard levels are obtained for the Ottawa area (Adams et al. 2009). Each UHS curve can be thought of as an envelope composite of all possible earthquakes that contribute most strongly to the hazard at the specified probability level (Atkinson and Beresnev, 1998). The UHS provides the response spectrum requirements for structures as a function of vibration period (where the response spectrum is the maximum response of a single-degree-offreedom oscillator with $5 \%$ damping). The response spectrum curves for the three seismic hazard levels being considered are shown in Figure 3.7.

Due to the fact that the UHS represents a composite of different earthquakes and not just a single event, theoretically no recorded earthquake event will generate a 
matching response spectrum as represented by the UHS. For this research time histories are generated to closely fit the UHS. This approach is adopted because there are not many actual earthquake records available for the Ottawa area and the approach of generating simulated ground motion that match the full period range of UHS values as given by the Geological Survey of Canada is conservative. From the seismology point of view, numerous studies have shown that simulated records and real records are functionally equivalent, from both linear and non-linear points of view (Atkinson and Beresnev, 1998).

Towards the end of this research, the Ottawa area experienced a seismic event of magnitude 5.0 occurring on June 23,2010 with epicenter about $50 \mathrm{~km}$ from Ottawa (Lin and Adams, 2010). Selected scaled ground motion records from this event are included in the risk assessment here.

\subsubsection{Simulated Ground Motions}

For Ottawa, artificially simulated ground motions compatible to the UHS with peak ground accelerations of $50 \%, 10 \%$ and $2 \%$ probability of exceedance are generated using the ground motion simulation program SIMQKE (Gasparini et al., 1976).

The SIMQKE program uses response spectrum parameters provided by the user and outputs simulated ground motions which closely correlate with the specified parameters. The input data includes various details of the desired response 
spectrum, the intensity envelope used for the transient response, and the desired ground acceleration to be produced.

The method used by SIMQKE to generate artificial ground motions that correlate with a given response spectrum are as follows: (i) the spectral density function is derived from the given response spectrum, (ii) the generated peak acceleration is adjusted to match the target value, and (iii) the ordinates of the spectral density function are adjusted to smoothen the match (Garsparini et al., 1976).

The SIMQKE program takes the input data for a specified smooth response spectrum and from it computes a power spectral density function. It then generates statistically independent artificial acceleration time histories through the superposition of sinusoids having random phase angles, $\varphi_{n}$, and amplitudes, $A_{n}$, which are derived from the stationary power spectral density function, $G(\omega)$. To simulate the transient characteristics of real earthquakes, an envelope function, $I(t)$, is used by the program resulting in the final simulated motion, $z(t)$, as given in Equation 3-5 (Garsparini et al., 1976).

$$
z(t)=I(t) \sum_{n} A_{n} \sin \left(\omega_{n} t+\varphi_{n}\right)
$$

For each probability level of interest $(50 \%, 10 \%$ and $2 \%$ in 50 -years $)$ SIMQKE has been applied to generate 10 ground motions that are compatible with the corresponding response spectrum. The response spectra of the ground motion acceleration time histories generated by SIMQKE are shown in Figures 3.8 to 3.10 
along with the corresponding uniform hazard spectra for Ottawa. The generated ground motion records are shown in Figures 3.11 to 3.13 .

\subsubsection{Scaled Ground Motions}

On June 23, 2010 a magnitude 5.0 earthquake occurred with epicenter near the town of Val-des-Bois, Quebec. This earthquake produced some of the strongest shaking Ottawa and surrounding area has ever felt. The epicenter is located at latitude 45.9 and longitude 75.5 and has a depth of $16 \mathrm{~km}$ (Lin and Adams, 2010). Although strong shaking was felt throughout the epicentral area of the earthquake, the intensity of the earthquake is still only $1 / 6$ of the design earthquake specified in the National Building Code of Canada (2005).

Two earthquake motion records from the June 23, 2010 Val-des-Bois earthquake are used in the present risk assessment analysis. Two records are selected from the earthquake record database by the Geological Survey of Canada (Lin and Adams, 2010). The two selected records are from stations on bedrock sites. The selected ground motion records are scaled to the hazard level being investigated $[50 \%, 10 \%$ and $2 \%$ in 50 probability of exceedance). The ground motions are scaled so that the acceleration response at the first modal period matches that of the specific hazard level. Figure 3.14 shows an example of the resulting response spectra for the scaled 
ground motions. Figures 3.15 to 3.20 show the scaled ground motions used for the bridge hazard cases considered.

\subsubsection{Hazard Curve}

As described in Chapter 2, based on the seismicity hazard model developed by the Geological Survey of Canada (Adams et al., 2009), the seismic hazard curve of the sites as represented by the relationship of the magnitude of the spectral acceleration of the first structural mode shape against the return periods are shown in Figures 3.21 and 3.22. The data follows the characteristic fit represented by Equation 2-8. The resulting coefficients for the expansion bearing Blair Bridge case are $k_{0}=1.0 \times 10^{-5}$ and $=1.351$, for the fixed bearing Blair Bridge case $k_{0}=$ $4.0 \times 10^{-5}$ and $k=1.354$ and for the Nicholas Bridge are $k_{0}=7.0 \times 10^{-5}$ and $k=1.456$.

\subsection{Demand Analysis}

Nonlinear time history analyses of the bridge models by direct integration method have been carried out to evaluate the nonlinear dynamic behavior of the bridge subjected to the prescribed earthquake ground motions. The numerical integration

method used for the time history analysis is Newmark's Average Acceleration 
method $(\gamma=0.5$ and $\beta=0.25)$. The thirty simulated time histories described in Section 3.3.2 and two scaled ground motions have been utilized as input excitations to the models in the longitudinal and transverse direction of the bridge separately. The effects from the transverse loading are negligible for the Blair Bridge model. Therefore only the demand in the longitudinal direction is utilized here for estimating the seismic demand of the Blair Bridge. For the Nicholas Bridge the transverse loading has a small effect and so is considered in the analysis here. The combination of $100 \%$ loading in one direction with $30 \%$ loading in the perpendicular direction are considered. By examining the response drift ratio of the piers of the bridge when subjected to each time history case a demand model is developed. Fitting the results to a lognormal distribution as discussed in Section 2.3, a best fit line is fitted through the resulting drift ratio verses $S_{a}\left(T_{1}\right)$ data for the bridge models as shown in Figures 3.23 and 3.24 . The resulting regression coefficients $a$ and $b$ are 0.1681 and 0.957 respectively for the expansion bearing Blair Bridge case, 0.0503 and 0.9674 for the fixed bearing Blair Bridge case and 0.0314 and 1.0048 for the Nicholas Bridge.

Using the demand as determined from the obtained seismic hazard relationship, the probability relationship of a particular drift ratio occurring is developed by applying the previously mentioned closed form solution shown in Equation 2-10. The resulting probability curves for the three hazard levels for each bridge are shown in Figures 3.25 and 3.26. This probability level can also be looked at in term of the 
overall probability of a particular level of drift ratio occurring in a given year as shown in Figures 3.27 and 3.28 which is developed from Equation 2-12.

\subsection{Probabilistic Damage Evaluation}

Knowing the relationship between drift ratio and seismic hazard, it is possible to determine the probability relationship between damage level and seismic hazard. This first requires an interim step of determining the relationship between damage level and demand as mentioned in Chapter 2. This section discusses the interim relationship and that developed from combining the interim model with the demand model developed in the preceding section.

As previously mentioned, there are various interim models relating damage and demand. This investigation uses the approach developed by Berry and Eberhard (2003) for various reasons. This relationship is developed from column experiments done in various countries including Canada and involves the input of different structural parameters into the mathematical relationship such as transverse reinforcement ratio, longitudinal reinforcement ratio and axial load ratio. Other mentioned approaches only considered damage to existing bridges in a particular area which is thus limited in scope and more restrictive in its applicability. There is the uncertainty how representative the bridges of that area are to the bridges being investigated. 
In the present study the drift ratio demand parameter is used as an indicator of damage. This investigation uses the approximate (scalar) analysis used in Mackie et al. (2008) in which it is assumed that damage to bridge structural elements can be quantified into discrete damage states (spalling of concrete or longitudinal bar buckling) that can adequately capture the damage to the bridge in aggregate.

As discussed in Chapter 2, the relationship estimating the probability of concrete spalling or longitudinal bar buckling developed by Berry and Eberhard (2003) can be adjusted to represent the probability of these damage levels occurring for a particular column of interest. This process has been carried out for the fixed columns of the Blair Bridge since these columns are expected to experience larger displacement demand due to the rigid connectors with the deck forcing them to move with the deck as compared to the case with free translational bearing support. For the Nicholas Bridge, pier 1 is investigated. Using the relationships developed by Berry and Eberhard (2003), the estimated drift ratios at the initiation of spalling are calculated to be $2.5 \%$ and $1.92 \%$ for the Blair and Nicholas Bridge, respectively, based on Equation 2-15, whereas and the estimated drift ratios at the onset of bar buckling are estimated to be $7.93 \%$ and $5.17 \%$, respectively, based on Equation 216. These ratios are used to scale the damage probability curves discussed in Chapter 2 to obtain a relationship between damage and demand for the sample bridges' columns. The resulting scaled curves are shown in Figure 3.29 and 3.30 . 
The relationships of probability of demand given a seismic event and probability of damage given demand are combined to obtain relationships for damage given a seismic event. To obtain these relationships the coefficients and dispersions from the relationships developed for the preceding phases are applied in Equation 2-14 to calculate the probability of each damage measure in terms of seismic events. For this relation it is assumed that the median drift ratio for each damage state is the value of the damage measure variable. The resulting probability of damage given a particular level of seismic event are presented in Figures 3.31 and 3.32.

\subsection{Discussions}

The results show that under the low seismic hazard event there is less than one percent probability of occurrence of concrete spalling and zero percent chance of longitudinal bar buckling. At this low seismic event hazard level, the results corroborate with the expected performance which is under earthquakes of small magnitude and shaking intensity, bridges are not expected to suffer any structural damage that can affect its seismic resistance capacity.

Under the moderate level of seismic hazard loading which may be considered equivalent to the design earthquake, the probability of concrete spalling ranges from $2.1 \%$ to $5.9 \%$, and the probability of longitudinal bar buckling ranges from $0.08 \%$ to $0.42 \%$. Under the design level of seismic hazard, loaded bridges are 
considered to have acceptable performance if they remain intact and can continue to provide service even though some structural repairs may be necessary after the earthquake. The results show that the probability of longitudinal bar buckling for the evaluated bridges is extremely small which means the probability that the strength of the structure would be compromised is unlikely to occur. There is also a low probability of concrete spalling which agrees with the desired performance level that minor damage may need to be repaired but the bridge remains in full operational conditions.

Under the extreme seismic event loading for which the desired performance level would be collapse prevention, the probability of spalling ranges from $18.4 \%$ to $25.4 \%$ and the probability of longitudinal bar buckling ranges from $2.3 \%$ to $4.8 \%$. These results again satisfy the desired performance level. It is likely that concrete spalling will occur and there is a small probability that longitudinal bar buckling will occur. With minor longitudinal bar buckling the bridge would not collapse but however would require major repairs. 
Table 3.1: General Characteristics of Blair Bridge

\begin{tabular}{|c|c|}
\hline Parameter & Value/Description \\
\hline General Bridge Description & $\begin{array}{l}\text { Prestressed hollow core deck bridge with } \\
\text { multi-column bents with } 4 \text { spans }\end{array}$ \\
\hline Total Length of bridge & $85.5 \mathrm{~m}$ \\
\hline Length of each spans & $22.4 m, 20.3 m, 20.3 m, 22.4 m$ \\
\hline Total Deck Width & $22.9 m$ \\
\hline Deck Depth & $0.8 \mathrm{~m}$ \\
\hline No. of columns per bent & 4 \\
\hline Clear Height of columns & $\begin{array}{l}\text { Bent } 1, \mathrm{Hcol}=6.6 \mathrm{~m} \\
\text { Bent } 2, \mathrm{Hcol}=6.8 \mathrm{~m} \\
\text { Bent } 3, \mathrm{Hcol}=6.8 \mathrm{~m}\end{array}$ \\
\hline Column Diameters & $0.9 \mathrm{~m}$ \\
\hline Column Reinforcing & $\begin{array}{l}\text { Longitudinal Reinforcement: } 12-\# 9,76.2 \mathrm{~mm} \\
\text { cover } \\
\text { Spiral Reinforcement: } \# 5,82.6 \mathrm{~mm} \text { pitch }\end{array}$ \\
\hline Deck Centroid from bottom of deck & $0.42 \mathrm{~m}$ \\
\hline Support Conditions & Fixed Foundation \\
\hline Material properties for superstructure & $\mathrm{fc}^{\prime}=34.4 \mathrm{MPa}$ \\
\hline Material properties for columns & $\begin{array}{l}\mathrm{fc}^{\prime}=27.6 \mathrm{MPa} \\
f_{\mathrm{ye}}=300 \mathrm{MPa} \text { (Effective yield stress) }\end{array}$ \\
\hline
\end{tabular}


Table 3.2: General Characteristics of Nicholas Bridge

\begin{tabular}{|l|l|}
\hline Parameter & Value/Description \\
\hline \hline General Bridge Description & $\begin{array}{l}\text { Prestressed hollow core deck bridge with } 2 \\
\text { single-column bents and 3 continuous spans }\end{array}$ \\
\hline Total Length of bridge & $74.0 \mathrm{~m}$ \\
\hline Length of each spans & $18.5 \mathrm{~m}, 37.0 \mathrm{~m}, 18.5 \mathrm{~m}$ \\
\hline Total Deck Width & $8.65 \mathrm{~m}$ \\
\hline Deck Depth & $1.3 \mathrm{~m}$ \\
\hline No. of columns per bent & 1 \\
\hline Clear Height of columns & $\begin{array}{l}\text { Bent } 1, \mathrm{Hcol}=5.86 \mathrm{~m} \\
\text { Bent } 2, \mathrm{Hcol}=5.873 \mathrm{~m}\end{array}$ \\
\hline Column Diameters & $1.45 \mathrm{~m}$ \\
\hline Column Reinforcing & $\begin{array}{l}\text { Longitudinal Reinforcement: } 34-\# 9,40 \mathrm{~m} \\
\text { clear cover } \\
\text { Spiral Reinforcement: \#5, 70mm pitch }\end{array}$ \\
\hline Deck Centroid from bottom of deck & $0.782 \mathrm{~m}$ \\
\hline Support Conditions & Fixed Foundation \\
\hline Material properties for superstructure & $\mathrm{fc}^{\prime}=35 \mathrm{MPa}$ \\
\hline Material properties for columns & $\begin{array}{l}\text { fc' }=30 \mathrm{MPa} \\
\mathrm{f}_{\text {ye }}=400 \mathrm{MPa} \text { (Effective yield stress) }\end{array}$ \\
\hline
\end{tabular}


Table 3.3: Properties of Hollow Core Deck Section for Blair Bridge

\begin{tabular}{|lrl|lrl|}
\hline $\mathrm{A}=$ & 12887329.1 & $\mathrm{~mm}^{2}$ & $\mathrm{~S}_{2}=$ & $4.25 \mathrm{E}+10$ & $\mathrm{~mm}^{3}$ \\
$\mathrm{~J}=$ & $3.68 \mathrm{E}+12$ & $\mathrm{~mm}^{4}$ & $\mathrm{~S}_{3}=$ & $2.27 \mathrm{E}+09$ & $\mathrm{~mm}^{3}$ \\
$\mathrm{I}_{2}=$ & $4.66 \mathrm{E}+14$ & $\mathrm{~mm}^{4}$ & $\mathrm{Z}_{2}=$ & $6.79 \mathrm{E}+10$ & $\mathrm{~mm}^{3}$ \\
$\mathrm{I}_{3}=$ & $9.12 \mathrm{E}+11$ & $\mathrm{~mm}^{4}$ & $\mathrm{Z}_{3}=$ & $3.32 \mathrm{E}+09$ & $\mathrm{~mm}^{3}$ \\
$\mathrm{AS}_{2}=$ & $1.09 \mathrm{E}+07$ & $\mathrm{~mm}^{2}$ & $\mathrm{r} 2=$ & 6014.7 & $\mathrm{~mm}$ \\
$\mathrm{AS}_{3}=$ & $1.07 \mathrm{E}+07$ & $\mathrm{~mm}^{2}$ & $\mathrm{r} 3=$ & 266.7 & $\mathrm{~mm}$ \\
\hline
\end{tabular}


Table 3.4: Properties of Hollow Core Deck Section for Nicholas Bridge

\begin{tabular}{|lrl|lrl|}
\hline $\mathrm{A}=$ & 7480077 & $\mathrm{~mm}^{2}$ & $\mathrm{~S}_{2}=$ & $9.7 \mathrm{E}+09$ & $\mathrm{~mm}^{3}$ \\
$\mathrm{~J}=$ & $4.55 \mathrm{E}+12$ & $\mathrm{~mm}^{4}$ & $\mathrm{~S}_{3}=$ & $2.2 \mathrm{E}+09$ & $\mathrm{~mm}^{3}$ \\
$\mathrm{I}_{2}=$ & $4.2 \mathrm{E}+13$ & $\mathrm{~mm}^{4}$ & $\mathrm{Z}_{2}=$ & $1.5 \mathrm{E}+10$ & $\mathrm{~mm}^{3}$ \\
$\mathrm{I}_{3}=$ & $1.30 \mathrm{E}+12$ & $\mathrm{~mm}^{4}$ & $\mathrm{Z}_{3}=$ & $3.3 \mathrm{E}+09 \mathrm{~mm}^{3}$ \\
$\mathrm{AS}_{2}=$ & 6233397.5 & $\mathrm{~mm}^{2}$ & $\mathrm{r} 2=$ & $2370 \mathrm{~mm}$ \\
$\mathrm{AS}_{3}=$ & 6233397.5 & $\mathrm{~mm}^{2}$ & $\mathrm{r}=$ & $417 \mathrm{~mm}$ \\
\hline
\end{tabular}




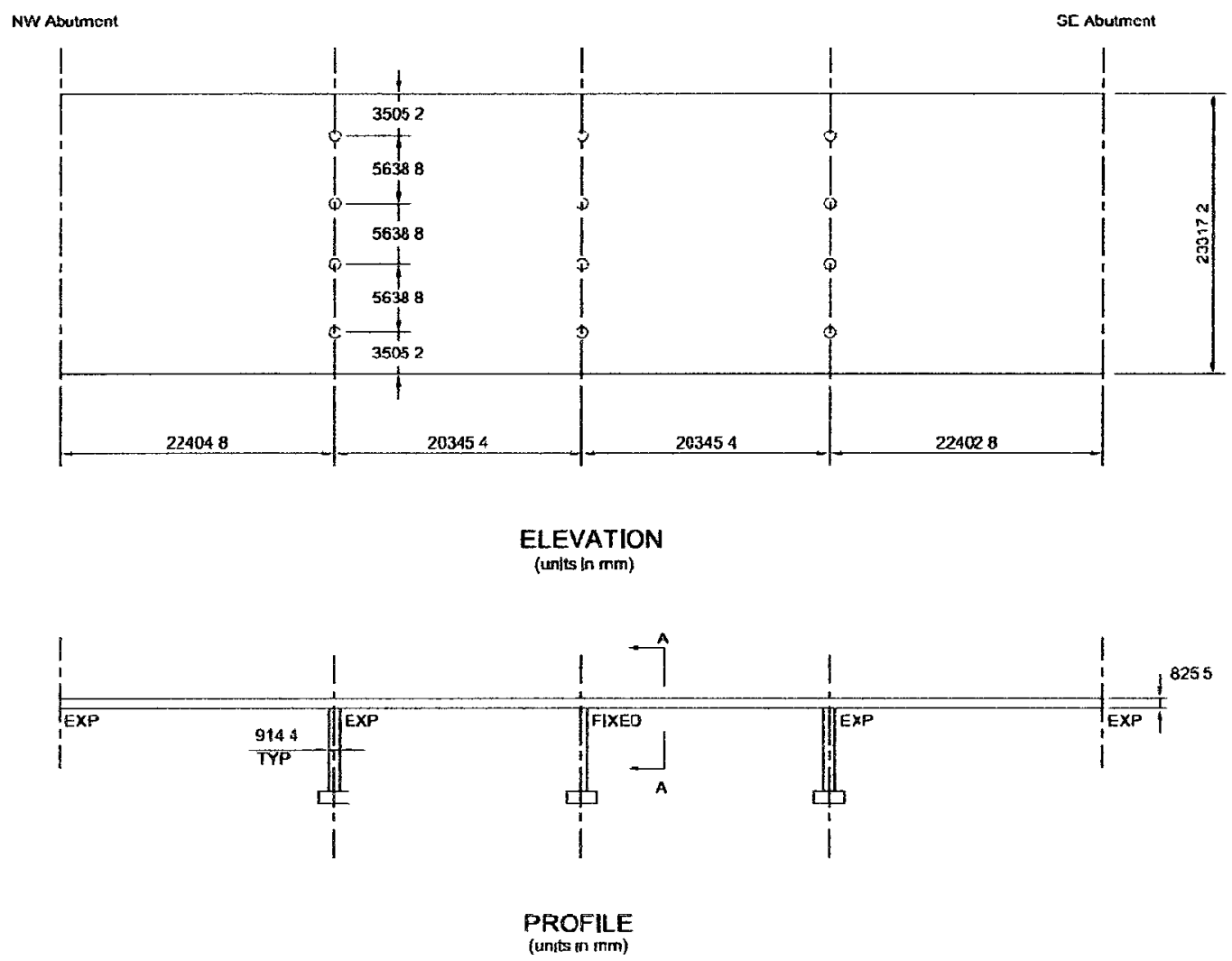

Figure 3.1: Blair Road Bridge elevation and profile 

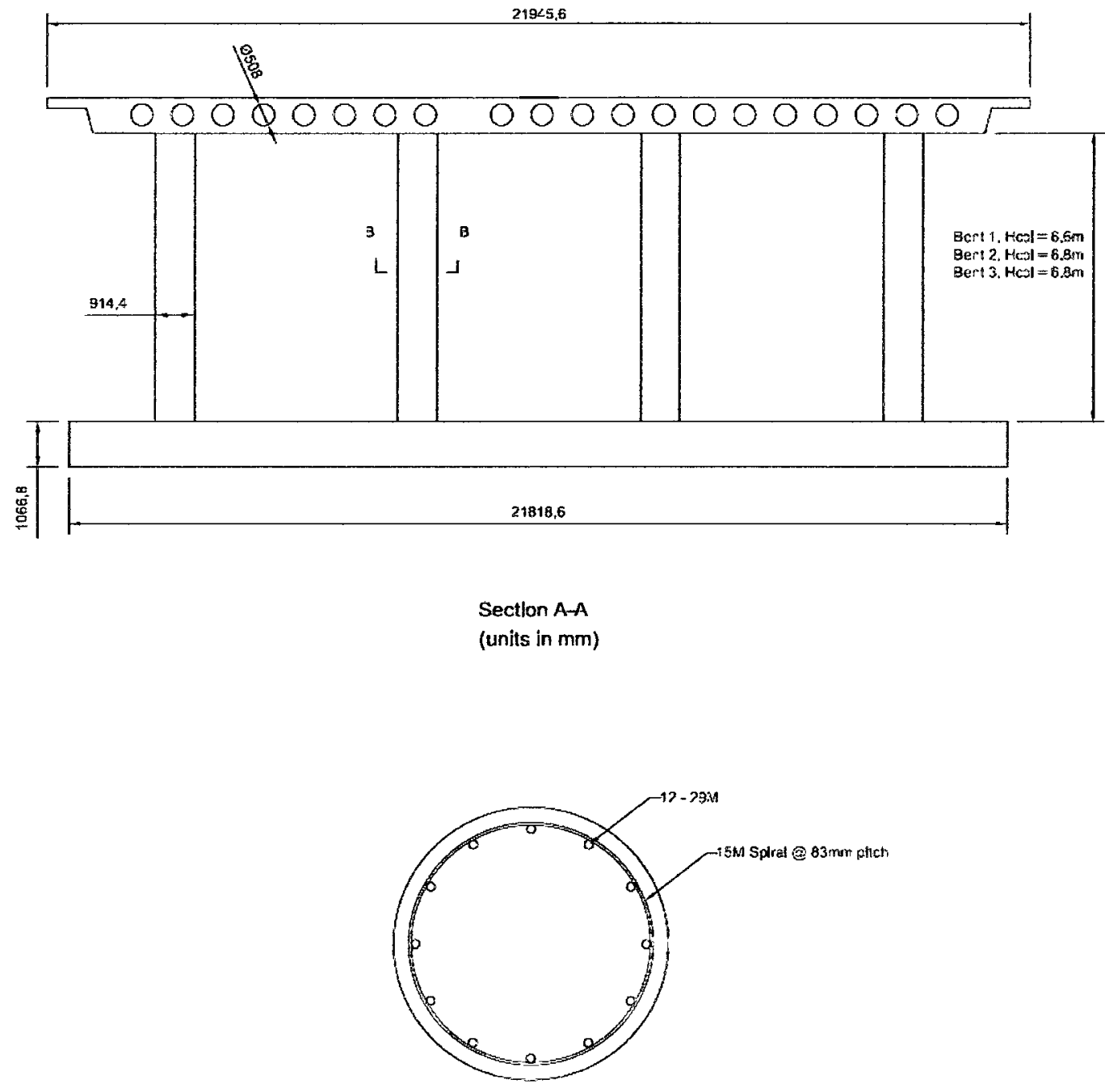

Sectlon B-B (unlts in mm)

Figure 3.2: Blair Road Bridge deck and typical column cross-section 

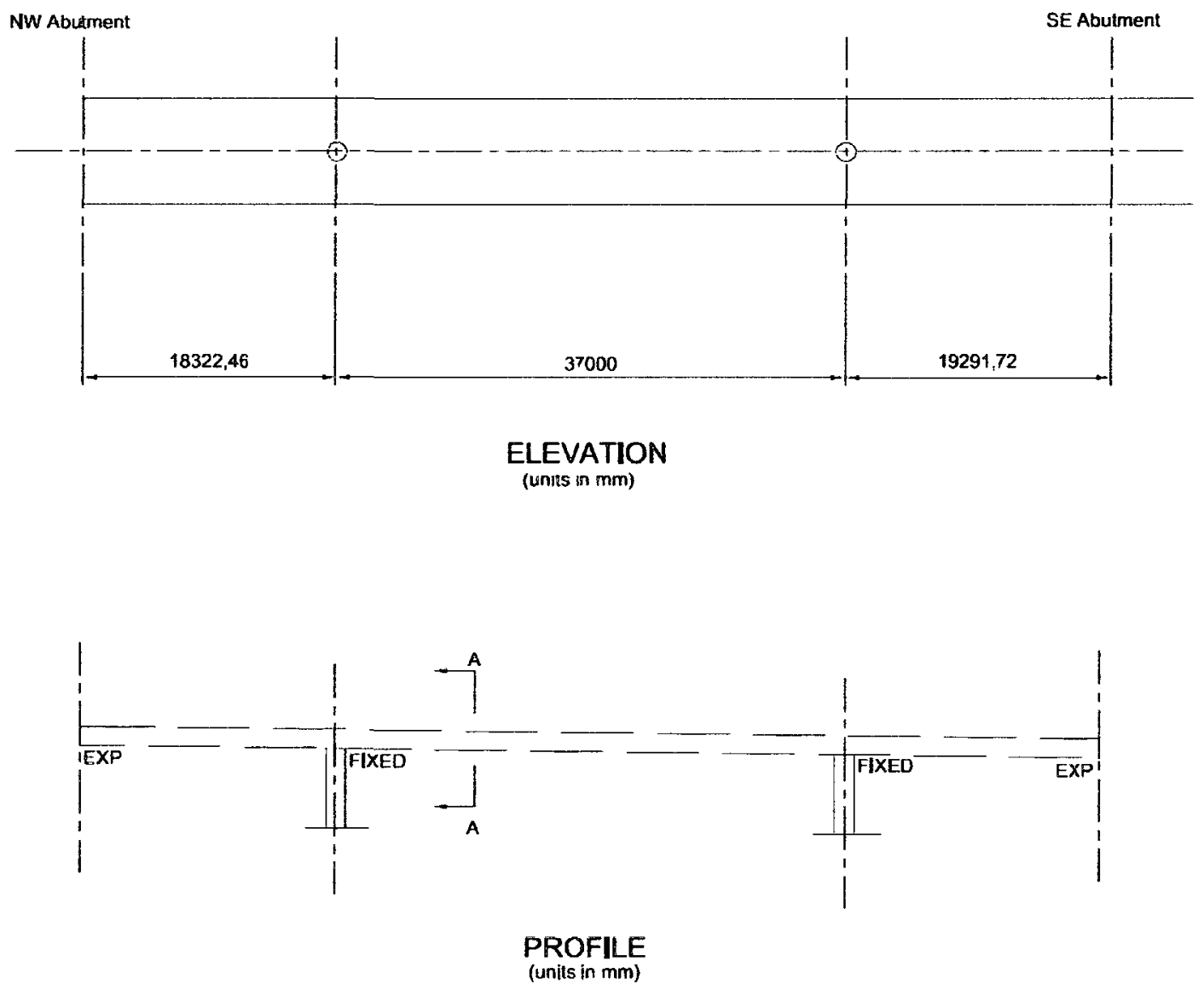

Figure 3.3: Nicholas Street Bridge elevation and profile 


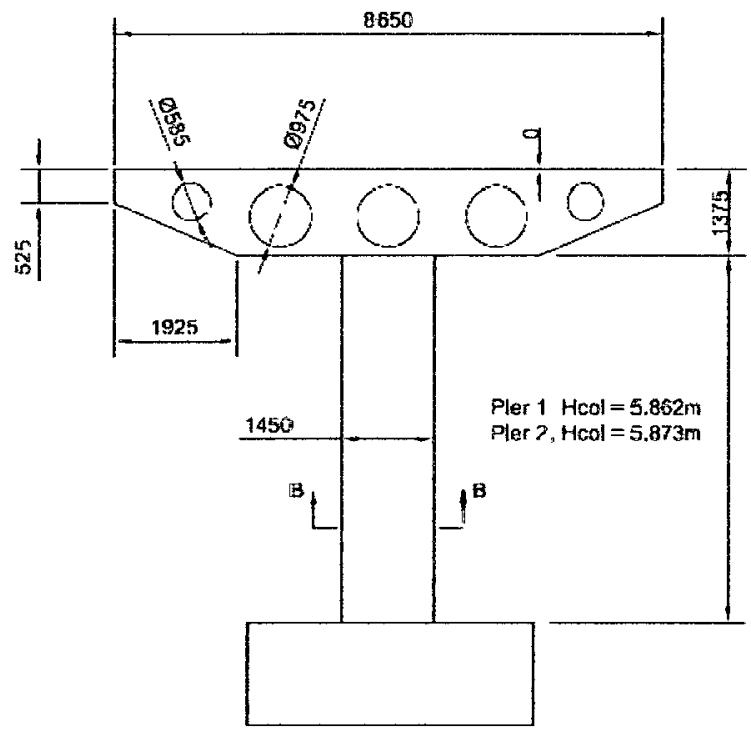

Section A-A

(units in $\mathrm{mm}$ )

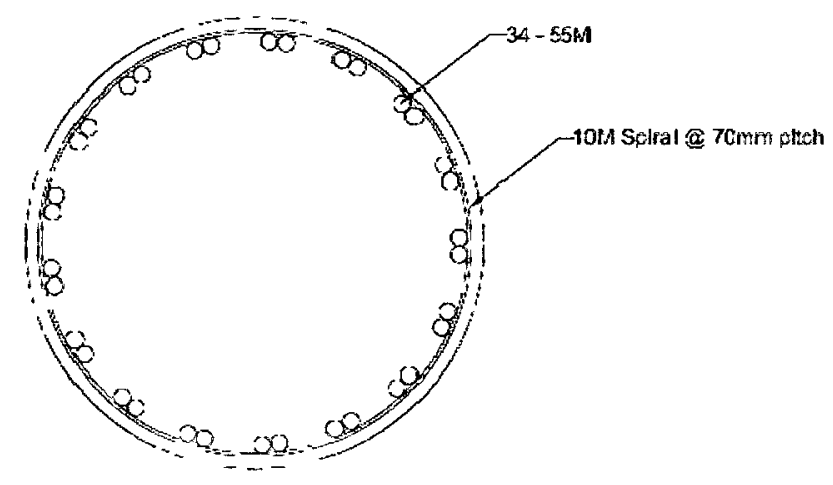

Sectlon B-B (units in $\mathrm{mm}$ )

Figure 3.4: Nicholas Street Bridge deck and typical column cross-section 


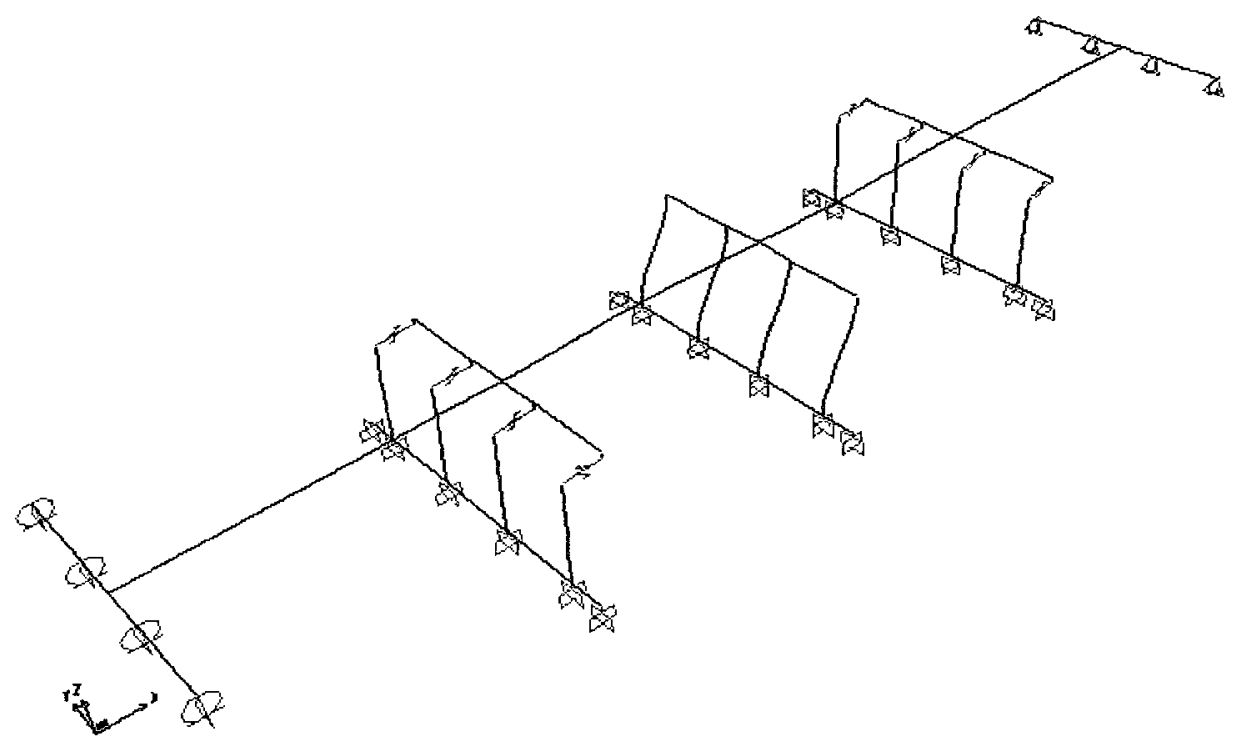

a) First modal shape for bridge with expansion bearings $\left(T_{1}=1.75\right)$

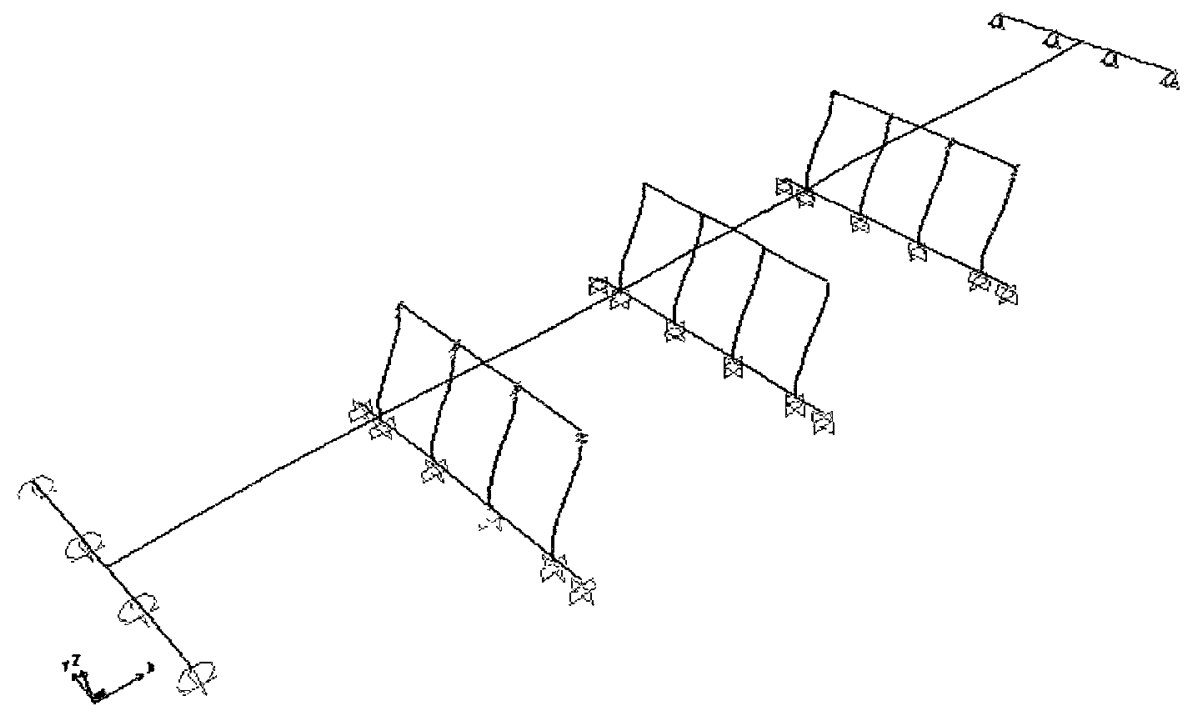

b) First modal shape for bridge with fixed bearing $\left(T_{2}=0.98 \mathrm{~s}\right.$ )

Figure 3.5: First modal shapes for Blair Bridge modeled scenarios 


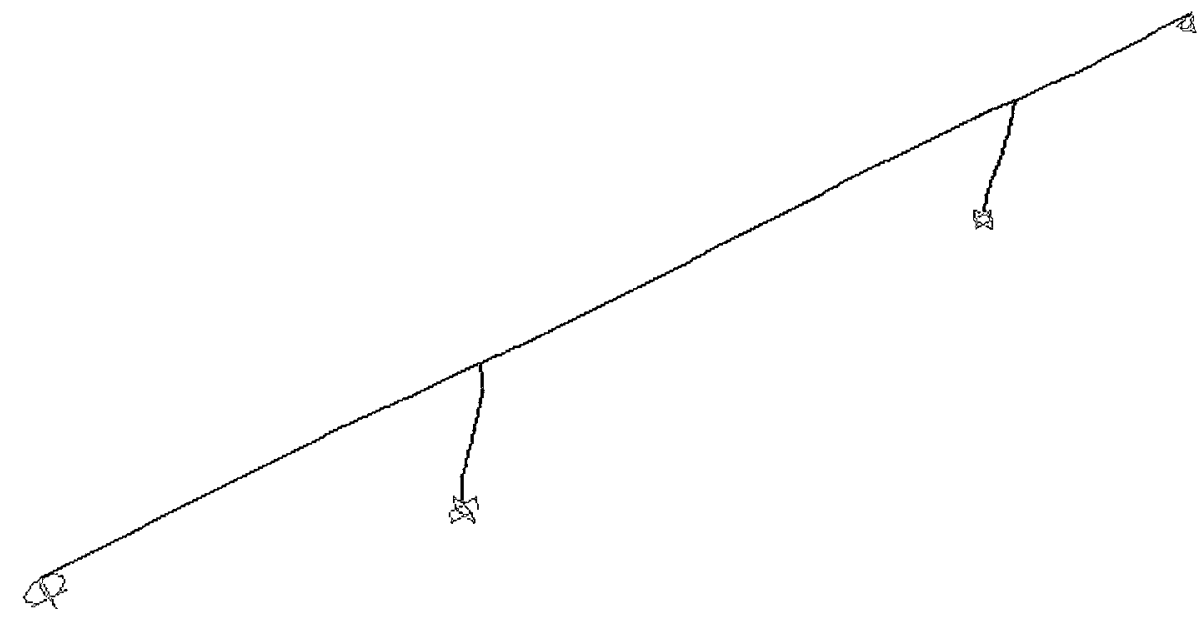

Figure 3.6: First modal shape for Nicholas Street Bridge $\left(T_{1}=0.60 \mathrm{~s}\right)$ 


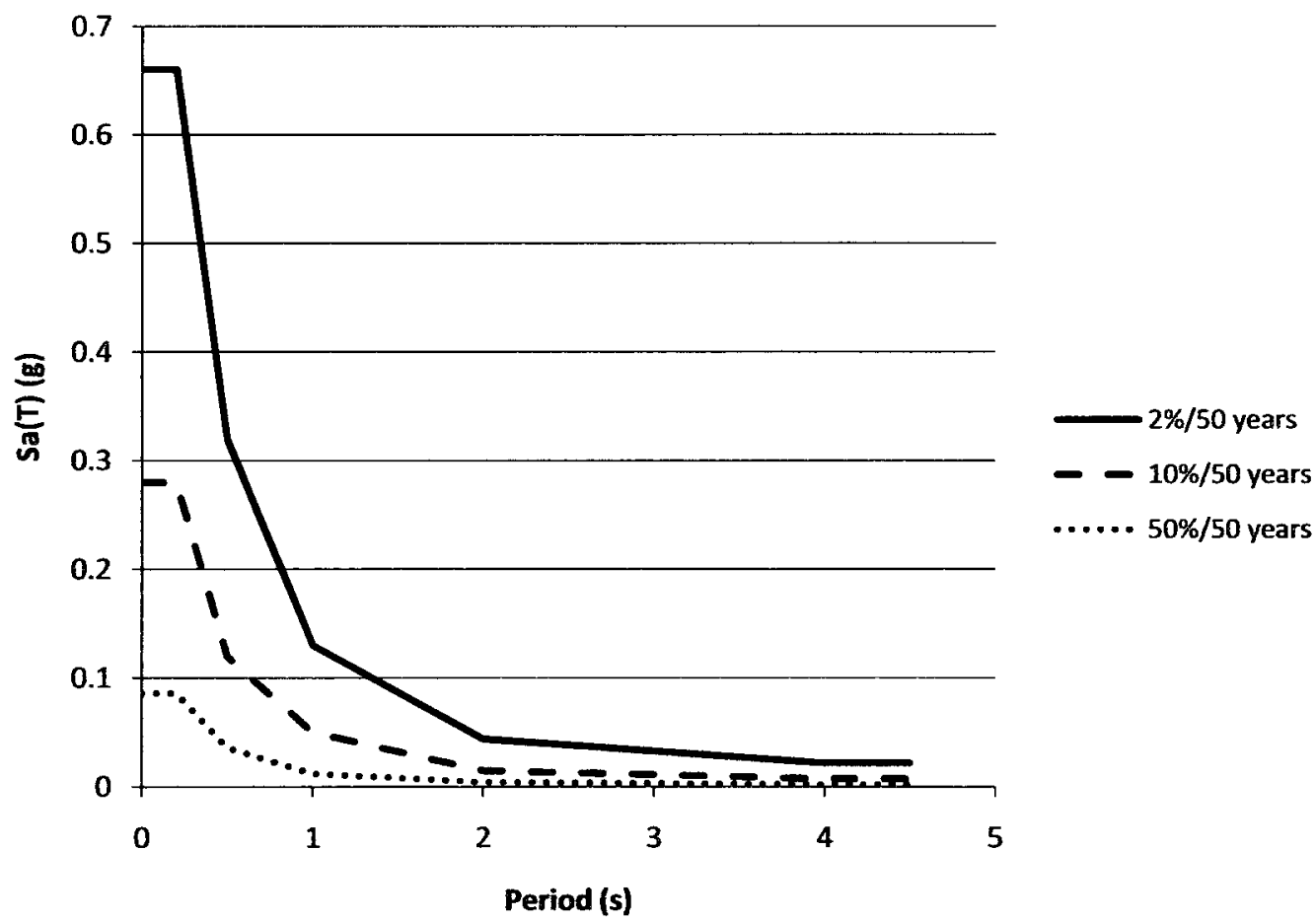

Figure 3.7: Uniform hazard response spectra for Ottawa, Ontario (Site Class C) for $50 \%, 10 \%$ and $2 \%$ in 50 -years probability of exceedance 


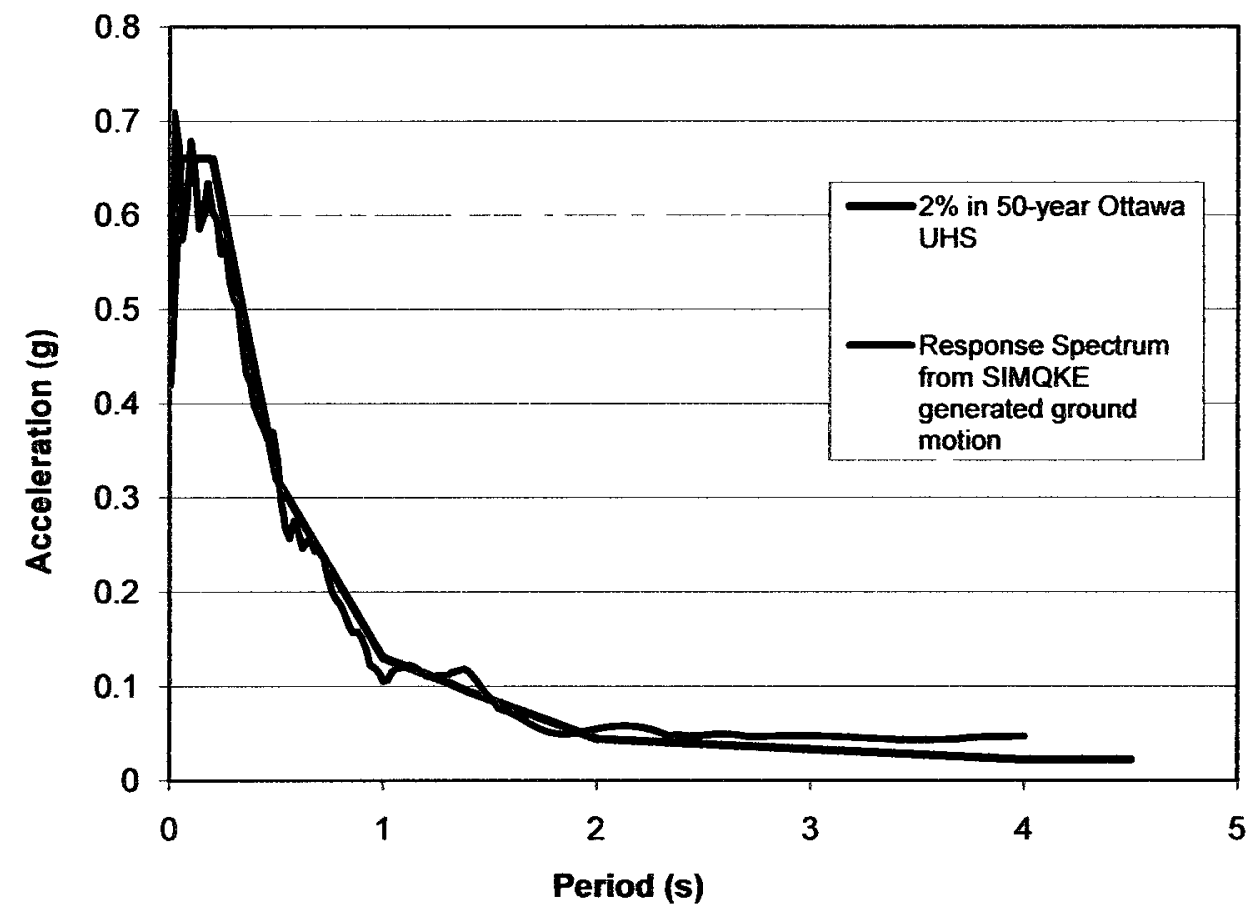

Figure 3.8: Response spectrum for SIMQKE generated ground motions compared to Ottawa $2 \%$ in 50-years UHS 


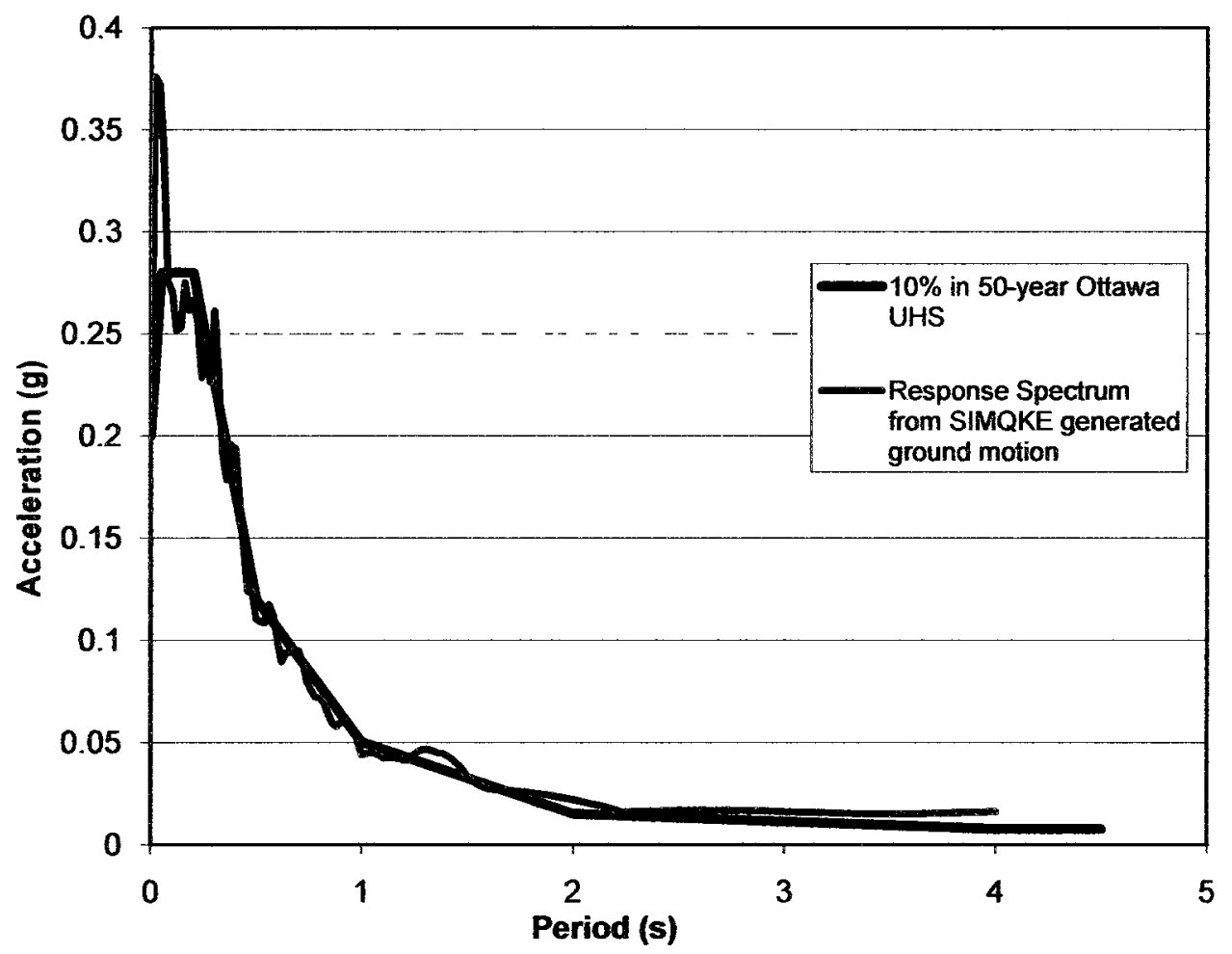

Figure 3.9: Response spectrum for SIMQKE generated ground motions compared to Ottawa $10 \%$ in 50-years UHS 


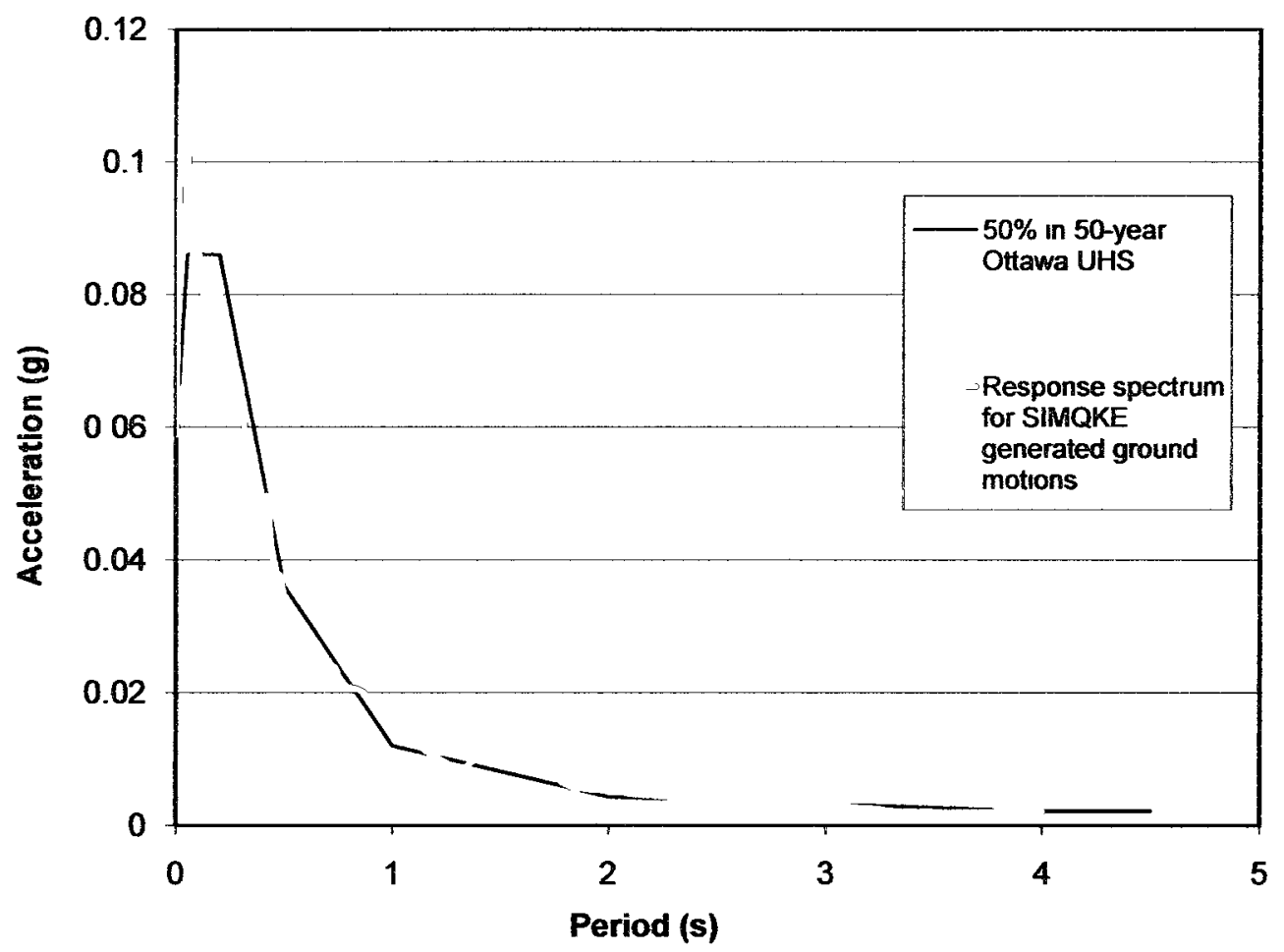

Figure 3.18: Response spectrum for SIMQKE generated ground motions compared to Ottawa $50 \%$ in 50-vears UHS 

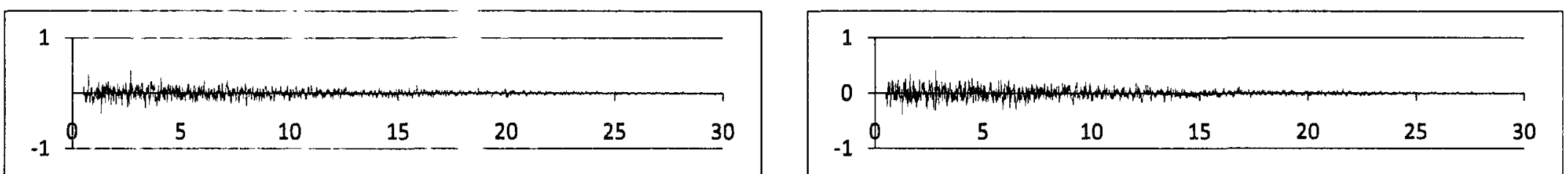

a) Trial 1

f) Trial 6

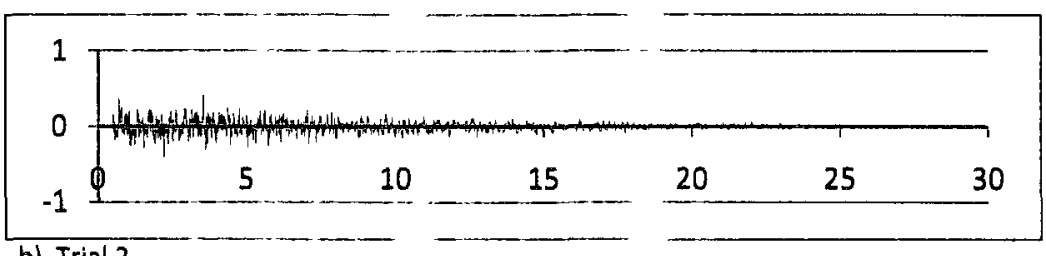

b) Trial 2

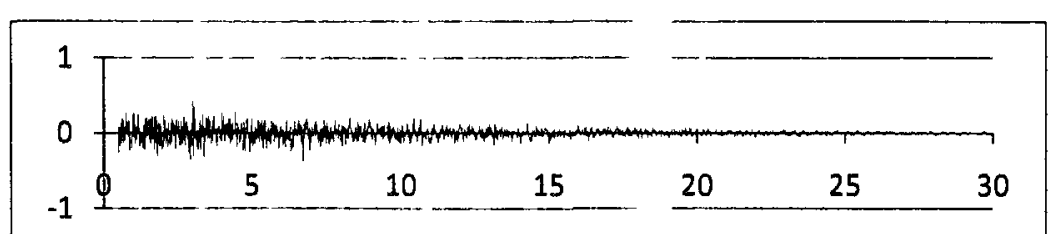

c) Trial 3
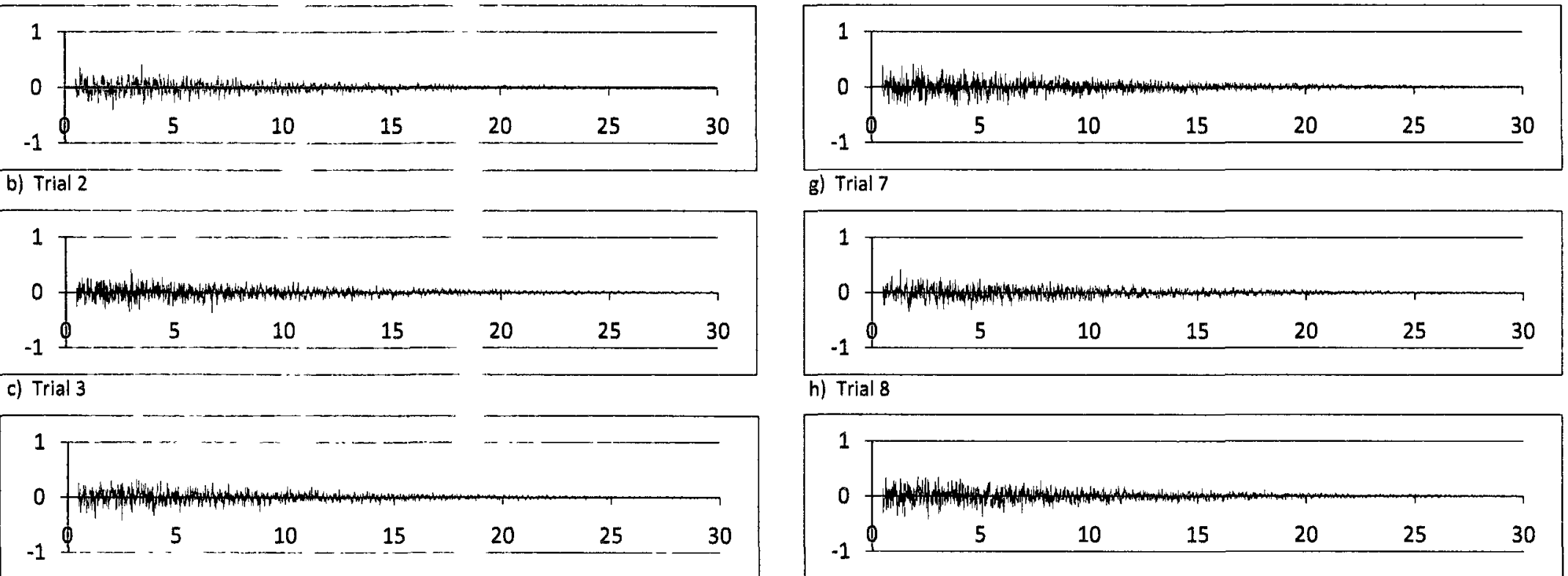

d) Trial 4

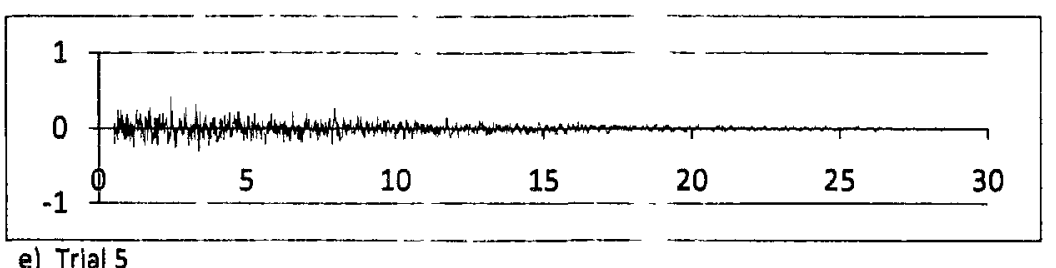

e) Trial 5

Figure 3.11: Simulated ground motions for $2 \%$ in 50 -years probability of exceedance for the Ottawa region

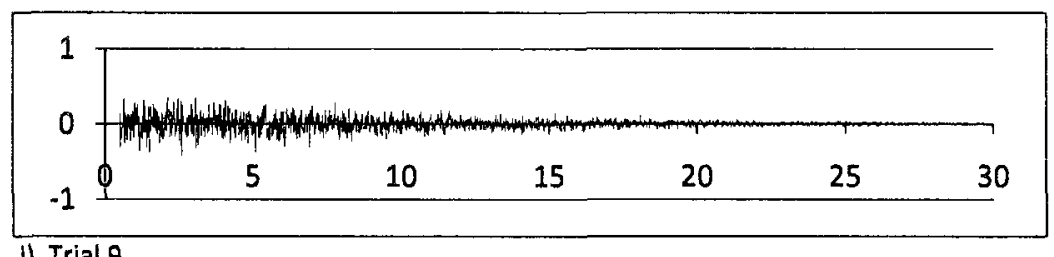

1) Trial 9

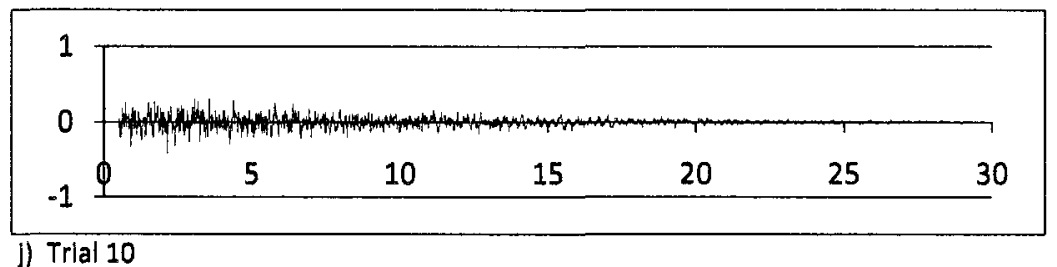



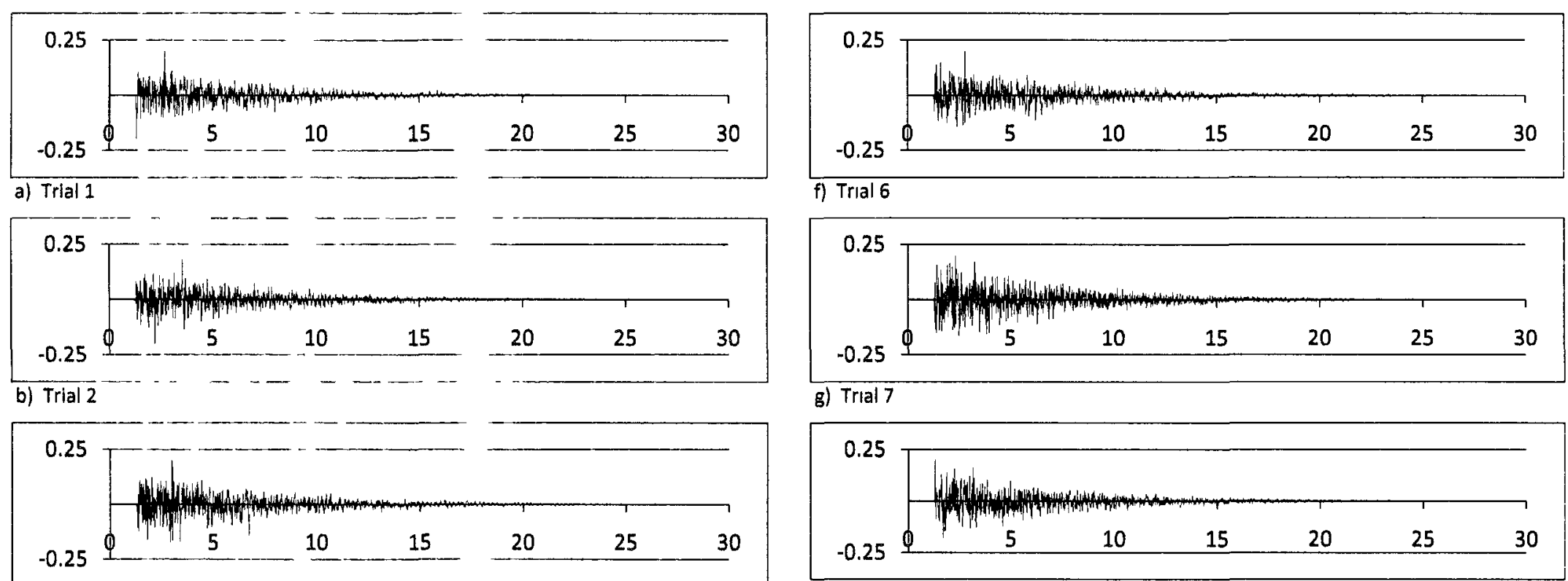

g) Trial 7
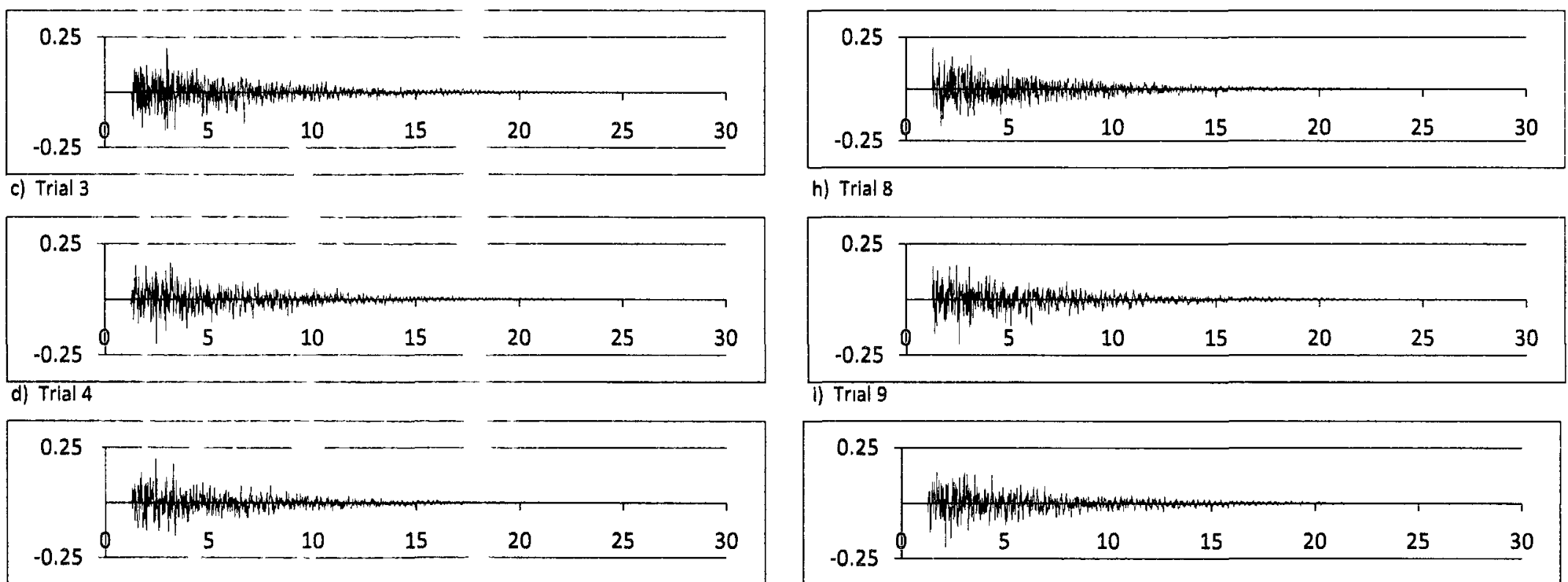

e) Trial 5

h) Trial 8

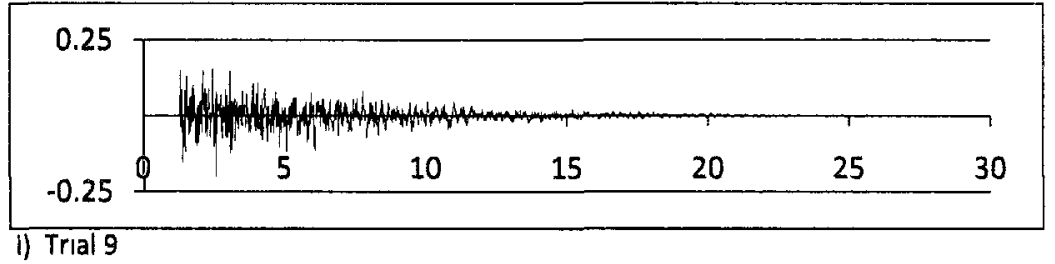

1) Trial 9

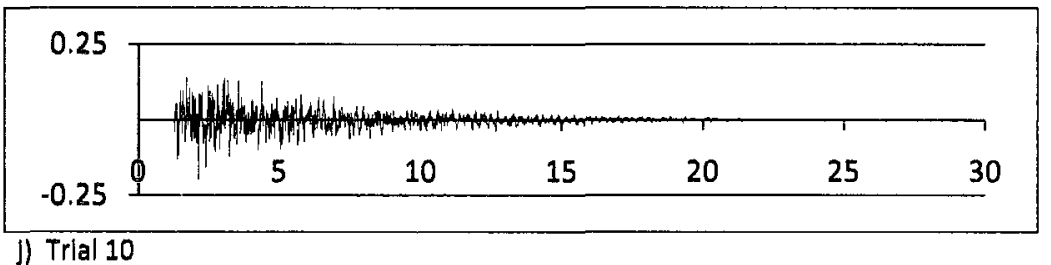

Figure 3.12: Simulated ground motions for $10 \%$ in 50 -years probability of exceedance for the Ottawa region 

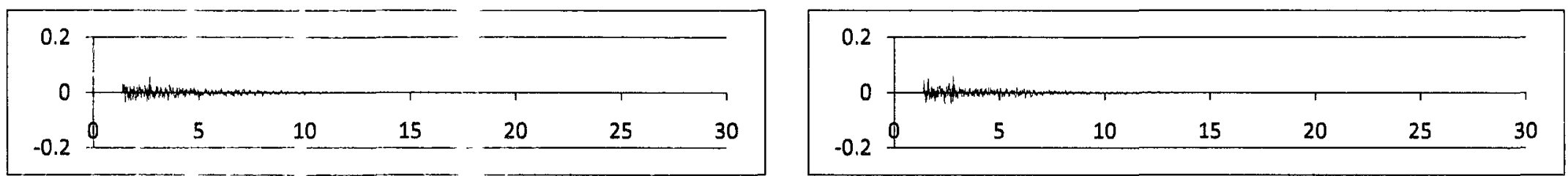

a) Trial 1

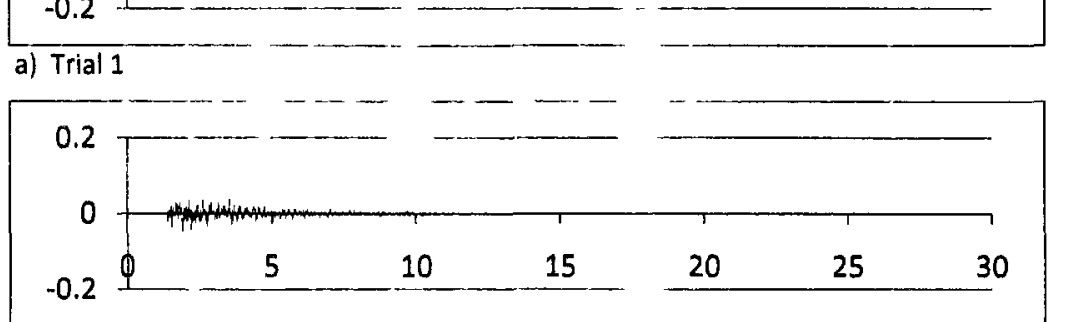

f) Trial 6

b) Trial 2

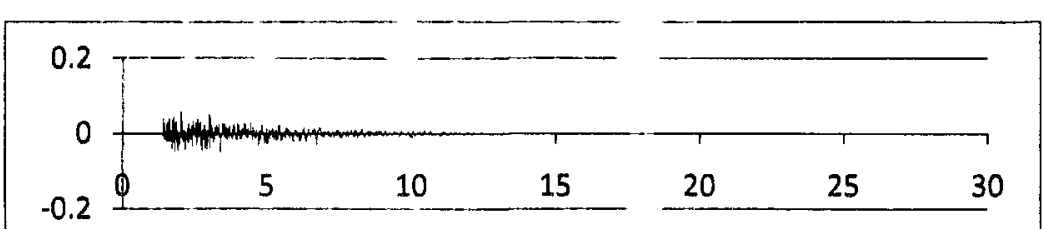

c) Trial 3
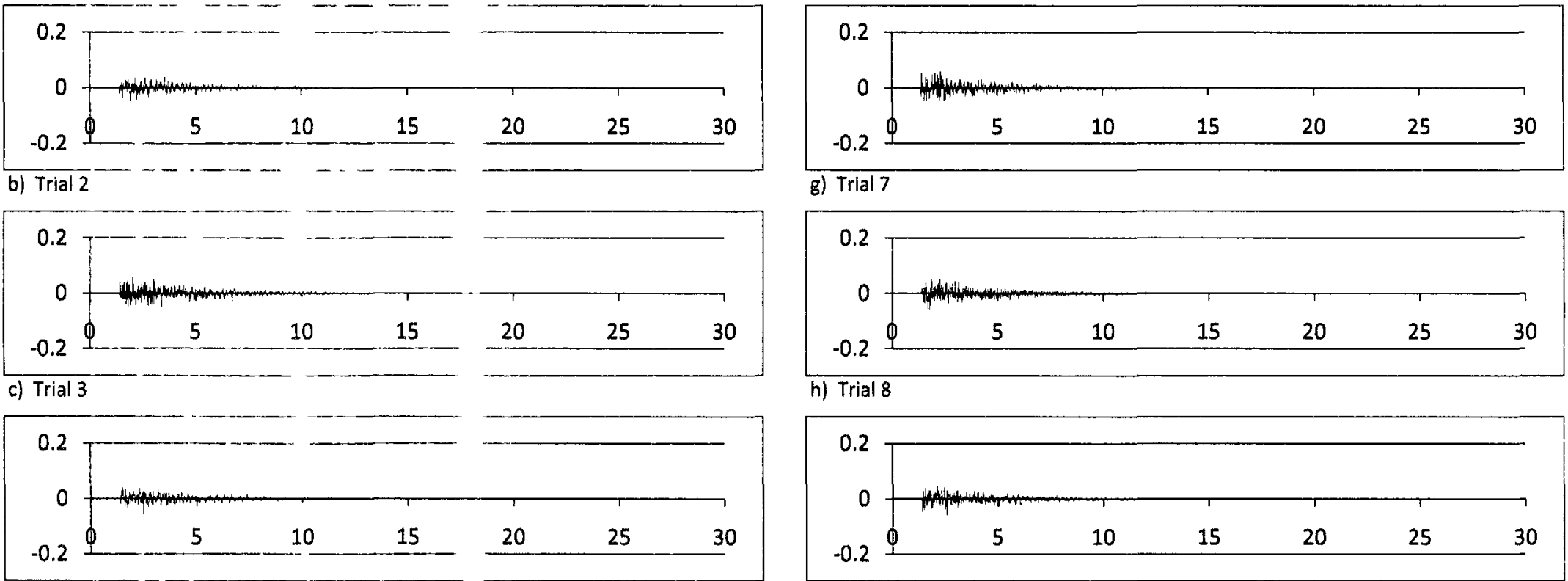

d) Trial 4

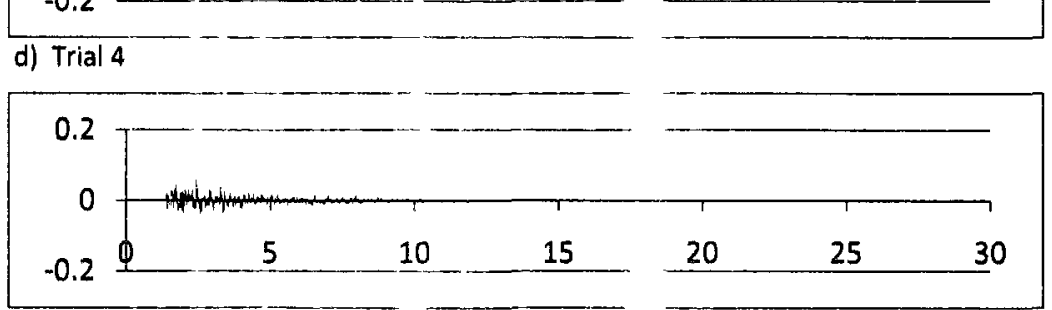

e) Trlal 5

Figure 3.13: Simulated ground motions for $50 \%$ in 50 -years probability of exceedance for the Ottawa region 


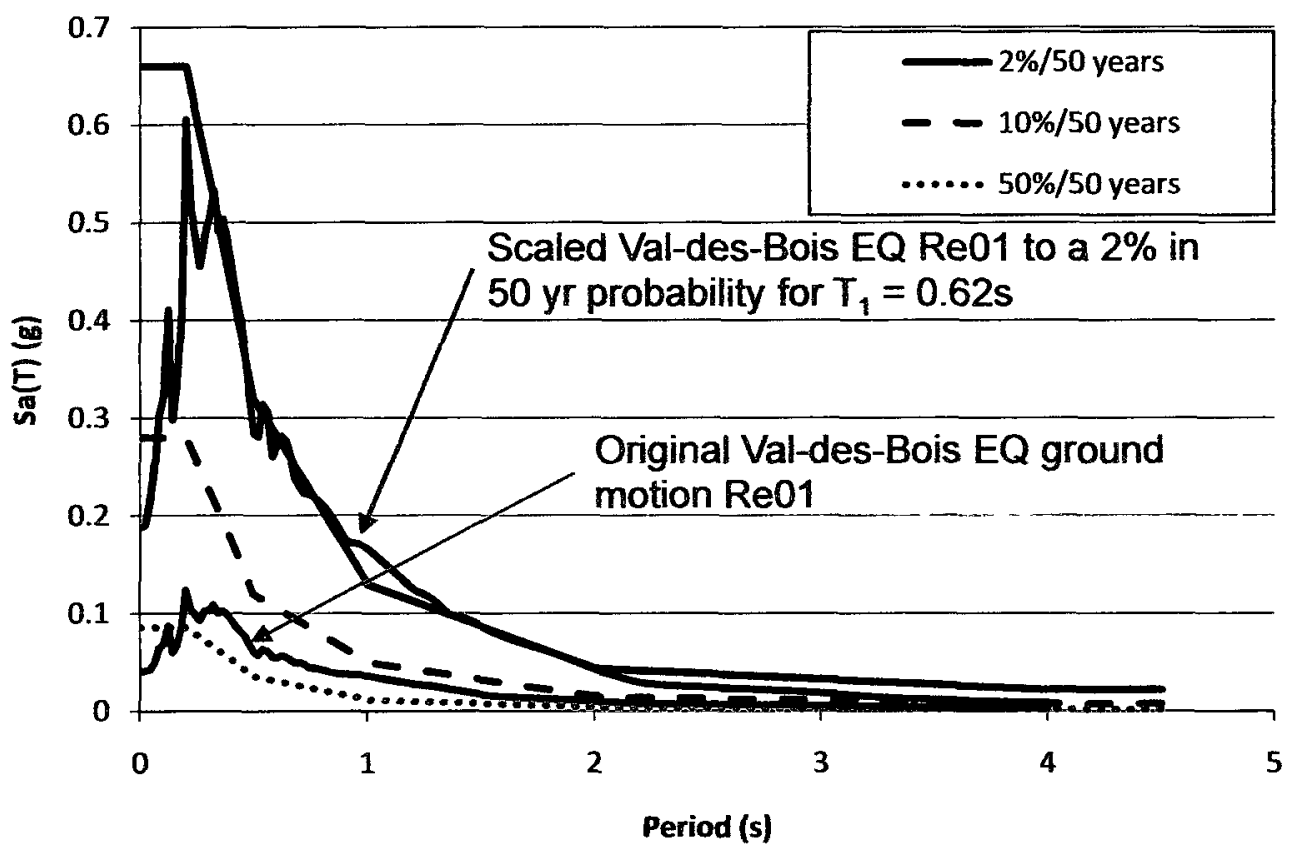

Figure 3.14: Scaled response spectrum from Val-des-Bois Earthquake ground motion Re01 compared to Ottawa $2 \%$ in 50 -years UHS 


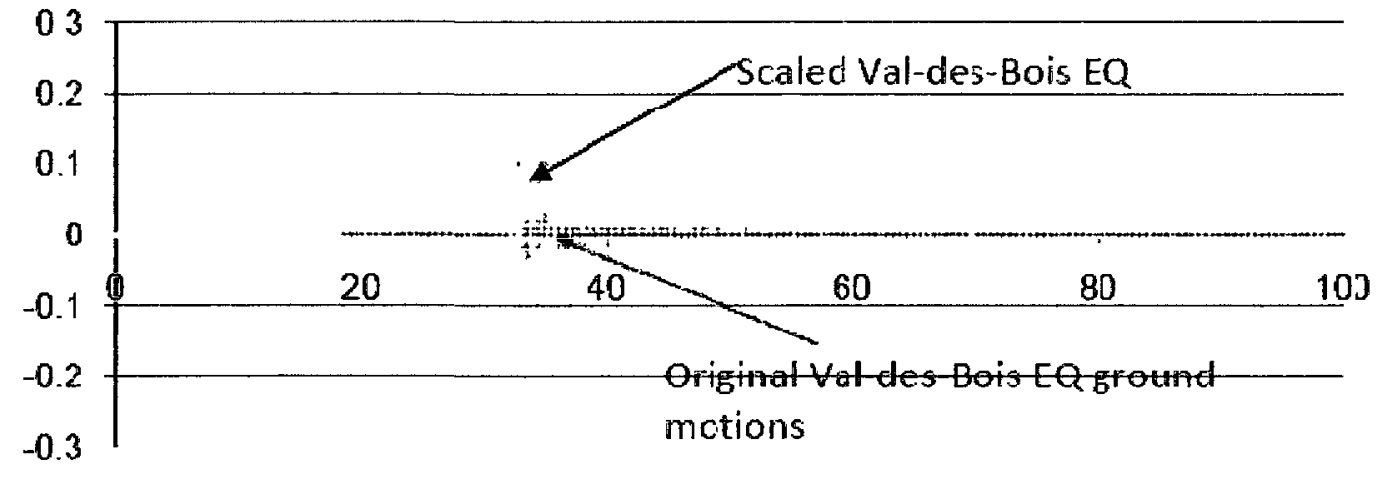

a) Val-des-Bois Earthquake ground motion Re01 scaled for $\mathrm{T} 1 \mathbf{= 0 . 6 2 \mathrm { s }}$

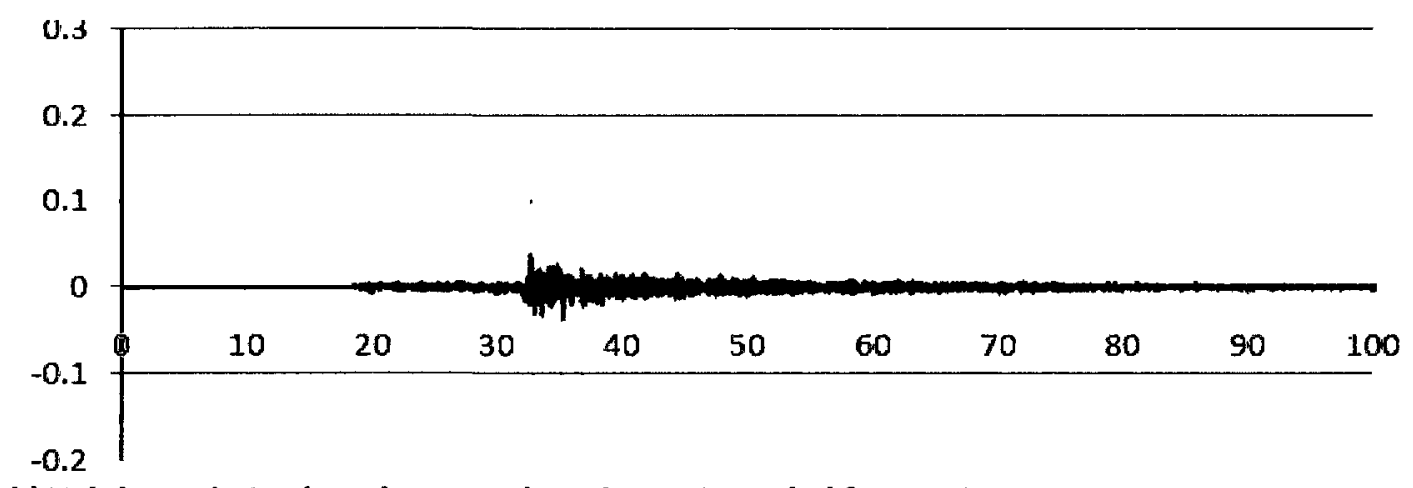

b) Val-des-Bois Earthquake ground motion Re01 scaled forT1 $=0.92 \mathrm{~s}$

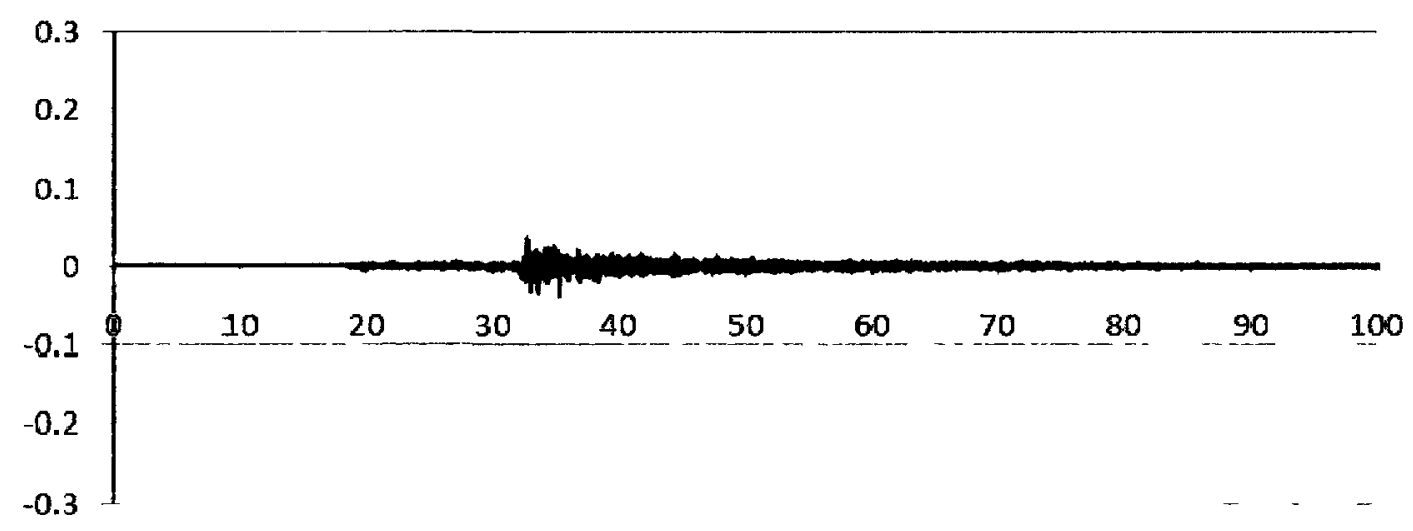

c) Val-des-Bois Earthquake ground motion Re01 scaled for T1 $=1.7 \mathrm{~s}$

Figure 3.15: Scaled Val-des-Bois Earthquake ground motion RE01 scaled to match the Ottawa $2 \%$ in 50-years UHS 


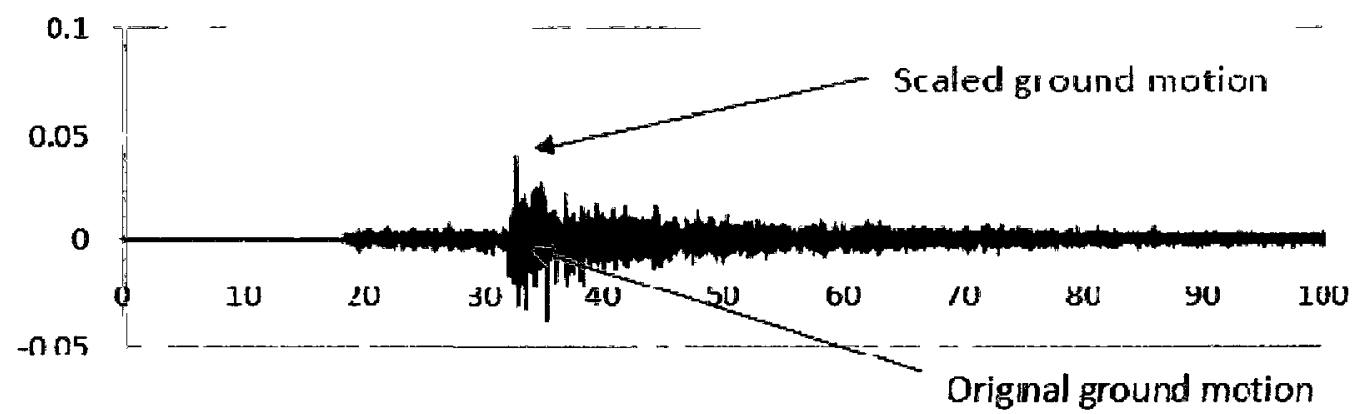

$-0.1$

a) Val-des-Bois Earthquake ground motion Re01 scaled for $\mathrm{T} 1=\mathbf{0 . 6 2 \mathrm { s }}$

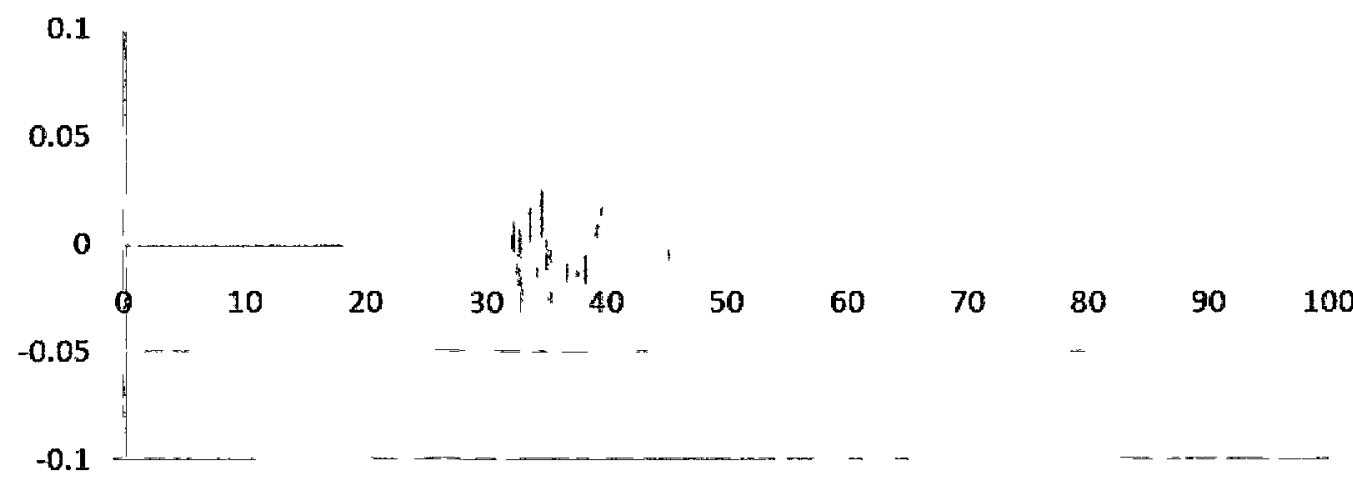

b) Val-des-Bois Earthquake ground motion Re01 scaled forT1 $=0.92 \mathrm{~s}$

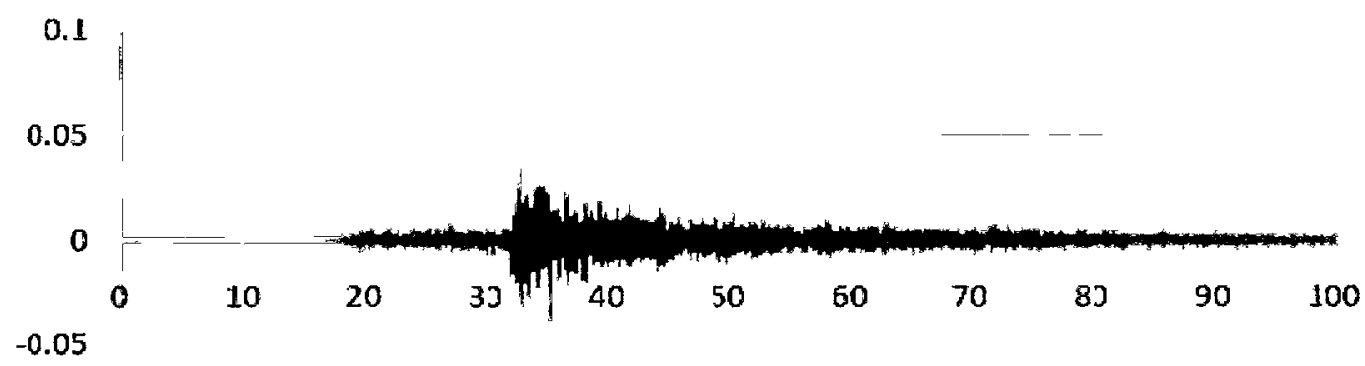

$-0.1$

c) Val-des-Bois Earthquake ground motion Re01 scaled for T1 $=1.7 \mathrm{~s}$

Figure 3.16: Scaled Val-des-Bois Earthquake ground motion RE01 scaled to match the Ottawa $10 \%$ in 50 -years UHS 


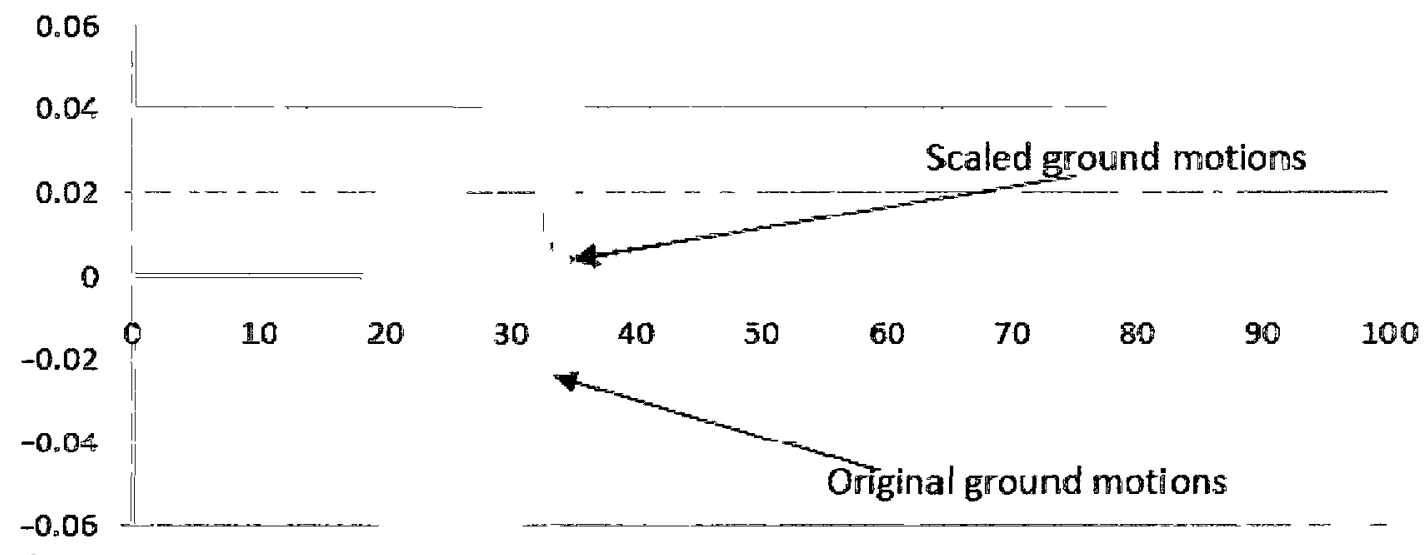

a) Val-des-Bois Earthquake ground motion Re01 scaled for $\mathrm{T} 1=\mathbf{0 . 6 2 \mathrm { s }}$

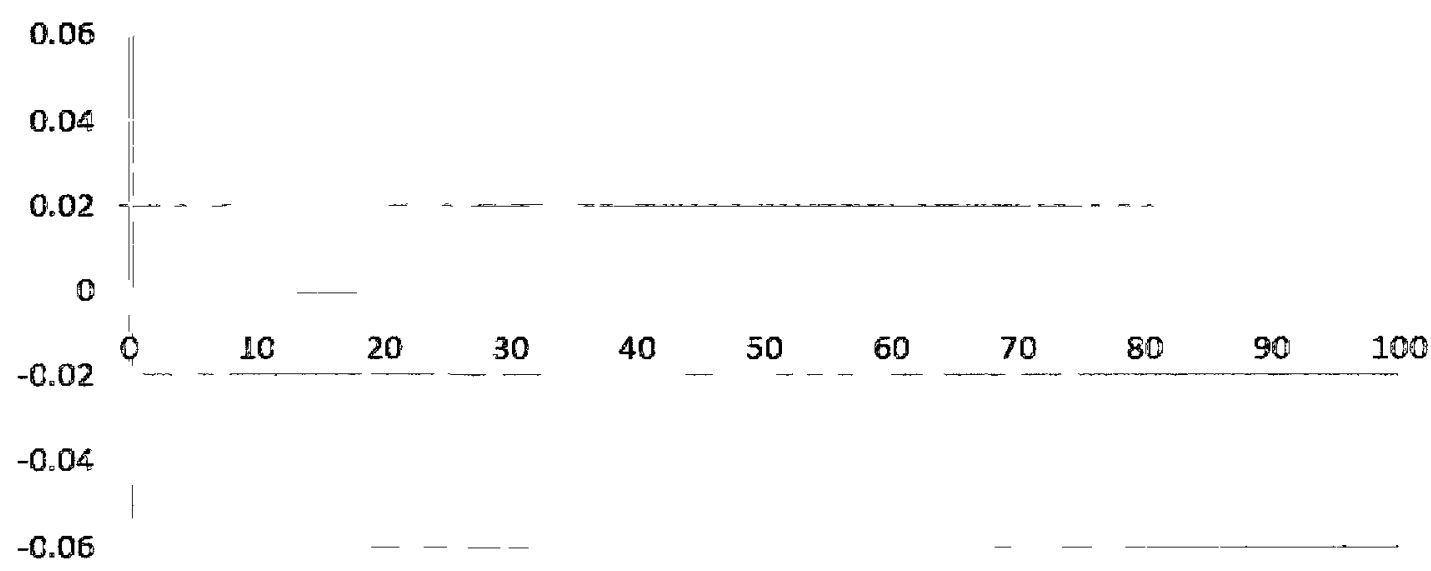

b) Val-des-Bois Earthquake ground motion Re01 scaled forT1 $=0.92 \mathrm{~s}$

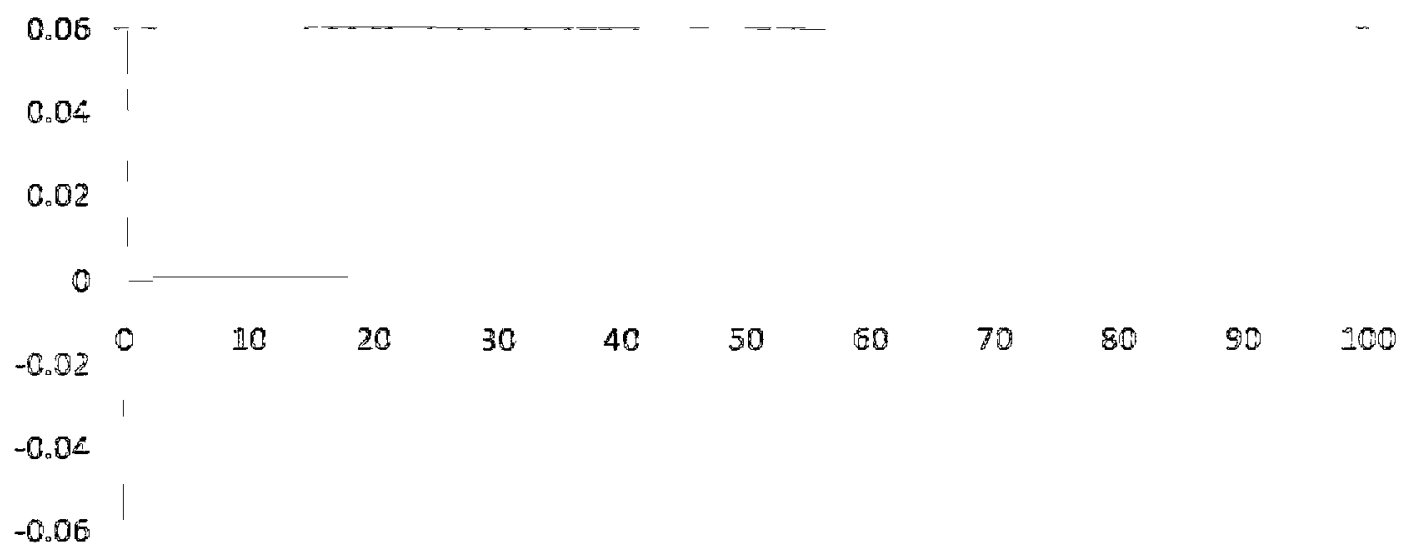

c) Val-des-Bois Earthquake ground motion Re01 scaled for T1 $=1.7 \mathrm{~s}$

Figure 3.17: Scaled Val-des-Bois Earthquake ground motion RE01 scaled to match the Ottawa $50 \%$ in 50 -years UHS 


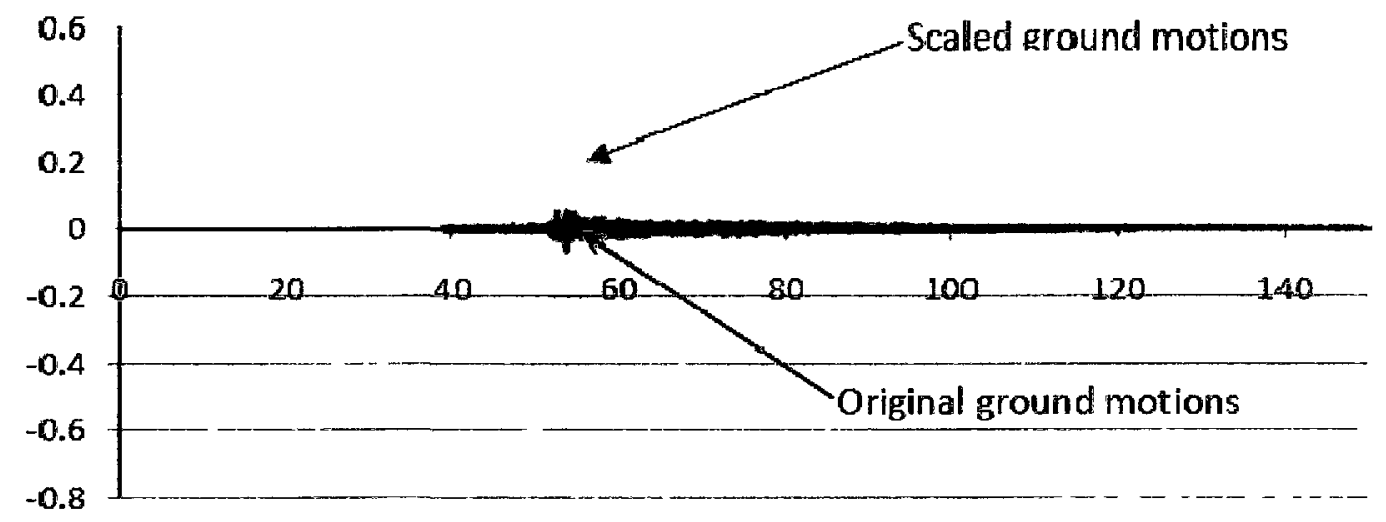

a) Val-des-Bois Earthquake ground motion Re01 scaled for $\mathrm{T} 1=\mathbf{0 . 6 2 \mathrm { s }}$

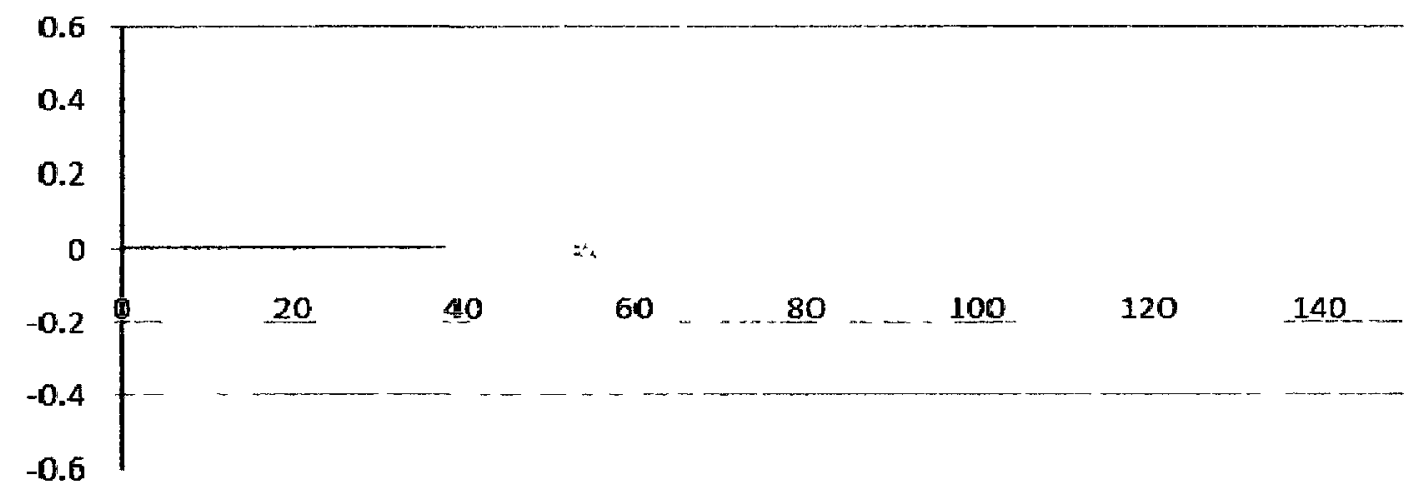

b) Val-des-Bois Earthquake ground motion Re01 scaled forT1 $=0.92 \mathrm{~s}$

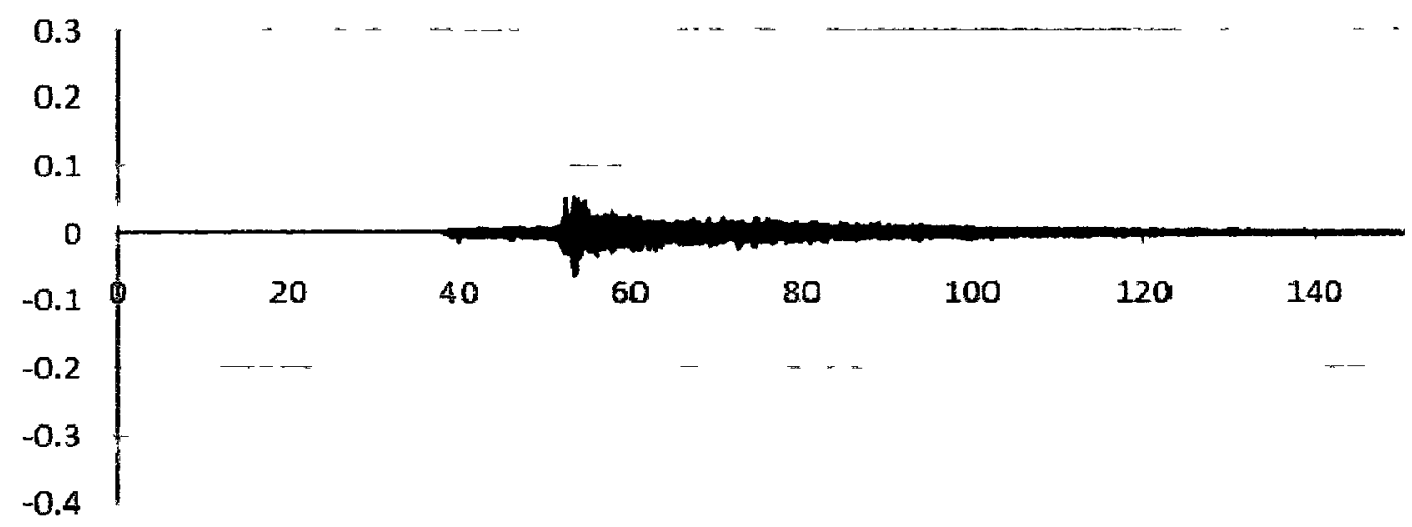

c) Val-des-Bois Earthquake ground motion Re01 scaled for T1 $=1.7 \mathrm{~s}$

Figure 3.18: Scaled Val-des-Bois Earthquake ground motion RE02 scaled to match the Ottawa $2 \%$ in 50-years UHS 


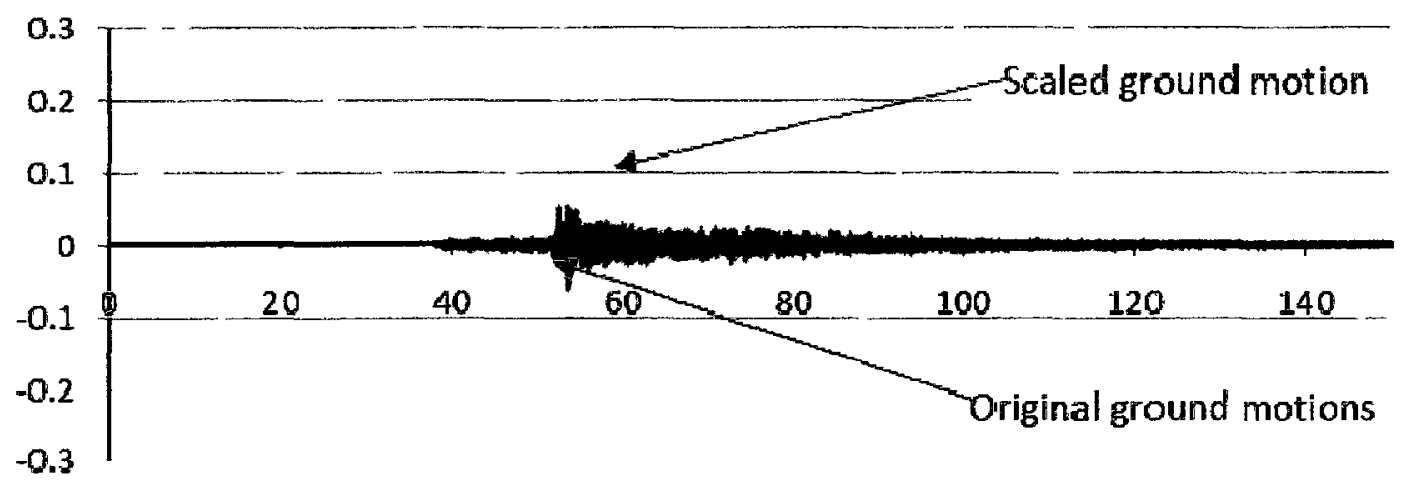

a) Val-des-Bois Earthquake ground motion Re01 scaled for $\mathrm{T} 1=0.62 \mathrm{~s}$

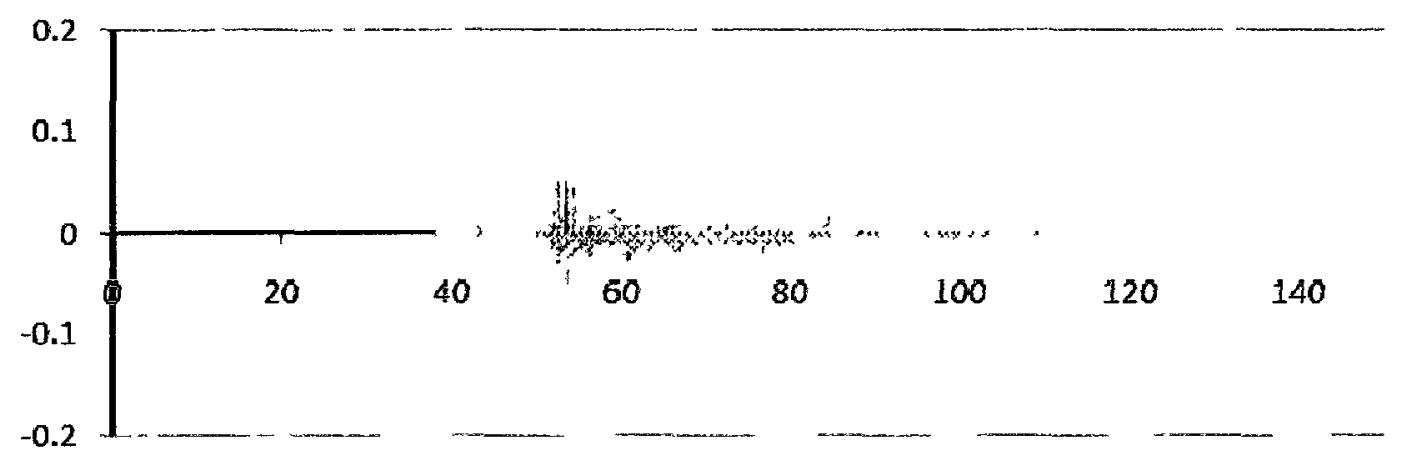

b) Val-des-Bois Earthquake ground motion Re01 scaled forT1 $=0.92 \mathrm{~s}$

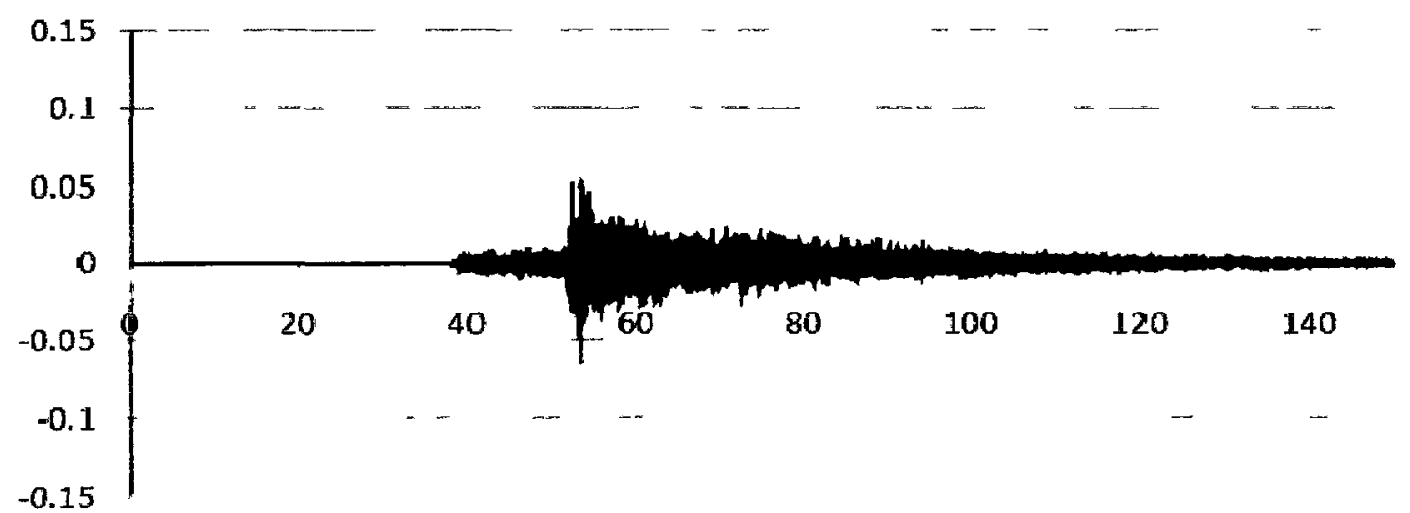

c) Val-des-Bois Earthquake ground motion Re01 scaled for $\mathrm{T} 1=1.7 \mathrm{~s}$

Figure 3.19: Scaled Val-des-Bois Earthquake ground motion RE02 scaled to match the Ottawa $10 \%$ in 50 -years UHS 


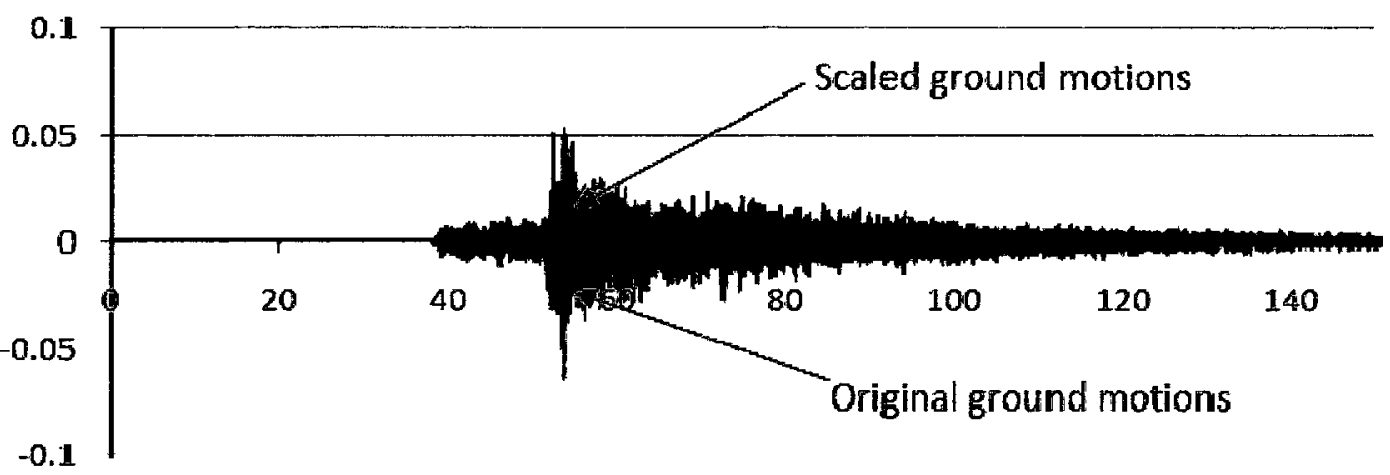

a) Val-des-Bois Earthquake ground motion Re01 scaled for $\mathrm{T} 1=\mathbf{0 . 6 2 \mathrm { s }}$

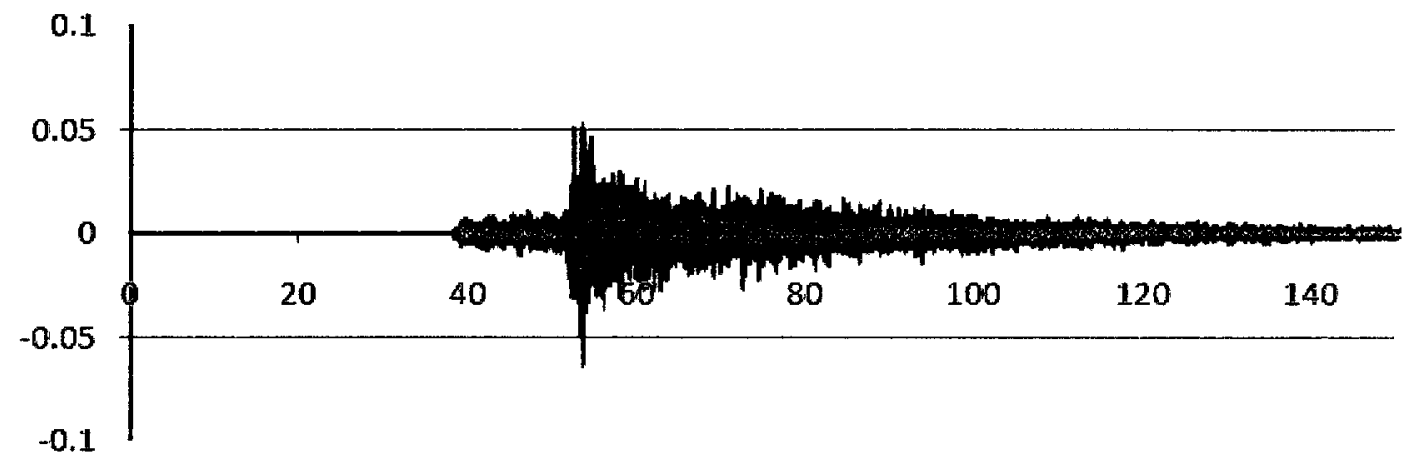

b) Val-des-Bois Earthquake ground motion Re01 scaled forT1 $=0.92 \mathrm{~s}$

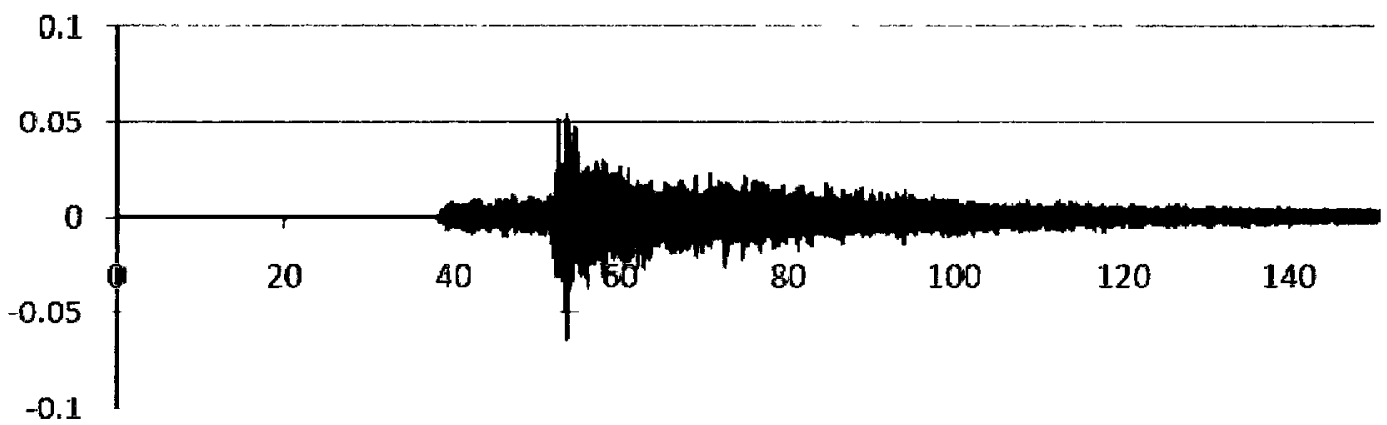

c) Val-des-Bois Earthquake ground motion Re01 scaled for $\mathrm{T} 1=1.7 \mathrm{~s}$

Figure 3.20: Scaled Val-des-Bois Earthquake ground motion RE02 scaled to match the Ottawa $50 \%$ in 50-years UHS 


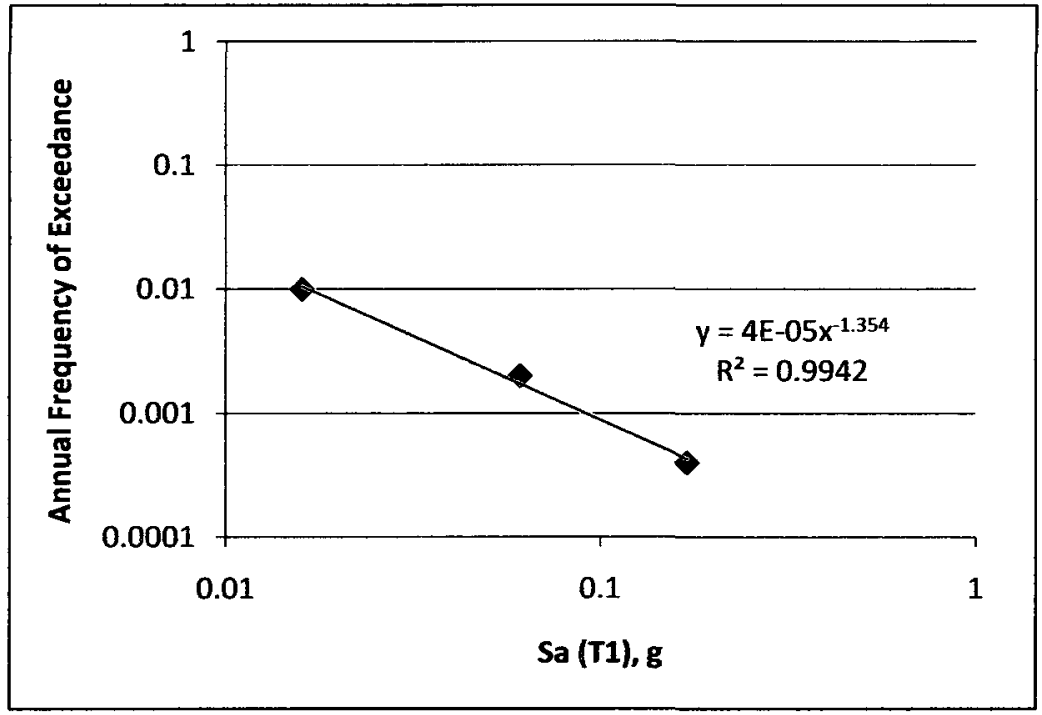

a) Hazard curve for bridge with fixed bearings $\left(T_{1}=0.92 \mathrm{~s}\right)$

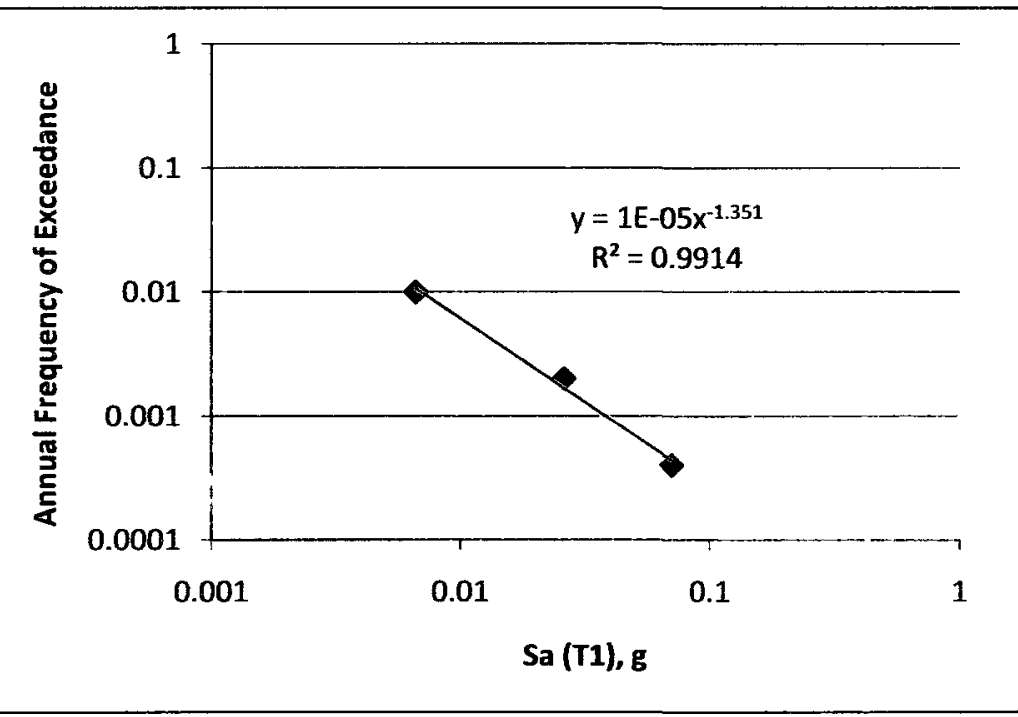

b) Hazard curve for bridge with expansion bearings $\left(T_{1}=1.7 \mathrm{~s}\right)$

Figure 3.21: Blair Bridge hazard curves 


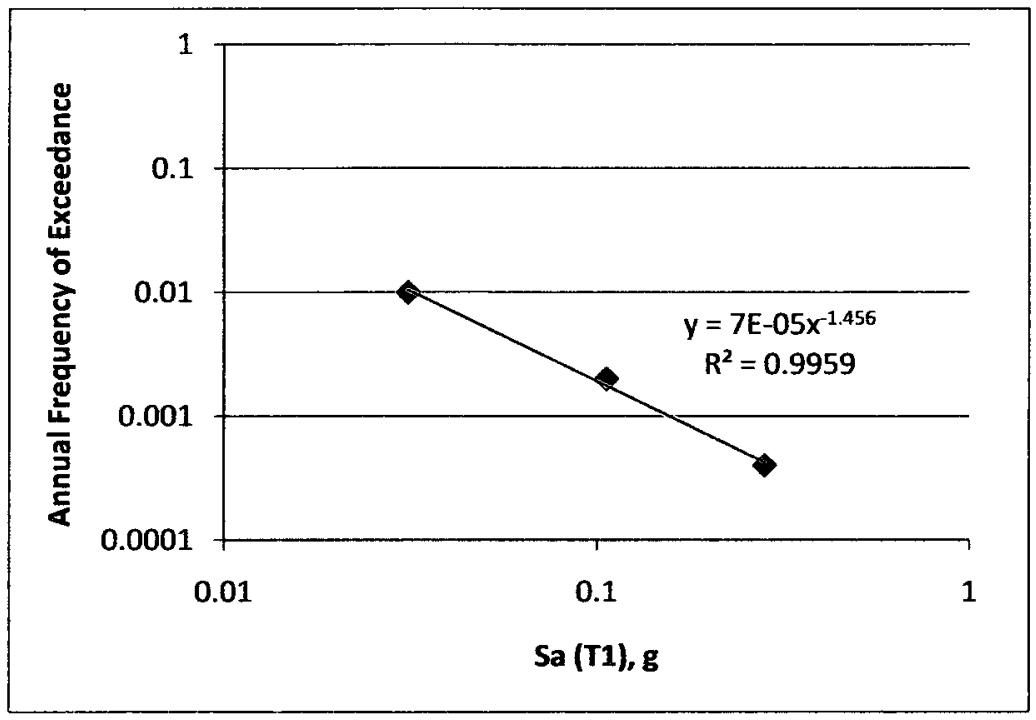

Figure 3.22: Nicholas Bridge hazard curves $\left(T_{1}=0.60 \mathrm{~s}\right)$ 


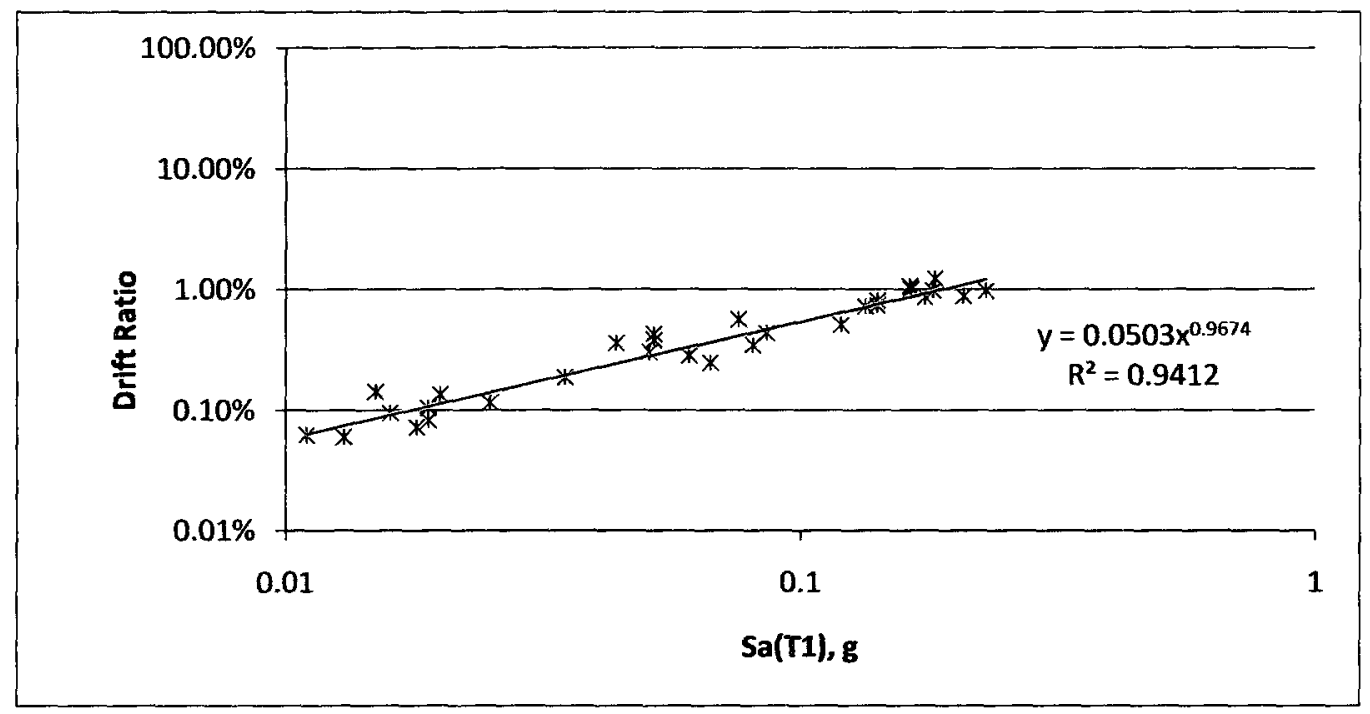

a) Demand curve for bridge with fixed bearing conditions $\left(T_{1}=0.925\right)$

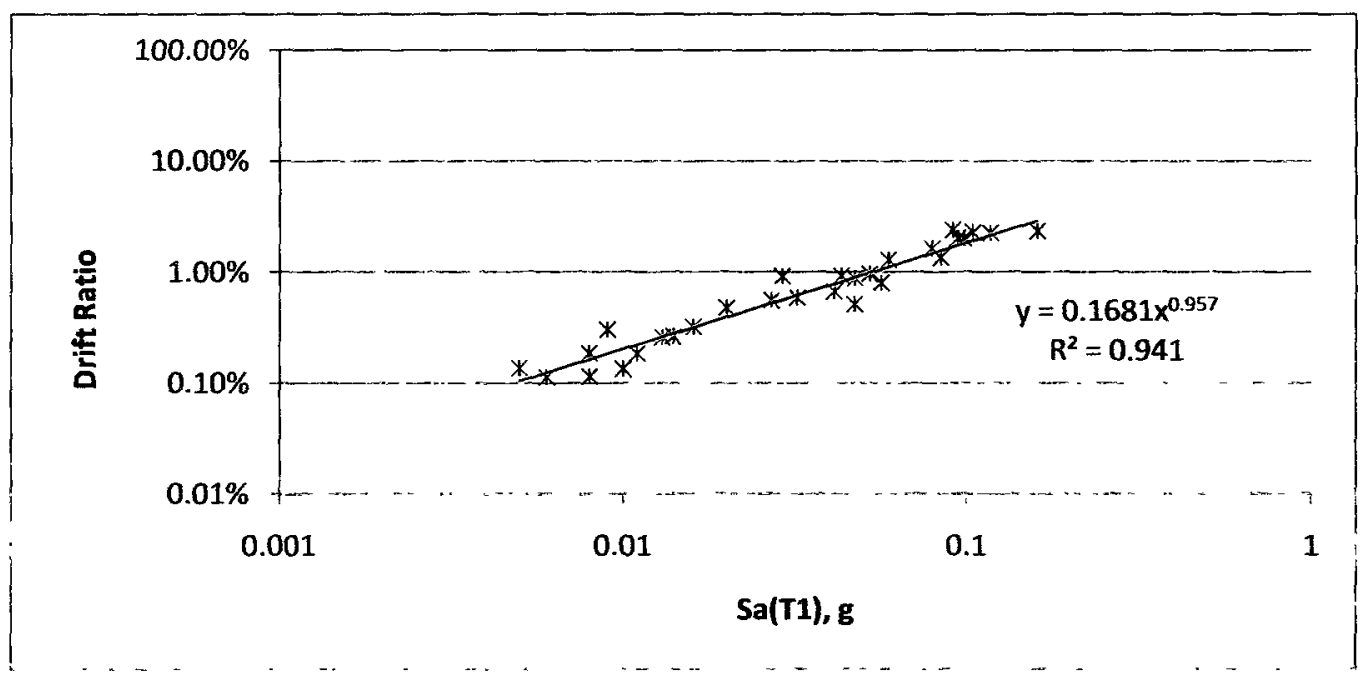

b) Demand curve for bridge with expansion bearing conditions $\left(T_{1}=1.7 \mathrm{~s}\right)$

Figure 3.23: Blair Bridge demand curves 


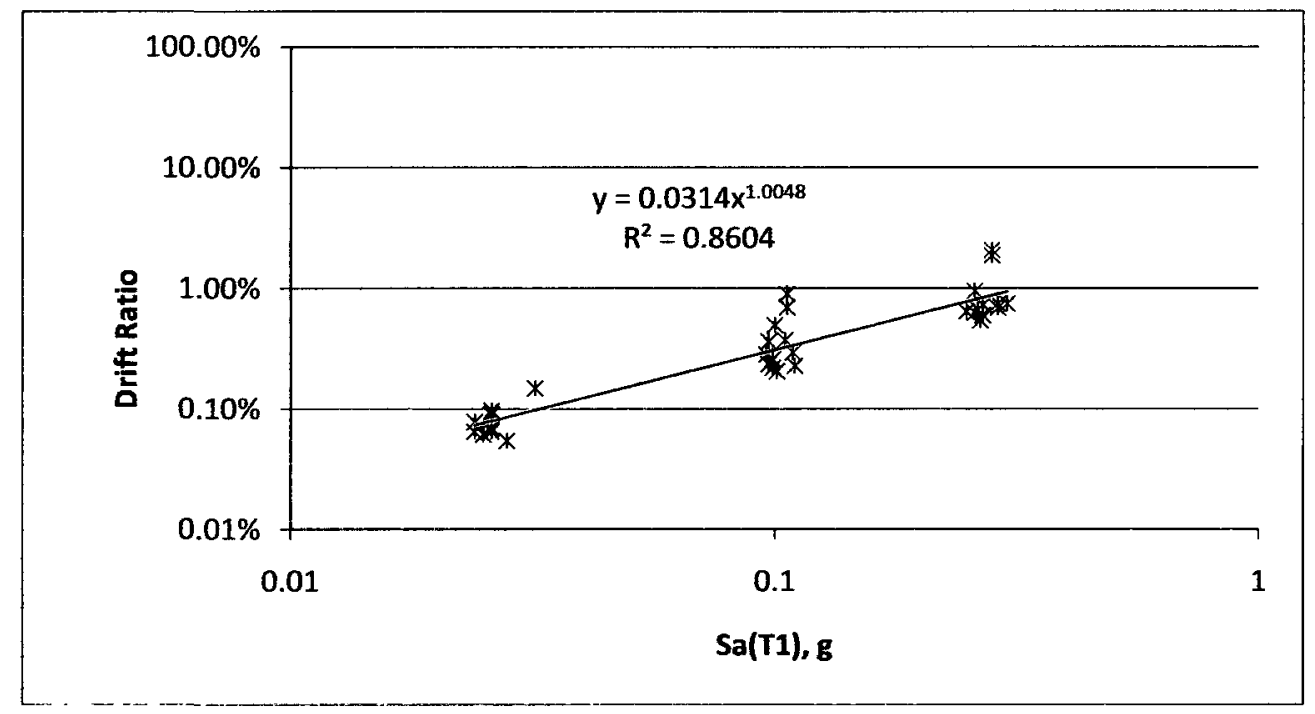

Figure 3.24: Nicholas Bridge demand curve $\left(T_{1}=0.60 \mathrm{~s}\right)$ 


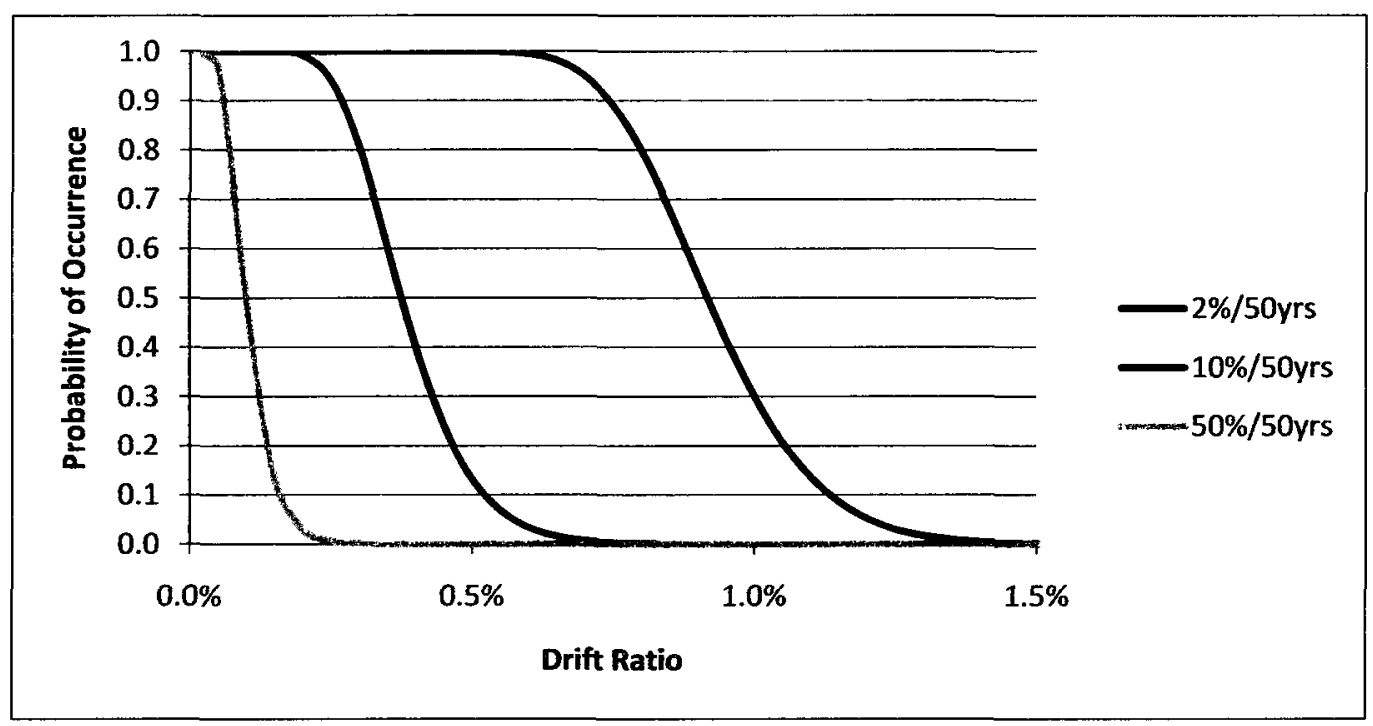

a) Probable drift ratio for bridge with fixed bearings $\left(T_{1}=0.92 \mathrm{~s}\right)$

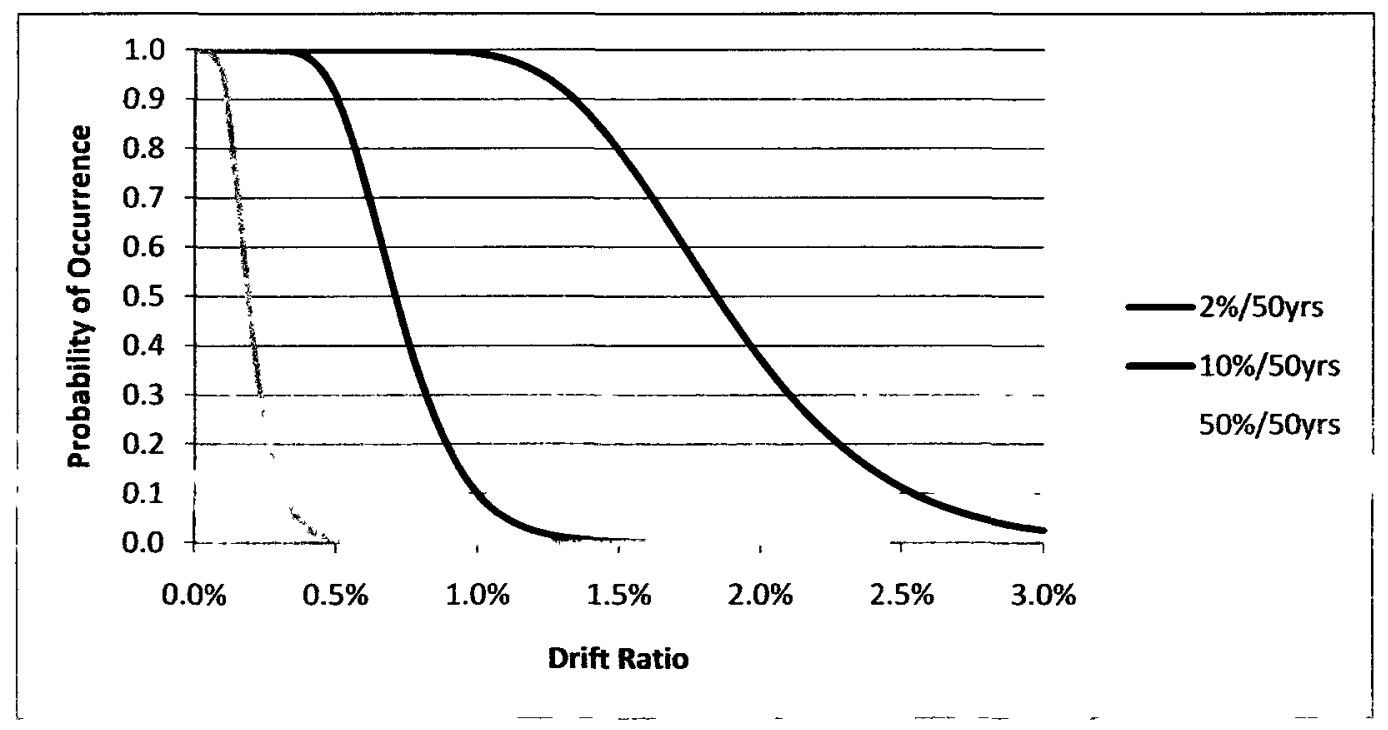

b) Probable drift ratio for bridge with expansion bearings $\left(T_{1}=1.7 \mathrm{~s}\right)$

Figure 3.25: Probable drift ratio of the Blair Bridge under low, moderate and high probable events 


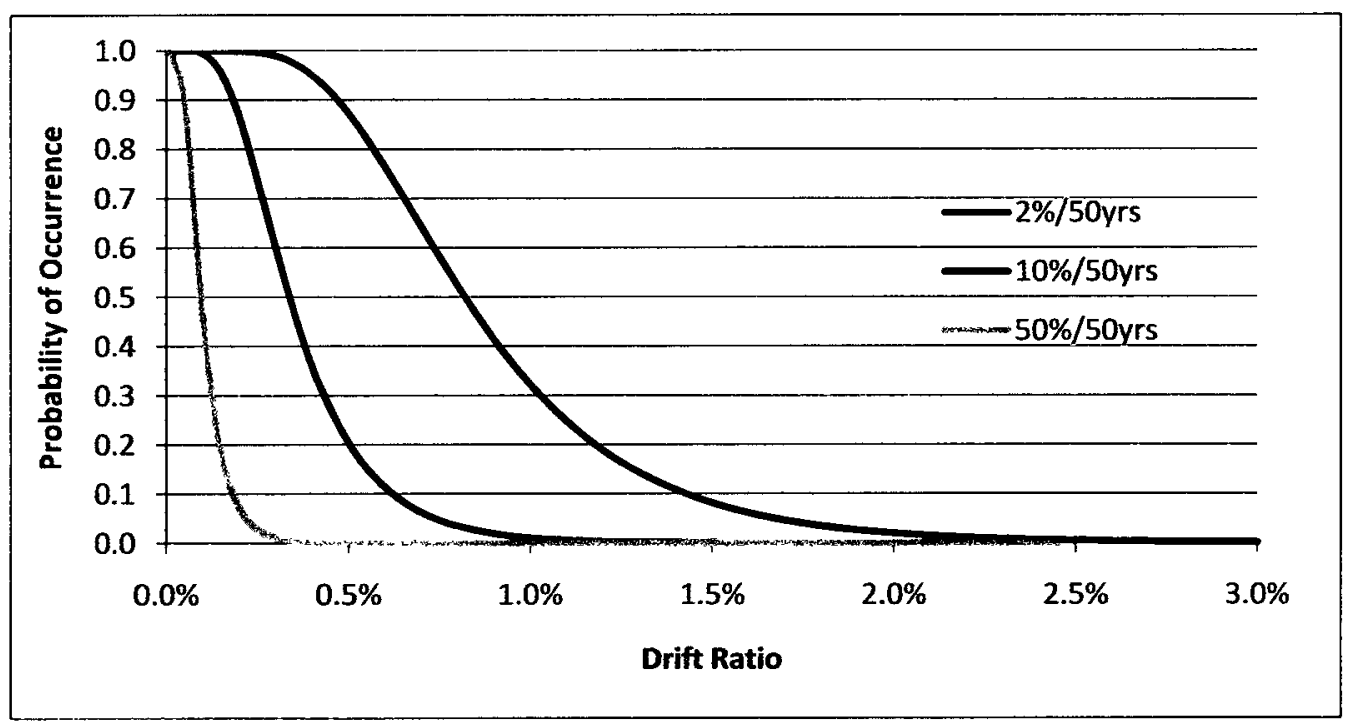

Figure 3.26: Probable drift ratio of the Nicholas Bridge under low, moderate and high probable events $\left(T_{1}=0.6 s\right)$ 


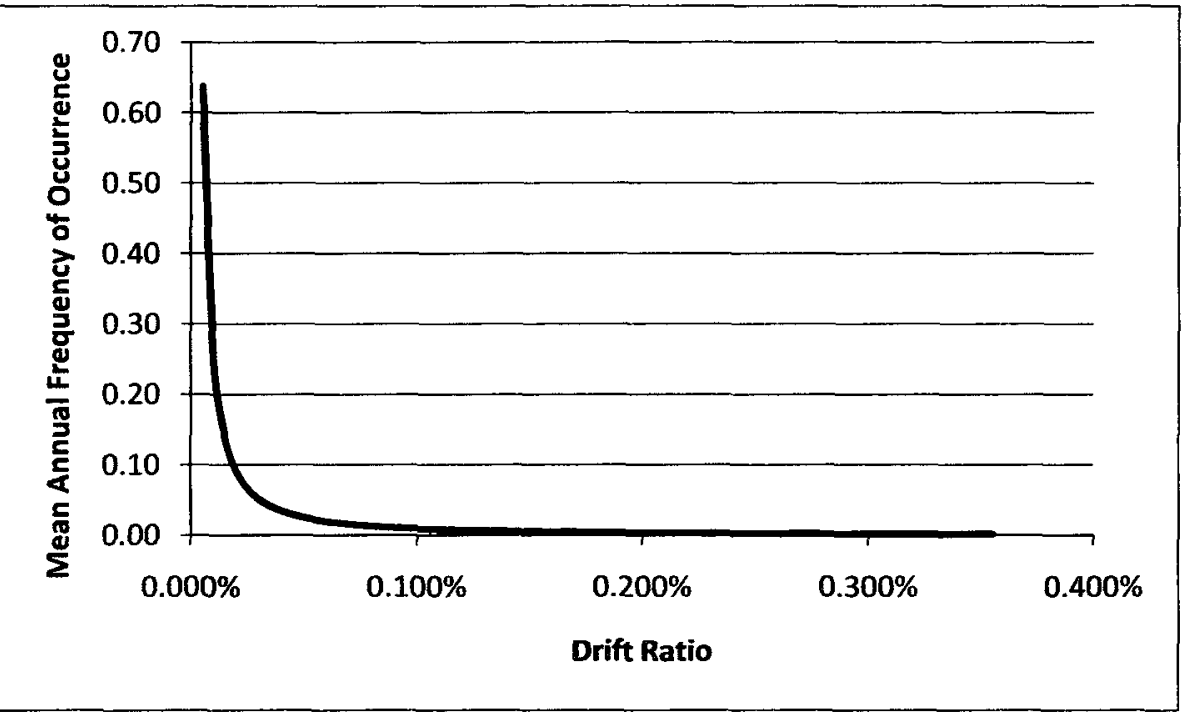

a) Mean annual frequency of exceeding a given drift ratio for bridge with fixed bearings $\left(T_{1}=0.92 \mathrm{~s}\right)$

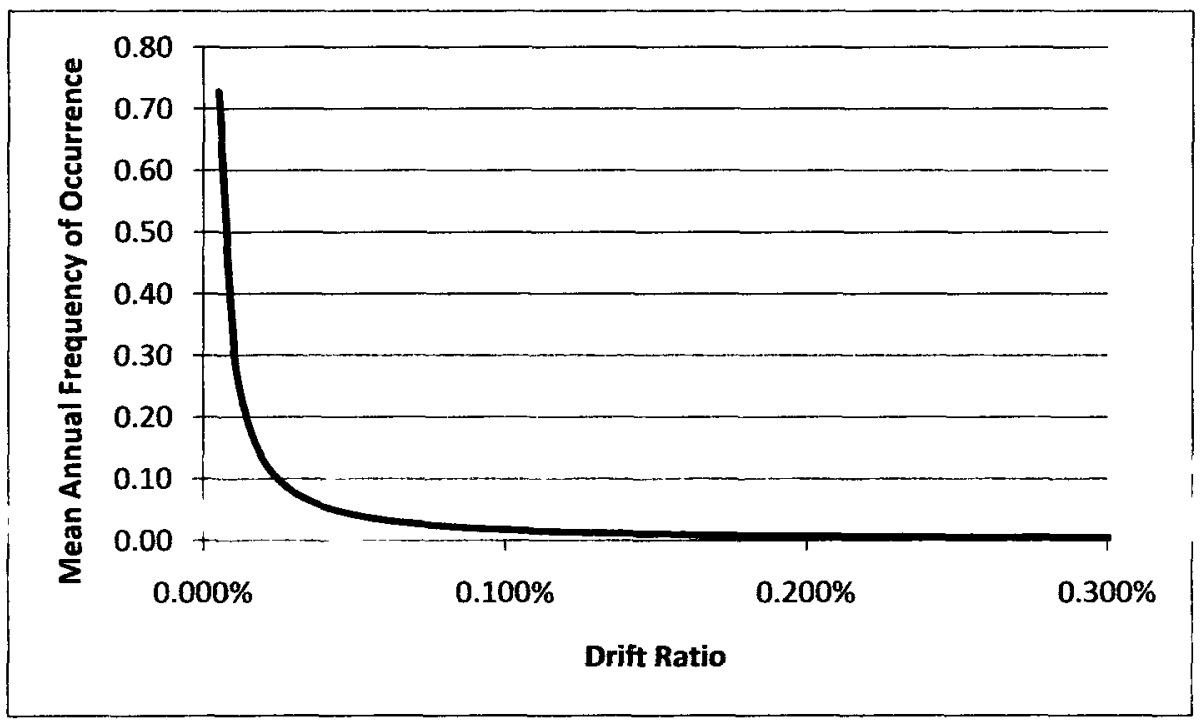

b) Mean annual frequency of exceeding a given drift ratio for bridge with expansion bearings $\left(T_{1}=1.7 \mathrm{~s}\right)$

Figure 3.27: Mean annual frequency of exceeding a given drift ratio for Blair Bridge 


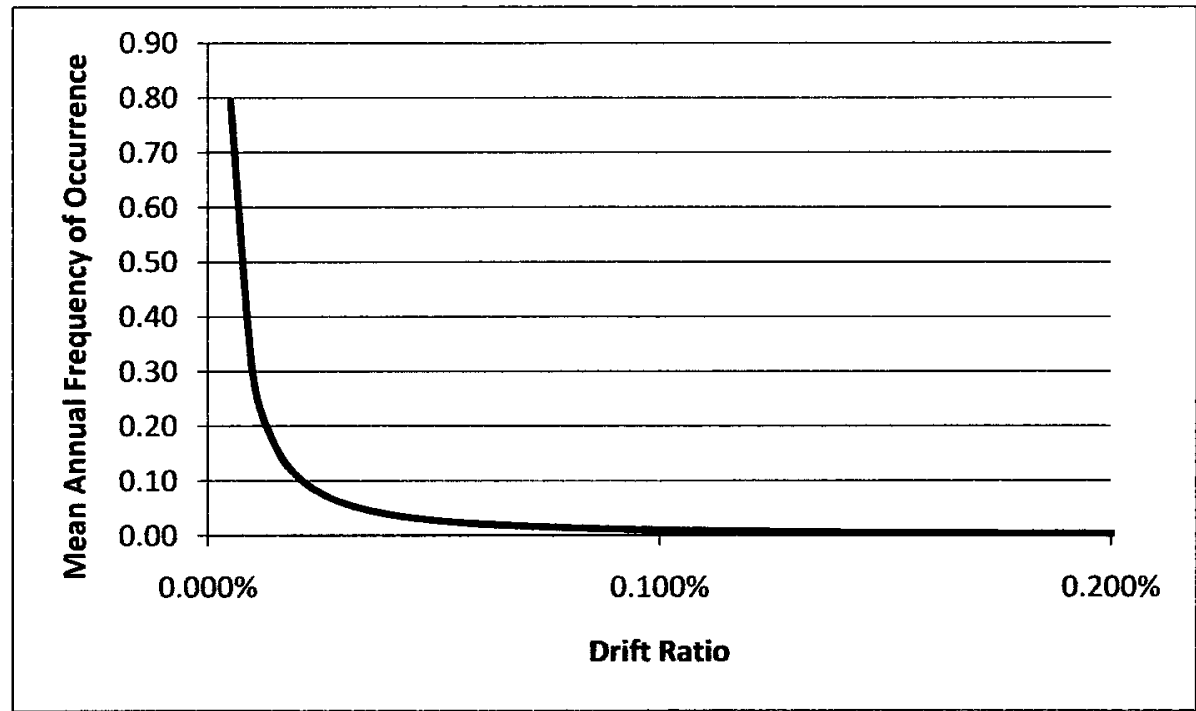

Figure 3.28: Mean annual frequency of exceeding a given drift ratio for the Nicholas Bridge $(\mathrm{T} 1=0.6 \mathrm{~s})$ 


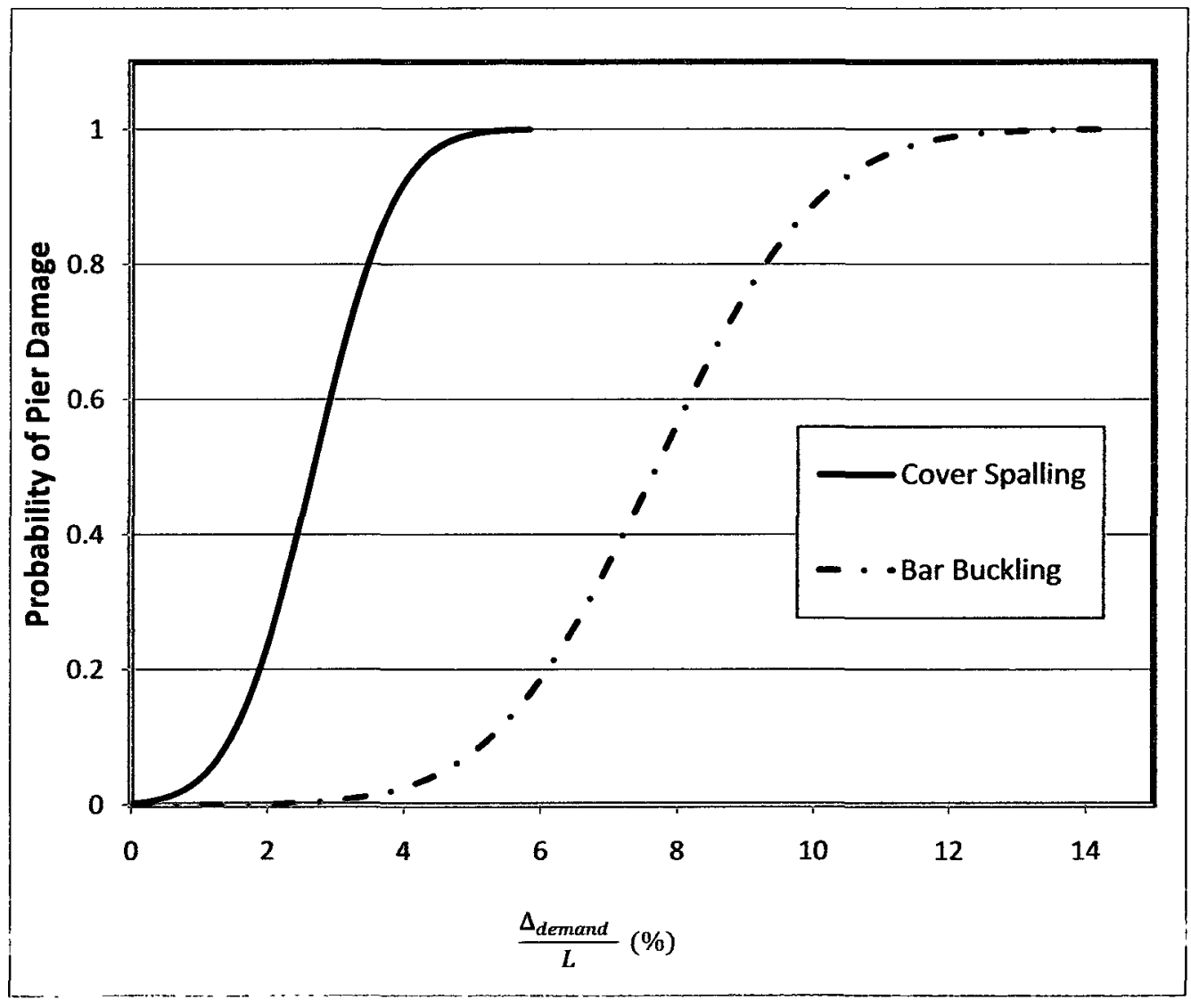

Figure 3.29: Damage fragility curve based on material and structural properties of the typical Blair bridge pier 


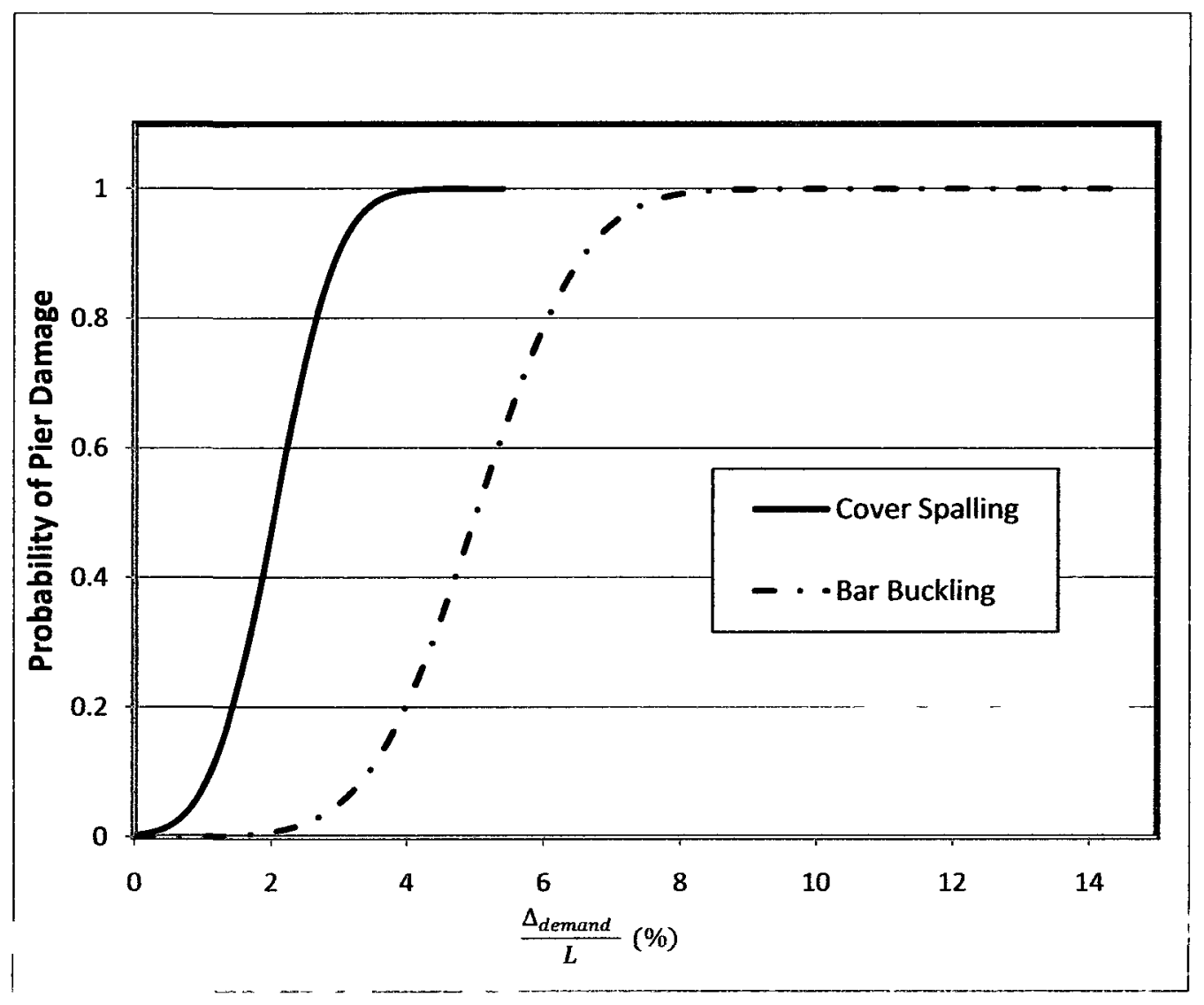

Figure 3.30: Damage fragility curve based on material and structural properties of the typical Nicholas Bridge pier 


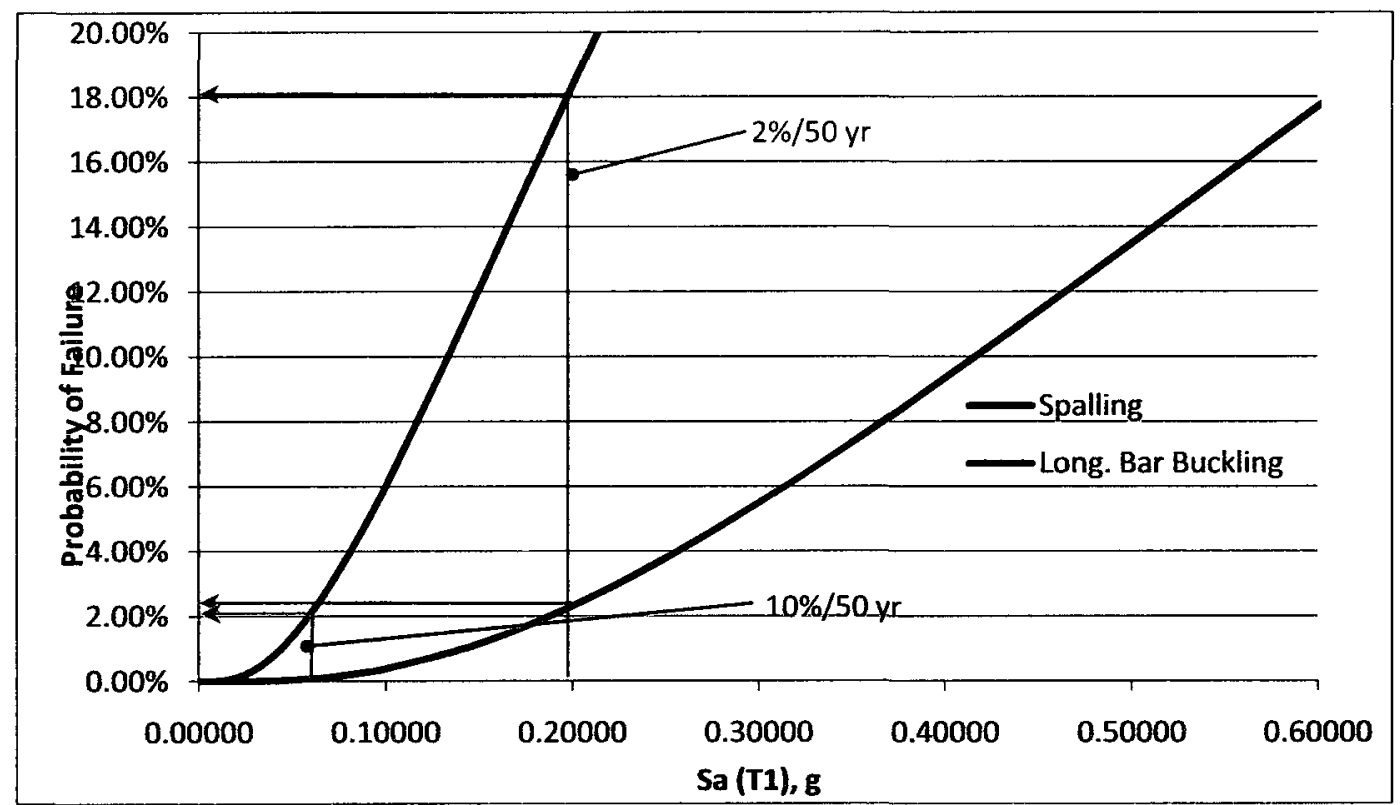

a) Probability of concrete spalling or longitudinal bar buckling for bridge with fixed bearings $\left(T_{1}\right.$ $=0.92 \mathrm{~s}$ )

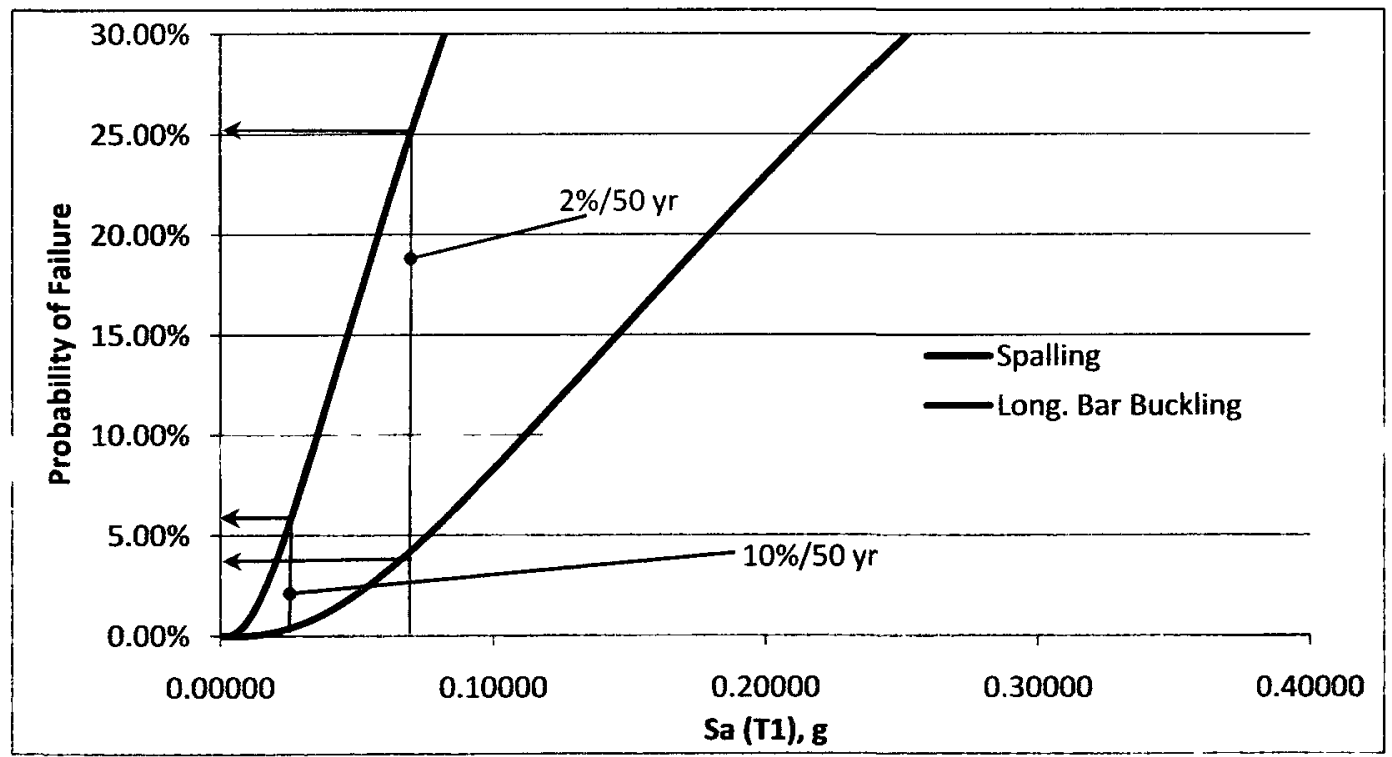

b) Probability of concrete spalling or longitudinal bar buckling given a level of seismic event for bridge with expansion bearings $\left(\mathrm{T}_{1}=1.7 \mathrm{~s}\right)$

Figure 3.31: Probability of concrete spalling or longitudinal bar buckling given a level of seismic event for the Blair Bridge 


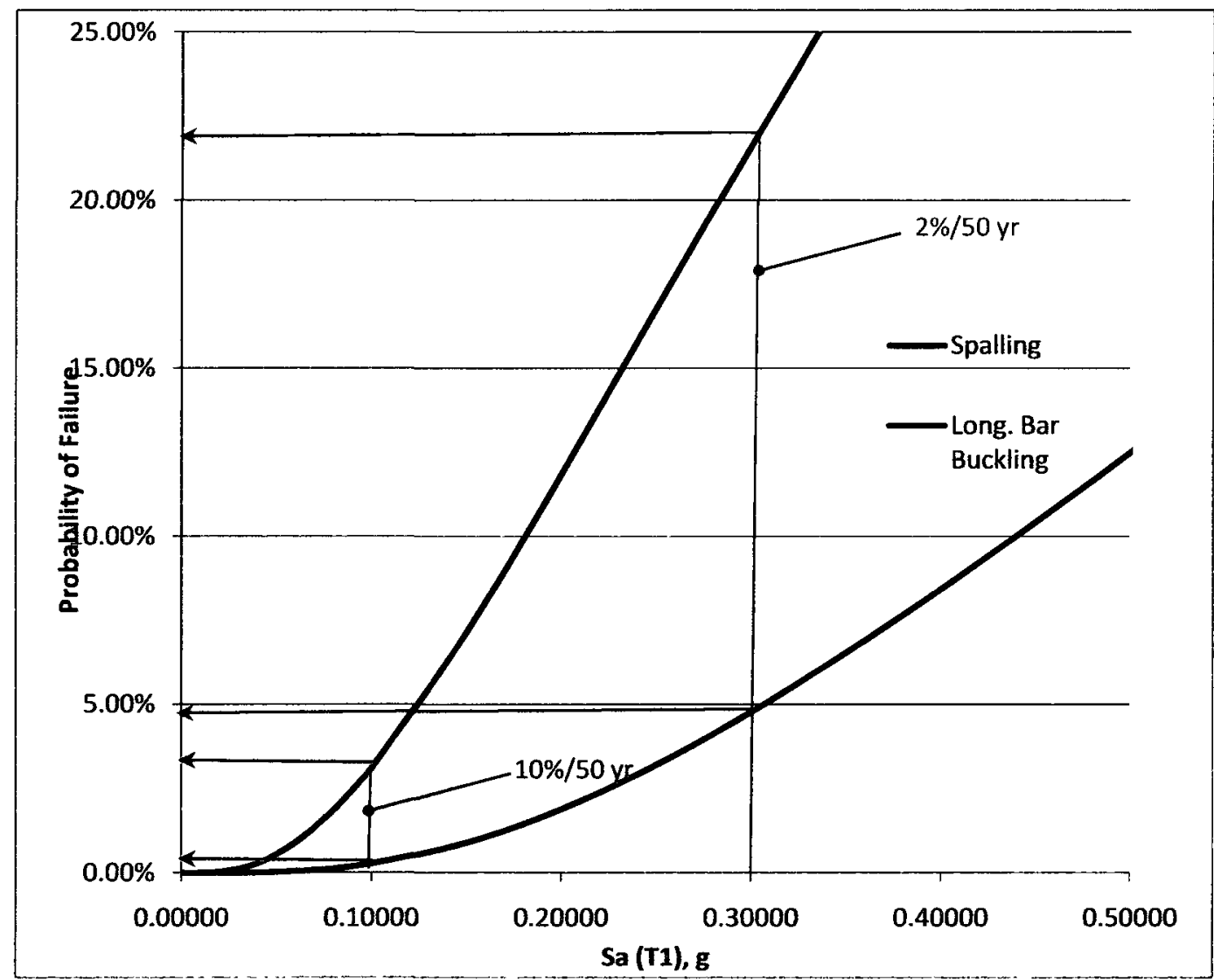

Figure 3.32: Probability of concrete spalling or longitudinal bar buckling given a level of seismic event for the Nicholas Bridge $\left(T_{1}=0.6 \mathrm{~s}\right)$ 


\section{Chapter 4 Performance-Based Seismic Risk Evaluation of Sample Bridge Inventory}

\subsection{General}

It is recognized from past research as well as from field observations and experience that existing bridge infrastructure designed and constructed using now obsolete standards decades ago are vulnerable to suffer severe damage or collapse during major earthquakes. It is therefore important to have a methodology capable to evaluate and quantify the seismic risk and vulnerability of existing inventory of bridge systems from a system perspective, not just for individual bridge structures. As it is not realistic to carry out nonlinear time-history analyses of all the bridges in an inventory, it is of interest to develop an evaluation approach that can provide

system performance information on the seismic risk and vulnerability of groups of 
bridges requiring only a relatively simple assessment procedure and analysis. Based on extensive literature review of published research no such approach has been developed.

Bridge structures can be grouped into categories based on structural layout and design detailing characteristics. In the development of the seismic risk assessment methodology it is assumed that bridges with similar characteristics will perform in a similar manner when subjected to similar earthquake loading. Theoretically, by developing fragility relationships in terms of selected structural characteristic parameters, a performance-based seismic risk assessment methodology can be developed that would be suitable for quick evaluation of the vulnerability of a large bridge inventory from a system perspective in a city, region or nationally. The system perspective information and assessment results from the developed methodology can be used to establish priority that would help with better decision making on resource allocation for more efficient and effective bridge infrastructure maintenance and management.

This research looks at two key failure mechanisms of bridge piers: spalling and longitudinal bar buckling of reinforced concrete bridges. The first failure mode of spalling of concrete cover in a reinforced concrete bridge column does not necessarily signify severe deterioration in the seismic resistance capacity of the bridge. It represents the exceedance of the linear elastic limit in the column member behavior which is the initiation of the damage state of the bridge structure. In the 
case of the second failure mechanism, longitudinal bar buckling does represent a significant deterioration of the moment capacity of pier column member. The consequence of longitudinal reinforcing bar buckling can have significant impact on the safety of the bridge depending on the configuration of the bridge under consideration. Comparing to typical multi-story buildings bridges tend to have less or limited redundancy and thus are more at risk to progressive collapse. If a bridge with single column piers, like the Nicholas Street Bridge discussed in Chapter 3, experiences longitudinal bar buckling in one of its piers resulting in that pier losing a significant part of its flexural capacity, the load it carried will get redistributed to the other remaining parts of the bridge of other piers or abutments. This redistribution can significantly increase the demand on adjacent piers which may result in their failure leading progressively to the total collapse of the structure. On the other hand, if a bridge has multi-column piers, like the Blair Road Bridge discussed in Chapter 3, the system may have more redundancy compared to a single column pier bent. When one of the columns in a multi-column bent experiences longitudinal bar buckling, the load it carries will first be redistributed to the remaining columns in the pier bent. If the load continues to increase or sustain at the same level, these other columns may also fail resulting in the load being redistributed to other remaining piers or abutments that are still intact and have capacity to resist seismic lateral load.

There are other failure mechanisms associated with seismic bridge damage and collapse, such as shear failure of piers especially of relatively stiff short pier 
columns, and loss of a span support. It is noted, however, the vulnerability of loss of span failure is directly related to the bearing and/or support seat width available and the relative displacement demand of the bridge structure. While the support seat width can be easily identified by examination of construction drawings of the bridge or by field inspection, the relative displacement demand can be estimated from the response or design spectrum which represents the seismic hazard of the bridge site considering the relevant dominant vibration modal period of the bridge for the loss of span failure, such as the vibration mode in the longitudinal direction, and the typical expected ductility capacity of the bridge structural members. It is therefore noted that loss of span support can be considered as a discrete event failure mechanism. By following the aforementioned estimation procedure, the potential of loss of span failure of a bridge can be evaluated by a relatively simple deterministic approach and thus is not included for assessment in the development of the quick probabilistic seismic risk assessment methodology for bridge inventories here.

In this chapter, the probabilistic performance based seismic risk assessment methodology developed in Chapter 3 is adapted to evaluate the seismic vulnerability of a representative sample inventory of bridges in the City of Ottawa. This work demonstrates how the methodology can be used to identify vulnerable bridges and establish priority among bridges. The presented work is a preliminary study as only a sample inventory of bridge are assessed to illustrate the overall approach of the assessment process. For actual application of the methodology, the fragility 
relationships may need to be calibrated by the detailed dynamic analysis of more bridges to improve their accuracy. Furthermore, the representative sample inventory consists of only a single type or class of bridges. The assessment methodology should be adapted for application to other types of bridges such as skewed, curved and steel bridges.

\subsection{Sample Bridge Inventory}

In collaboration with the City of Ottawa, 16 representative bridges are selected as the sample bridge inventory. This sample inventory includes bridges constructed between 1966 and 2005 and of varying geometric layout. Table 4.1 provides a list of the sample bridge inventory along with their geometric, material and structural properties that can be obtained or easily calculated from the available structural drawings. Sample Bridges 2 and 10 are the Blair Road Bridge and Nicholas Street Bridge for which detailed evaluations have been performed as discussed in Chapter 3. Sample Bridge 2 is split into two separate bridges ( $2 a$ and $2 b$ ) because of the two scenarios evaluated in Chapter 3 for the expansion bearing case (2a) and the fixed bearing case ( $2 \mathrm{~b})$. 


\subsection{Seismic Risk Assessment of Sample Bridge Inventory}

The basic premise of the assessment methodology developed in the present work is that structural performance of bridges is related to structural characteristic parameters. In order for the methodology to be developed suitable for easy application to a large inventory of bridges, these structural characteristic parameters should be easily identified with minimal effort from as-built or design drawings of the bridge. Three structural properties are selected for this investigation which include longitudinal reinforcement ratio $\left(\rho_{L}\right)$, volumetric transverse reinforcement ratio $\left(\rho_{s}\right)$ and span over column height ratio (Span/L). These characteristic properties are included in the sample inventory list presented in Table 4.1.

In the detailed evaluations discussed in Chapter 3 , the damage phase in the assessment methodology relates structural damage to demand given by drift ratio when bridge damage initiates. Therefore the structural characteristic parameters selected here should be parameters that are related to or would affect drift ratio behavior of the bridge so that the relationship between these selected structural characteristic parameters and seismic bridge damage can be established. It is expected that $\rho_{L}$ is a valid performance parameter in this regard since the amount of longitudinal reinforcement is directly related to the bending strength of the pier which directly affects the rigidity and ductility capacity of pier columns as can be described in terms of drift ratio. 
Drift ratio is also directly affected by the stiffness property of piers which provides resistance to the lateral seismic load. During earthquakes, the seismic effect is primarily the result of the inertia mass effect of the bridge mass undergoing acceleration response. Since the span of a bridge tributary to a lateral load resisting pier is directly related to the bridge mass, and the stiffness is proportional to the height of the pier, it is therefore expected that bridges with similar span to pier height ratio would have been designed similarly based on similar load requirements and thus can be expected to experience similar displacements during earthquakes. The ratio of span over pier height is therefore also selected as a performance parameter.

The amount of shear reinforcement in a pier column affects, not only the shear stiffness and shear deformation of the bridge column, but also affects the flexural displacement capacity due to bending. The ties or spirals provide confinement to the longitudinal reinforcement and concrete which have great influence to the ultimate drift capacity of the column pier. The confinement property also affects the cracking behavior of the concrete, and as a result affects the effective moment of inertia of the pier. Based on these considerations, it is expected that there may be a good correlation between $\rho_{s}$ and performance. 


\subsubsection{Fragility Relationship based on Pier Longitudinal Reinforcement Ratio}

To examine the probability of occurrence of the two failure modes of spalling and longitudinal bar buckling for the bridges in the inventory at the three hazard levels, first a relationship is developed to relate the probability of occurrence of each of the two failure modes as determined in Chapter 3 to the longitudinal reinforcement ratio $\left(\rho_{L}\right)$ of the pier. Table 4.2 presents the probability of occurrence of the two failure modes for each of the three hazard levels investigated for the Nicholas Bridge and the Blair Bridge determined from nonlinear time history analysis. In order for a relationship to be developed from these probabilities with the corresponding $\rho_{L}$ of the bridge columns, the structural characteristic parameter $\rho_{L}$ is modified based on the tributary lateral load carried by the bridge column. It can be expected that bridges designed during a particular period would have similar designs and capacities based on similar lateral load design requirements. In this investigation, the representative bridge inventory includes a variety of bridges of different geometric layout. Therefore an effective longitudinal reinforcement ratio $\left(\rho_{L}{ }^{*}\right)$ needs to be determined to compare the loading experienced by each pier. For this effective parameter, first an effective number of spans supported by a bridge pier column is determined by examining the bridge span between deck supports with lateral restraints. This is equal to the actual number of spans subtracting the number of bents supporting the deck between expansion bearings and subtracting 
half the abutment supports with expansion bearing as shown in Equation 4-1. The structural characteristic parameter $\rho_{L}$ is then modified by multiplying the total span of the bridge with the total bridge width to get the total deck area, and then dividing it by the product of the effective number of spans and the number of columns per bent to determine the tributary area per bridge column member, as shown in Equation 4-2, and then relating each bridge by dividing the result by a reference tributary area value, as shown in Equation 4-3. In this case, the reference area considered is the calculated area of the Sample Bridge 2a. Table 4.3 provides the parameters used in the modification of the structural characteristic parameter $\rho_{L}$ for each bridge in the inventory.

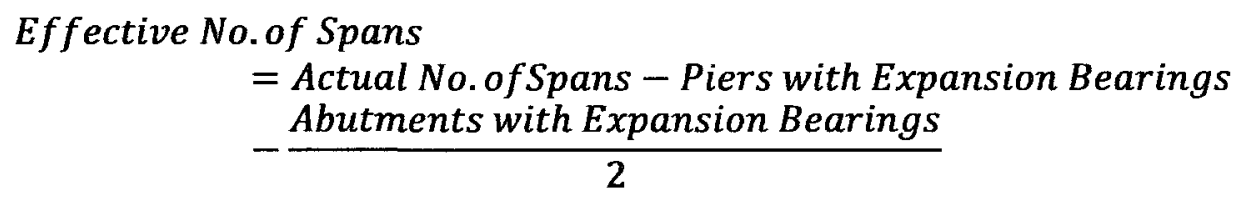

Tributary Span Area

$$
=\frac{\text { Bridge Length } \times \text { Bridge Width }}{\text { Effective No. of Spans } \times \text { No.of columns per pier }}
$$

$$
\rho_{L}^{*}=\frac{\text { Tributary Span Area }}{\text { Reference Span Area }}
$$

The approach to determining the modified tributary span carried by each pier is demonstrated in Figure 4.1 for the Blair Road Bridge with expansion bearings. As shown in Figure 4.1 the Blair Road Bridge has expansion bearings supporting the 
deck at the first and third pier as well as at both abutments. If the tributary spans supported by the piers are determined for gravity loads, the spans labeled actual tributary spans in Figure 4.1 would be used in the calculations. However, for determining the tributary span for which a pier provides resistance to the lateral motion response, the total span is divided amongst the supports with lateral restraints. In this case only the second pier provides lateral restraint in the longitudinal direction because of only vertical gravity load detailing design at the connections of the first and third pier with the deck. The seismic lateral load of the total bridge span is resisted by pier two only, as shown in Figure 4.1.

The effective longitudinal reinforcement ratio and the probabilities determined in Chapter 3 for each of the evaluated bridges have been plotted in Figures 4.2 to 4.7 for each hazard level and failure mechanism. Linear best fit curves to the data are plotted to represent the relationships between the probabilities of spalling or longitudinal bar buckling with the structural characteristic parameter $\rho_{L}{ }^{*}$. With only three data points, linear best fit is the reasonable trend choice. Although in reality the fragility relationship may be of higher order, it would be difficult to determine this high order relation using the limited data points because of uncertainty (or data scattering). More data points from nonlinear time history analysis are required to determine the trend of any higher order relationship. The correlation of the damage probabilities from all levels of seismic hazard show considerable scattering except with one exception. The correlation between the data points for probability of 
longitudinal bar buckling under the extreme event of $2 \%$ in 50 years is very high $\left(R^{2}=0.99\right)$.

Using the fragility relationships developed for each damage measure with respect to the modified structural characteristics parameter $\rho_{L}{ }^{*}$ probability of damage for the other bridges in the inventory are estimated. The results are shown in Table 4.3.

\subsubsection{Fragility Relationship Based on Span Over Pier Height Ratio}

Similar to the fragility relationship based on the longitudinal reinforcement ratio, a fragility relationship that relates the probability of bridge damage as discussed in Chapter 3 to the Span/L ratio is developed in this section. Similar to the discussion in Section 4.3.1, first a modified span/L ratio is determined based on the consideration of tributary lateral load resisted by each pier. This modification is done by determining the laterally supported tributary span carried by each column. The bridge span between deck supports with lateral resistance is determined as the actual number of spans subtracts the number of bents supporting the deck through expansion bearings and subtracts half the abutment supports with expansion bearing as previously discuss in Equation 4-1. The derivation of the effective span over pier height ratio (Span/L) as a structural characteristic parameter used in establishing a fragility relationship in the performance based seismic risk assessment of the sample inventory bridges are shown in Table 4.4. The effective 
span is then determined by dividing the total bridge length by the effective number of spans as shown in Equation 4-4. This effective span length is then used in the calculation of the effective span/L ratio which is plotted with the corresponding probabilities presented in Table 4.2 and a linear relationship is estimated for each hazard level for the probability of both failure modes of spalling of concrete cover and probability of longitudinal bar buckling, as shown in Figures 4.8 to 4.13 .

$$
\text { Effective Tributary Span Length }=\frac{\text { Span Length }}{\text { Effective No. of Spans }}
$$

The correlation of probability of damage with the structural characteristic parameter of effective span over pier height ratio show a very good correlation for all seismic hazard levels considered for the concrete spalling failure mechanism and for the low and moderate hazard events for the longitudinal bar buckling case. The extreme hazard event for the longitudinal bar buckling case had a poor correlation. The trend of the results is opposite to the fragility relationship based on the structural characteristic parameter of effective longitudinal reinforcement ratio $\rho_{L}{ }^{*}$.

Using the fragility relationships developed for each damage measure with respect to the effective structural characteristic parameter span/L*, probability of damage for the other bridges in the inventory are estimated. The results are shown in Table 4.4. 


\subsubsection{Fragility Relationship Based on Pier Transverse Reinforcement Ratio}

In this investigation, a fragility relationship that relates the probability of bridge damage to the transverse reinforcement ratio $\rho_{S}$ of bridge pier is also developed. As with the derivation of the fragility relationships based on the structural performance parameters $\rho_{L}{ }^{*}$ and span $/ L^{*}$, an effective transverse reinforcement ratio $\rho_{S}{ }^{*}$ is derived based on similar procedures adopted in the derivation of effective longitudinal reinforcement ratio $\rho_{L}{ }^{*}$ by considering the tributary bridge span area of which the seismic lateral load is resisted by a bridge pier. Table 4.5 shows the effective structural characteristic parameter $\rho_{S}{ }^{*}$ determined by following the same approach in the determination of $\rho_{L}{ }^{*}$.

The linear fragility relationships relating the probability of damage as determined in Chapter 3 with the structural characteristic parameters of effective transverse reinforcement ratio $\rho_{S}{ }^{*}$ for the evaluated bridges are plotted in Figures 4.14 to 4.19. The correlations between the damage probability from all levels of seismic hazard considered, are similar to those observed for $\rho_{L}{ }^{*}$.

Using the fragility relationships developed for each damage measure with respect to the effective structural characteristic parameter $\rho_{s}{ }^{*}$, probability of damage for the other bridges in the inventory are estimated. The results are shown in Table 4.5. 


\subsection{Discussions}

From observations of the results obtained, the selected structural performance characteristic parameters in the derivation of the fragility relationships of bridge damage or failure due to concrete spalling and longitudinal reinforcing bar buckling in pier column are effective indicators for quick assessment of a large stock of bridge inventory, especially at an extreme seismic hazard level ( $2 \%$ in 50 years).

Both effective structural characteristic parameters $\rho_{L}{ }^{*}$ and $\rho_{S}{ }^{*}$ have similar correlations between the effective parameter and the probabilities of failure for all levels of hazards. The correlation of the damage probabilities from all levels of seismic hazard show considerable scattering except with one exception. The correlation between the data points for probability of longitudinal bar buckling under the extreme event of $2 \%$ in 50 years is very high $\left(R^{2}=0.99\right)$ Longitudinal reinforcement ratio is a parameter directly related to strength and ductility and therefore under extreme seismic events when inelastic behavior is initiated there is a more consistent relationship as shown by the correlation. Transverse reinforcement ratio is indirectly related to the strength of the column. It provides confinement to the longitudinal reinforcement which provides the strength and ductility.

For the structural performance characteristic parameter of the effective span/L ratio, the results show an opposite trend compared to those observed from the 
fragility relationships based on structural characteristic parameters $\rho_{L}{ }^{*}$ and $\rho_{S}{ }^{*}$ results. The correlation of probability of damage with the structural characteristic parameter of effective span over pier height ratio show a very good correlation for all seismic hazard levels considered for the concrete spalling failure mechanism and for the low and moderate hazard events for the longitudinal bar buckling case. The extreme hazard event for the longitudinal bar buckling case has a poor correlation. These correlation results are likely due to the fact that Span/L is a geometric parameter rather than a strength parameter. It is related to strength and ductility behavior or performance of a bridge structure as an indirect parameter.

From these results, it appears the structural characteristics parameter of effective span/L ratio is a good performance parameter for quick assessment of the probability of the failure mechanism of spalling for all hazard levels and for the longitudinal bar buckling failure mode at low and moderate seismic hazard. For the extreme seismic hazard level of $2 \%$ in 50 years, both the effective structural characteristic parameter of $\rho_{L}{ }^{*}$ and $\rho_{S}{ }^{*}$ are good indicators for estimating the probability of longitudinal bar buckling failure of bridge columns. Table 4.6 shows a summary of the seismic risk assessment results of the sample inventory bridges using the probabilistic performance based seismic risk assessment methodology and the fragility relationships developed in this study. The performance based seismic risk assessment methodology can be employed to establish a priority list of vulnerable bridges for further more detailed evaluation. If the concern is to improve life safety and resilience the probable performance under the extreme seismic 
events should be investigated. Table 4.7 ranks the sample bridges based on the extreme seismic event and the results show that bridge 3,12 and 16 are bridges that should be investigated further. If the concern is to minimize repair costs and improve service by minimizing disruptions after an earthquake then the results of the low and moderate seismic events should be reviewed. Table 4.8 ranks the bridges in the sample inventory based on the probable performance under low and moderate seismic events. It is noted here that the observations presented here are preliminary results based on limited data. The purposed herein is to demonstrate the framework and steps in the new probabilistic performance based seismic risk assessment methodology based on easily determined structural characteristic parameters. The accuracy and reliability of the established fragility relationships between potential or probability of failure or bridge damage with the selected structural characteristic parameters should be improved by more nonlinear time history bridge analysis results in their calibration. 
Table 4.1: Sample Bridge Inventory General Properties

\begin{tabular}{|c|c|c|c|c|c|c|c|c|c|c|c|c|c|c|c|c|c|c|}
\hline & $\begin{array}{l}\text { Span } \\
\text { count }\end{array}$ & $\begin{array}{c}\text { Over all } \\
\text { span (m) }\end{array}$ & $\begin{array}{c}\text { Vax span } \\
\text { (min) }\end{array}$ & $\begin{array}{c}\text { Width } \\
\text { (iin] }\end{array}$ & Sleaw & I urve & $\begin{array}{c}\text { Pier beck } \\
\text { Supparts with } \\
\text { Expanston Hras }\end{array}$ & $\begin{array}{l}\text { Abutment Deck } \\
\text { suppopts with } \\
\text { bxpansion Brgs }\end{array}$ & $\underset{\text { Column per }}{\text { Bent }}$ & $\begin{array}{c}\mathrm{E}_{c}^{\prime} \\
\text { (Mpa) }\end{array}$ & $\begin{array}{c}f_{y} \\
\text { (mpa) }\end{array}$ & $\begin{array}{c}\mathrm{D} \\
\text { (inm) }\end{array}$ & $\mathbb{L}(n)$ & $\rho$. & $s(\mathrm{~nm})$ & Cover & $\rho$ 、 & 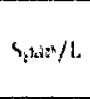 \\
\hline 1 & 2 & 160 & 181 & 77 & 28 & $\bar{v}$ & 0 & 2 & I & 38 & 230 & 7012 & 7 & $6.81 \%$ & 61.5 & 508 & 1981616 & 17 \\
\hline 2 & . & 863 & 22 & 249 & 11 & v & 2 & 2 & i & $3+=$ & 276 & $91 \%=$ & $6 B$ & $120 \%$ & 82.50 & 508 & $119 \%$ & 13 \\
\hline$:$ & $\frac{1}{8}$ & 븐 & 2765 & 241 & 0 & $v$ & 0 & 2 & 1 & 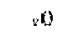 & $f(0)$ & 16100 & 61 & (1) $2 \mathrm{f} " \mathrm{wO}_{\mathrm{g}}$ & 1,0 & 70 & $0060^{\circ}$ & ; \\
\hline i & 2 & bl & $10=$ & 1945 & 1. & v & (1) & 2 & 1 & 10 & .00 & 400 & $\therefore 129$ & $220 \%$ & 70 & (0) & $1.83 \%$ & 39 \\
\hline$\ddot{z}$ & \& & $1=$ & $\because 8$ & 1. & 0 & v & 1 & 2 & 1 & .0 & $r(00)$ & 150 & 91 & $0601 \%_{0}$ & 150 & 80 & $102 \%$ & 60 \\
\hline$t_{3}$ & $i$ & 168 & $i=2$ & $1+7$ & 110. & 1 & 1 & 2 & 2 & 11 & . & 1067 & .79 & $.62^{114}$, & 1016 & , if 83 & $082 \%$ &, 9 \\
\hline$T$ & $i$ & 84 & 39 & 14 & 93 & v & (3) & 2 & 2 & (4) & .00 & 1300 & $i j$ & $20+1 \%$ & 96 & 80 & $067 \%^{\prime \prime}$ & 36 \\
\hline 8 & $\overline{3}$ & Dino & $14 ;$ & 12 & i) & v & 1 & 2 & 2 & 276 & 00 & 1219 & $i 2$ & 0 10. & 305 & 762 & $020 \%$ & $6:$ \\
\hline ' & $:$ & -71 & 214 & 197 & 0 & 1 & 0 & 2 & 1 & 300 & 230 & 9108 & 92 & $168 \%$ & 762 & 308 & $128 \%$ & 23 \\
\hline 10 & $\$$ & 72 & 37 & 78 & 1) & v & 0 & 2 & $i$ & 30 & 600 & $1 \leqslant 0$ & 50 & $031 \%$ & 70 & 80 & $0+2 \%$ & 63 \\
\hline 11 & fs, & 8409 & 26 & ; & 11 & v & $i$ & 2 & 1 & 3.5 & +00 & 1200 & 76 & $2 ! 20_{0}^{\circ}$ & 60 & 80 & $12 B^{\prime \prime}$ & a. \\
\hline 12 & . & 618 & $1 ; 0$ & 7 & 0 & v & 2 & 2 & $i$ & 276 & 275 & 827 & $\because 2$ & $02830^{\circ}$ & 381 & 014 & $007 " \%$ & 30 \\
\hline 11 & i & 114 & $\Leftrightarrow$ & 314 & 13 & v & 2 & 2 & 1 & $3 n\}$ & rov & 1 jous & $\therefore$ & 153146 & $\pi$ & 80) & $1]^{16,110}$ & y: \\
\hline 3 & $i$ & $\therefore$ & 18 & 61 & 0 & v & 1 & 2 & 2 & 3.3 & 500 & 1200 & 78 & $170 \%$ & 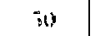 & 10 & 16216 & 23 \\
\hline 97 & $i$ & $3 \leqslant 2$ & $1=4$ & 10. & (1) & $v$ & i) & 2 & 2 & 276 & 600 & 0772 & 47 & $05 x / 6$ & 305 & 30) 8 & $(129 \%$ & 10 \\
\hline 16 & , & $8899 ;$ & 36 & 167 & 1, & v & 1 & 2 & 1 & 31) & 000 & $1 \leq 00$ & 6. & $100 / 6$ & 300 & 80 & 018,0 & 30 \\
\hline
\end{tabular}


Table 4.2: Probability of Spalling and Longitudinal Bar Buckling for Low, Moderate and Extreme Earthquake Events for the Evaluated Bridges

\begin{tabular}{|c|c|c|c|c|c|c|}
\hline \multirow{2}{*}{ Evaluationed inventory } & \multicolumn{3}{|c|}{ Probability of Spalling Failure } & \multicolumn{3}{|c|}{ Probability of Long. Bar Buckling } \\
\hline & $50 \% / 50 \mathrm{yr}$ & $20 \% / 50 y r$ & $28 / 50 \mathrm{yr}$ & $50 \% / 50 y r$ & $10 \% / 50 \mathrm{r}$ & $2 \% / 50 \mathrm{yr}$ \\
\hline $\begin{array}{l}\text { Nicholas Bndgc } \\
\text { Blarir Brdge (Expansion Bearng Case) }\end{array}$ & $\begin{array}{l}012 \% \\
030 \%\end{array}$ & $\begin{array}{l}3196 \\
59 \%\end{array}$ & $\begin{array}{l}216 \% \\
254 \%\end{array}$ & $\begin{array}{l}0003 \% \\
0006 \%\end{array}$ & $\begin{array}{l}0.27 \% \\
042 \%\end{array}$ & $\begin{array}{l}480 \% \\
430 \%\end{array}$ \\
\hline Blar Bndge (Fixed Bearng Case) & $011 \%$ & $21 \%$ & $184 \%$ & $0001 \%$ & $008 \%$ & $230 \%$ \\
\hline
\end{tabular}


Table 4.3: Estimated Probabilities of Spalling and Longitudinal Bar Buckling based on Effective Longitudinal Reinforcement Ratios

\begin{tabular}{|c|c|c|c|c|c|c|c|c|c|c|c|c|c|c|c|c|}
\hline & \multirow[b]{2}{*}{ Actual pa } & \multirow[b]{2}{*}{ 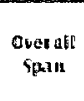 } & \multirow[b]{2}{*}{$\begin{array}{l}\text { Deek } \\
\text { W idth }\end{array}$} & \multirow[b]{2}{*}{$\begin{array}{l}\text { Spun } \\
\text { Count }\end{array}$} & \multirow{2}{*}{$\begin{array}{c}\text { Piet Deet Suppourts } \\
\text { wtht Qxpansiust } \\
\text { Bigs }\end{array}$} & \multirow{2}{*}{$\begin{array}{l}\text { Alvut ingent Deets } \\
\text { Supports with } \\
\text { Expans ion Brgs }\end{array}$} & \multirow{2}{*}{$\left|\begin{array}{c}\text { Ravilsed Span Caunt } \\
\text { chased ou tateral } \\
\text { load earrying piers) }\end{array}\right|$} & \multirow[b]{2}{*}{ Columun per } & \multirow[b]{2}{*}{\begin{tabular}{|} 
Trhutear yspan \\
Area per coltumn
\end{tabular}} & \multirow[b]{2}{*}{$p_{i}^{*}$} & \multicolumn{3}{|c|}{ Probuabilieg of Spalling L Lillure } & \multicolumn{3}{|c|}{ Probabllity of Long Ber Huckllise } \\
\hline & & & & & & & & & & & $50 \% / 50 y 6$ & $10 \% / 50 y r$ & $2 \% / 50 \mathrm{gr}$ & $50 \% / 50 y r$ & $10 \% / 50 y 1$ & $2 \mathrm{H}_{\mathrm{h}} / 50 \mathrm{yr}$ \\
\hline 1 & $441 \%$ & 366 & Lद & 2 & 0 & 2 & $\bar{I}$ & 2 & 287.7 & $80 \%$ & $007 \%$ & $036 y_{1}$ & $1357 \%$ & $000 \%$ & $000 \%$ & $000 \%$ \\
\hline $2 \theta$ & $120 \%$ & $8 i$ & 239 & 4 & 2 & 2 & $i$ & 4 & 5139 & $12 \%$ & $030 v_{1}$ & $59 \%$ & $2 F_{\mathrm{n}} 4 \gamma_{1}$ & onost & $42 y_{1}$ & $430 v_{1}$ \\
\hline 20 & $20 \%$ & sis & 239 & 4 & 0 & 2 & 3 & 4 & 171.3 & $36 \%$ & $011 \%$ & $21 \%$ & $1 \mathrm{R}+\mathrm{H} \%$ & acolix & $000 \%$ & $2.30 \%$ \\
\hline 3 & $1324 \%$ & 823 & 233 & i & is & 2 & 2 & $i$ & $9 \% 8.8$ & $01 y_{4}$ & 0203 & $4 \%$ & $2379 \%$ & $000 \%$ & $037 \%$ & $495 \%$ \\
\hline 4 & $320 \%$ & 61 & 1996 & 2 & (3) & 2 & $i$ & $i$ & 405.7 & $2 B Y_{i}$ & 0 otgy, & $311 \%$ & $2034 y_{1}$ & $000 \%$ & $018 \%$ & $295 \%$ \\
\hline 5 & $060 \%$ & $14^{5}$ & 14 & 3 & 1 & 2 & 1 & $i$ & 20300 & $02 y_{1}$ & $0204_{1}$ & $450 \%$ & $2376 \%$ & $000 \%$ & $097 \%$ & $494 \%$ \\
\hline 5 & 4624 & $6 \div 6$ & 197 & 3 & 1 & 2 & 1 & 2 & 449.4 & $53 y_{t}$ & D11\% & $179 \%$ & $17 \mathrm{~L} 0 \%$ & $000 y_{1}$ & Donos, & $108 \%$ \\
\hline 7 & 2040 & B? & 13 & 3 & 0 & 2 & 2 & 2 & 2698 & $39 \%$ & $0.13 y_{3}$ & $257 \%$ & $1892 \mathrm{z}$ & $000 y$ & $0.0 \%$ & $213 \%$ \\
\hline 8 & $030 \%$ & $15, G$ & 145 & ç & 3 & 2 & 1 & 2 & 11354 & $01 \gamma^{\prime}$ & $0.20 \%$ & 4513 & $2978 \%$ & $000 \xi_{1}$ & 0378 & $495 \%$ \\
\hline 9 & $16 \mathrm{~B} y$ & 5,71 & 197 & i & 0 & 2 & 2 & $i$ & 187.5 & $101 \%$ & $009 y$, & Door & $10 \mathrm{Bg}_{\mathrm{w}}$ & ucosy & $000 \gamma_{1}$ & $000 \%$ \\
\hline 10 & $011 \%$ & 35,2 & $7 \mathrm{~B}$ & 3 & $\mathbb{a}$ & 2 & 2 & 1 & 293.3 & $023 \%$ & $012 y_{3}$ & $11 \#_{1}$ & $216 \%$ & $000033_{3}$ & $027 \%$ & $480 \%$ \\
\hline 11 & $212 Y_{1}$ & 131,9 & 45 & $G$ & 3 & 2 & 2 & 1 & $30 \mathrm{Br} .0$ & $35 \%$ & 0148 & $271 y_{1}$ & $19.37 \%_{1}$ & $000 \%$ & $013 \%$ & $279 \gamma_{1}$ \\
\hline 12 & $028 \%$ & 6,37 & 7 & 4 & 2 & 2 & 1 & 1 & 445.9 & $03 y_{1}$ & $019 \gamma_{1}$ & $441 H_{1}$ & $2354 \%$ & $000 \%$ & $036 \%$ & $481 \gamma_{1}$ \\
\hline 13 & $113 \%$ & 113 & $\operatorname{ton} 3$ & 4 & 2 & 2 & 1 & 1 & 11639 & $05 \%$ & $019 \%$ & $432 \psi_{1}$ & $2731 \%$ & $000 \%$ & $034 Y_{5}$ & $467 \%$ \\
\hline 14 & $170 \%$ & 47 & 63 & 3 & 1 & 2 & 1 & 2 & 141.8 & $G_{2} \gamma_{4}$ & $0.10 \psi_{5}$ & $173 \%$ & $1596 \%$ & $0000 y^{\prime}$ & $0000 y_{1}$ & $042 \%$ \\
\hline 15 & $v 5_{54} y_{1}$ & 432 & $10 r_{0}$ & 4 & 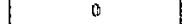 & 2 & 2 & 2 & 87 2 & $92 x_{4}$ & $015 \%$ & $290 y_{1}$ & $19 \mathrm{A2} 2 \mathrm{\gamma}_{3}$ & $000 x$ & $0.5 Y_{3}$ & $266 y_{2}$ \\
\hline 16 & $100 \%$ & 1895 & 169 & ; & 3 & 2 & l & 1 & 31647 & $02 \psi_{4}$ & $020 \%$ & $449 \%$ & $237 \sigma_{0} y_{s}$ & $000 \%$ & $037 \%$ & $49.3 \gamma_{1}$ \\
\hline
\end{tabular}


Table 4.4:-Estimated Probabilities of Spalling and Longitudinal Bar Buckling based on Effective Span over Pier Height Ratios

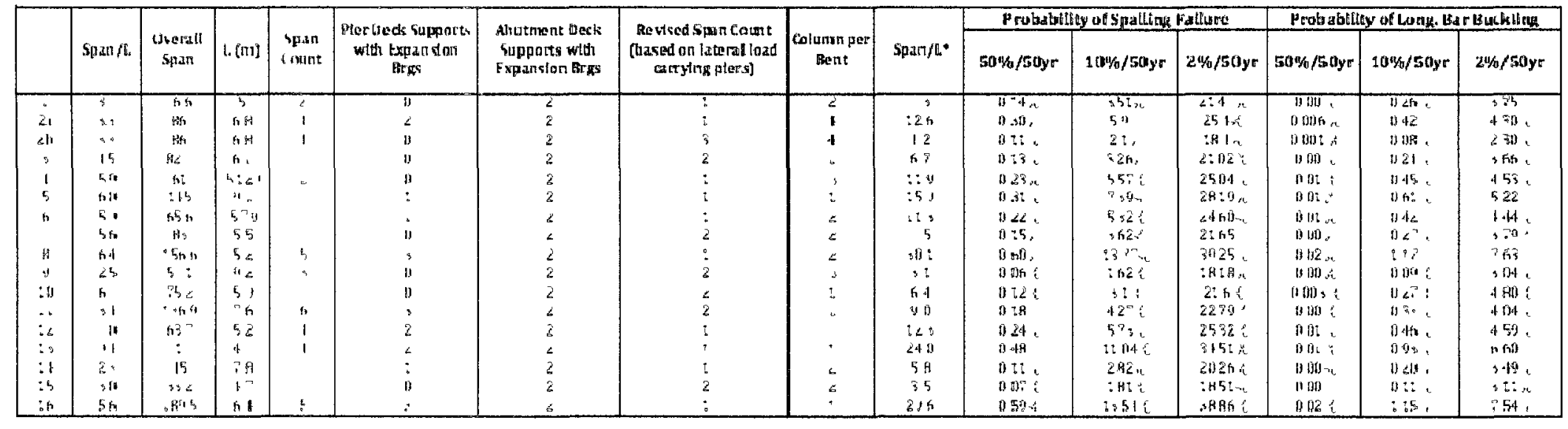


Table 4.5: Estimated Probabilities of Spalling and Longitudinal Bar Buckling based on Effective Transverse Reinforcement Batios

\begin{tabular}{|c|c|c|c|c|c|c|c|c|c|c|c|c|c|c|c|c|}
\hline & \multirow[b]{2}{*}{ Actullos } & \multirow[b]{2}{*}{ overall spasn } & \multirow[b]{2}{*}{ Be.k witth } & \multirow[b]{2}{*}{ spancestut } & \multirow{2}{*}{$\begin{array}{l}\text { 1'ier Deck } \\
\text { Supposts with } \\
\text { L.ppausion Brgy, }\end{array}$} & \multirow{2}{*}{ 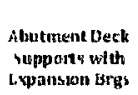 } & \multirow{2}{*}{ 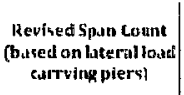 } & \multirow[b]{2}{*}{$\begin{array}{c}\text { Cot turmo per } \\
\text { Bent }\end{array}$} & \multirow{2}{*}{$\begin{array}{c}\text { Triluutsy } \\
\text { Sp.in Areaper } \\
\text { Columas }\end{array}$} & \multirow[b]{2}{*}{$p x^{*}$} & \multicolumn{3}{|c|}{ Probabillty ol 5 palling Faliure } & \multicolumn{3}{|c|}{ Prohab bit iy of Long, Bar Bucciling } \\
\hline & & & & & & & & & & & $5016 / 50 y r$ & $10 \mathrm{~m} / 50 \mathrm{yx}$ & $2 \% ; 50 y r$ & $501 \% / 50 \mathrm{yr}$ & $10 \% / 50 y$ & $2^{1106 / 50 y r}$ \\
\hline $\mathrm{t}$ & $195 \%$ & 365 & 155 & 2 & $\overline{0}$ & 2 & & 2 & 2837 & $35 \%$ & $013 \%$ & $240 \% / 3$ & 188956 & $000 \%$ & $010 \%$ & $23(9 / 4)$ \\
\hline $2 x$ & 11096 & HG & 2,11 & 1 & 2 & . & & 1 & 5130 & 1226 & 0,3016 & a orra & 2510,6 & $0.00661 \%$ & $012 \%$ & $130 \%$ \\
\hline $2 \mathbf{b}$ & $119 \%$ & Há & 244 & 4 & 0 & $\therefore$ & 3 & 4 & 1713 & $36 \%$ & $411 \%$ & $21 \%$ & $144 \%$ & $0.001 \%$ & $00 \mathrm{aty}$ & $230 \%$ \\
\hline 3 & $006 t^{2}$ & $H_{2}=$ & 243 & 3 & a & 2 & 2 & 1 & $45 \mathrm{H} 8$ & $a 0 \%$ & 0.236 & $508 \%$ & $2492 \%$ & $000 \%$ & $043 c_{i n}$ & 53656 \\
\hline $\begin{array}{l}4 \\
5\end{array}$ & $\begin{array}{l}1+1 \times 6 \\
102 c_{0}\end{array}$ & $\begin{array}{l}621 \\
115\end{array}$ & 11) 195 & 2 & 0 & 3 & & 3 & 4059 & $1 \mathrm{~km}, \mathrm{~s}$ & 0 & $372 \%$ & $21+1196$ & $0,00 n / 4$ & $0265 \%$ & $392^{2 \times 6}$ \\
\hline 6 & $\begin{array}{l}102 \% \\
0.82 \%\end{array}$ & $\begin{array}{l}115 \\
656\end{array}$ & 13 & 3 & i & 2 & & 1 & 20300 & $03 \%$ & $822 \%$ & $490 \%$ & $2453 \%$ & $000 \%$ & $0416 /$ & $517 \%$ \\
\hline$;$ & 06980 & ${ }_{H 3}$ & $\begin{array}{r}137 \\
18\end{array}$ & 3 & a & 2 & 2 & 2 & 4494 & $09 \%$ & $0120 \%$ & 4396 & $2336 \%$ & $000 \%$ & 0344,4 & $458 \%$ \\
\hline $\mathbb{g}$ & $020 \%$ & 1566 & 145 & 5 & 3 & $\dot{i}$ & 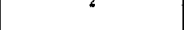 & 2 & $\begin{array}{l}2698 \\
11354\end{array}$ & $01 \%$ & $023 \%$ & $\begin{array}{l}4: 2 \% \\
503 \%\end{array}$ & $\begin{array}{l}22766^{2}, 3 \\
2481 \%\end{array}$ & $\begin{array}{l}0.00 \% \\
000 \%\end{array}$ & 0 & $\begin{array}{l}128 \% \% \\
531 \% \%\end{array}$ \\
\hline 9 & $1280_{0}$ & $57 t$ & 197 & 3 & a & 2 & : & 3 & 1875 & $35 \%$ & $013 \%$ & $242 \%$ & $1891 \%$ & $000 \%$ & $0: 1 \%$ & $234 \%$ \\
\hline 10 & $\ln 1246$ & 992 & 98 & 1 & 0 & . & 2 & ! & 293.3 & $071 \%$ & 01266 & $+16 \%$ & $216 \%$ & $0003 \%$ & $0.27 \%$ & 1806 \\
\hline l & $12 \mathrm{B4}$ & 1369 & 15 & 6 & 3 & 2 & 2 & l & 3040 & $21 \%$ & $017 \%$ & $147 \%$ & $2 \mathrm{t} .27 \%$ & $000 \times 5$ & $023 \%$ & $353 \%$ \\
\hline $1 !$ & $0107 \%$ & 6i?? & 7 & 1 & 2 & 2 & & 1 & 4459 & 0146 & $023 \%$ & $504 \%$ & 86 & $000 \%$ & $042 \%$ & $532 \%$ \\
\hline 13 & 1196 & 113 & 153 & 1 & 2 & 2 & & 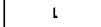 & 11639 & $05 \%$ & $0.21 \%$ & $170 \%$ & $2106 \%$ & $000 \%$ & & 10.36 \\
\hline 14 & $162^{2}$ & 45 & 63 & 1 & 1 & 2 & & 2 & 141.8 & $59 \%$ & $006 \%$ & $0163 \%$ & $14 \mathrm{B5 \%}$ & $000 \%$ & $000 \%$ & $030 \%$ \\
\hline 15 & $029 r_{4}$ & 312 & 105 & 3 & 0 & $\therefore$ & 2 & 2 & 872 & $17 \%$ & $0.18 \%$ & $379 \%$ & $22020 \%$ & $000 \%$ & $0.27 \%$ & $790 \%$ \\
\hline 16 & $0.10_{4}$ & 1895 & 169 & & & & & & 3164 ? & $000 x_{0}$ & & $50 \mathrm{~B} \mathrm{~S}_{1,1}$ & $24936 \%$ & $000 \%$ & $013 \%$ & 53966 \\
\hline
\end{tabular}


Table 4.6: Summary of EstimatedPerformance Probabilities for Sample Inventory

\begin{tabular}{|c|c|c|c|c|c|c|}
\hline & \multicolumn{3}{|c|}{ Probability of Spalling Failure } & \multicolumn{3}{|c|}{ Probability of Long. Bar Buckling } \\
\hline & $50 \% / 50 y r$ & $10 \% / 50 y r$ & $2 \% / 50 y r$ & $50 \% / 50 y r$ & $10 \% / 50 y r$ & $2 \% / 50 y \mathbf{r}$ \\
\hline 1 & $0.14 \%$ & $3.51 \%$ & $21.47 \%$ & $0.00 \%$ & $0.26 \%$ & $2.31 \%$ \\
\hline $2 a$ & $0.30 \%$ & $5.9 \%$ & $25.4 \%$ & $0.006 \%$ & $0.42 \%$ & $4.30 \%$ \\
\hline $2 b$ & $0.11 \%$ & $2.1 \%$ & $18.4 \%$ & $0.001 \%$ & $0.08 \%$ & $2.30 \%$ \\
\hline 3 & $0.13 \%$ & $3.26 \%$ & $21.02 \%$ & $0.00 \%$ & $0.24 \%$ & $5.36 \%$ \\
\hline 4 & $0.23 \%$ & $5.57 \%$ & $25.04 \%$ & $0.01 \%$ & $0.45 \%$ & $3.82 \%$ \\
\hline 5 & $0.31 \%$ & $7.39 \%$ & $28.19 \%$ & $0.01 \%$ & $0.61 \%$ & $5.17 \%$ \\
\hline 6 & $0.22 \%$ & $5.32 \%$ & $24.60 \%$ & $0.01 \%$ & $0.42 \%$ & $4.58 \%$ \\
\hline 7 & $0.15 \%$ & $3.62 \%$ & $21.65 \%$ & $0.00 \%$ & $0.27 \%$ & $4.28 \%$ \\
\hline 8 & $0.60 \%$ & $13.77 \%$ & $39.25 \%$ & 0.02\% & $1.17 \%$ & $5.31 \%$ \\
\hline 9 & $0.06 \%$ & $1.62 \%$ & $18.18 \%$ & $0.00 \%$ & $0.09 \%$ & $2.34 \%$ \\
\hline 10 & $0.12 \%$ & $3.1 \%$ & $21.6 \%$ & $0.003 \%$ & $0.27 \%$ & $4.80 \%$ \\
\hline 11 & $0.18 \%$ & $4.27 \%$ & $22.79 \%$ & $0.00 \%$ & $0.33 \%$ & $3.53 \%$ \\
\hline 12 & $0.24 \%$ & $5.73 \%$ & $25.32 \%$ & $0.01 \%$ & $0.46 \%$ & $5.32 \%$ \\
\hline 13 & $0.48 \%$ & $11.04 \%$ & $34.51 \%$ & $0.01 \%$ & $0.93 \%$ & $4.93 \%$ \\
\hline 14 & $0.11 \%$ & $2.82 \%$ & $20.26 \%$ & $0.00 \%$ & $0.20 \%$ & $0.30 \%$ \\
\hline 15 & $0.07 \%$ & $1.81 \%$ & $18.51 \%$ & $0.00 \%$ & $0.11 \%$ & $3.90 \%$ \\
\hline 16 & $0.59 \%$ & $13.54 \%$ & $38.86 \%$ & $\mathbf{0 . 0 2} \%$ & $1.15 \%$ & $5.37 \%$ \\
\hline
\end{tabular}


Table 4.7: Priority List of Bridge Inventory to Improve Life Safety

\begin{tabular}{|c|c|c|c|c|c|c|}
\hline & \multicolumn{3}{|c|}{ Probability of Spalling Failure } & \multicolumn{3}{|c|}{ Probability of Long. Bar Buckling } \\
\hline & $50 \% / 50 y r$ & $10 \% / 50 \mathrm{yr}$ & $2 \% / 50 \mathrm{yr}$ & $50 \% / 50 \mathrm{yr}$ & $10 \% / 50 y r$ & $2 \% / 50 y r$ \\
\hline 16 & $0.59 \%$ & $13.54 \%$ & $38.86 \%$ & $0.02 \%$ & $1.15 \%$ & $5.37 \%$ \\
\hline 3 & $0.13 \%$ & $3.26 \%$ & $21.02 \%$ & $0.00 \%$ & $0.24 \%$ & $5.36 \%$ \\
\hline 12 & $0.24 \%$ & $5.73 \%$ & $25.32 \%$ & $0.01 \%$ & $0.46 \%$ & $5.32 \%$ \\
\hline 8 & $0.60 \%$ & $13.77 \%$ & $39.25 \%$ & $0.02 \%$ & $1.17 \%$ & $5.31 \%$ \\
\hline 5 & $0.31 \%$ & $7.39 \%$ & $28.19 \%$ & $0.01 \%$ & $0.61 \%$ & $5.17 \%$ \\
\hline 13 & $0.48 \%$ & $11.04 \%$ & $34.51 \%$ & $0.01 \%$ & $0.93 \%$ & $4.93 \%$ \\
\hline 10 & $0.12 \%$ & $3.1 \%$ & $21.6 \%$ & $0.003 \%$ & $0.27 \%$ & $4.80 \%$ \\
\hline 6 & $0.22 \%$ & $5.32 \%$ & $24.60 \%$ & $0.01 \%$ & $0.42 \%$ & $4.58 \%$ \\
\hline $2 a$ & $0.30 \%$ & $5.9 \%$ & $25.4 \%$ & $0.006 \%$ & $0.42 \%$ & $4.30 \%$ \\
\hline 7 & $0.15 \%$ & $3.62 \%$ & $21.65 \%$ & $0.00 \%$ & $0.27 \%$ & $4.28 \%$ \\
\hline 15 & $0.07 \%$ & $1.81 \%$ & $18.51 \%$ & $0.00 \%$ & $0.11 \%$ & $3.90 \%$ \\
\hline 4 & $0.23 \%$ & $5.57 \%$ & $25.04 \%$ & $0.01 \%$ & $0.45 \%$ & $3.82 \%$ \\
\hline 11 & $0.18 \%$ & $4.27 \%$ & $22.79 \%$ & $0.00 \%$ & $0.33 \%$ & $3.53 \%$ \\
\hline 9 & $0.06 \%$ & $1.62 \%$ & $18.18 \%$ & $0.00 \%$ & $0.09 \%$ & $2.34 \%$ \\
\hline 1 & $0.14 \%$ & $3.51 \%$ & $21.47 \%$ & $0.00 \%$ & $0.26 \%$ & $2.31 \%$ \\
\hline $2 b$ & $0.11 \%$ & $2.1 \%$ & $18.4 \%$ & $0.001 \%$ & $0.08 \%$ & $2.30 \%$ \\
\hline 14 & $0.11 \%$ & $2.82 \%$ & $20.26 \%$ & $0.00 \%$ & $0.20 \%$ & $0.30 \%$ \\
\hline
\end{tabular}


Table 4.8: Priority List of Bridge Inventory to Minimize Repair Costs

\begin{tabular}{|c|c|c|c|c|c|c|}
\hline & \multicolumn{3}{|c|}{ Probability of Spalling Failure } & \multicolumn{3}{|c|}{ Probability of Long. Bar Buckling } \\
\hline & $50 \% / 50 y r$ & $10 \% / 50 y r$ & $2 \% / 50 y r$ & $50 \% / 50 y r$ & $10 \% / 50 y r$ & $2 \% / 50 y \mathrm{r}$ \\
\hline 8 & $0.60 \%$ & $13.77 \%$ & $39.25 \%$ & $0.02 \%$ & $1.17 \%$ & $5.31 \%$ \\
\hline 16 & $0.59 \%$ & $13.54 \%$ & $38.86 \%$ & $0.02 \%$ & $1.15 \%$ & $5.37 \%$ \\
\hline 13 & $0.48 \%$ & $11.04 \%$ & $34.51 \%$ & $0.01 \%$ & $0.93 \%$ & $4.93 \%$ \\
\hline 5 & $0.31 \%$ & $7.39 \%$ & $28.19 \%$ & $0.01 \%$ & $0.61 \%$ & $5.17 \%$ \\
\hline $2 a$ & $0.30 \%$ & $5.9 \%$ & $25.4 \%$ & $0.006 \%$ & $0.42 \%$ & $4.30 \%$ \\
\hline 12 & $0.24 \%$ & $5.73 \%$ & $25.32 \%$ & $0.01 \%$ & $0.46 \%$ & $5.32 \%$ \\
\hline 4 & $0.23 \%$ & $5.57 \%$ & $25.04 \%$ & $0.01 \%$ & $0.45 \%$ & $3.82 \%$ \\
\hline 6 & $0.22 \%$ & $5.32 \%$ & $24.60 \%$ & $0.01 \%$ & $0.42 \%$ & $4.58 \%$ \\
\hline 11 & $0.18 \%$ & $4.27 \%$ & $22.79 \%$ & $0.00 \%$ & $0.33 \%$ & $3.53 \%$ \\
\hline 7 & $0.15 \%$ & $3.62 \%$ & $21.65 \%$ & $0.00 \%$ & $0.27 \%$ & $4.28 \%$ \\
\hline 1 & $0.14 \%$ & $3.51 \%$ & $21.47 \%$ & $0.00 \%$ & $0.26 \%$ & $2.31 \%$ \\
\hline 3 & $0.13 \%$ & $3.26 \%$ & $21.02 \%$ & $0.00 \%$ & $0.24 \%$ & $5.36 \%$ \\
\hline 10 & $0.12 \%$ & $3.1 \%$ & $21.6 \%$ & $0.003 \%$ & $0.27 \%$ & $4.80 \%$ \\
\hline 14 & $0.11 \%$ & $2.82 \%$ & $20.26 \%$ & $0.00 \%$ & $0.20 \%$ & $0.30 \%$ \\
\hline $2 b$ & $0.11 \%$ & $2.1 \%$ & $18.4 \%$ & $0.001 \%$ & $0.08 \%$ & $2.30 \%$ \\
\hline 15 & $0.07 \%$ & $1.81 \%$ & $18.51 \%$ & $0.00 \%$ & $0.11 \%$ & $3.90 \%$ \\
\hline 9 & $0.06 \%$ & $1.62 \%$ & $18.18 \%$ & $0.00 \%$ & $0.09 \%$ & $2.34 \%$ \\
\hline
\end{tabular}




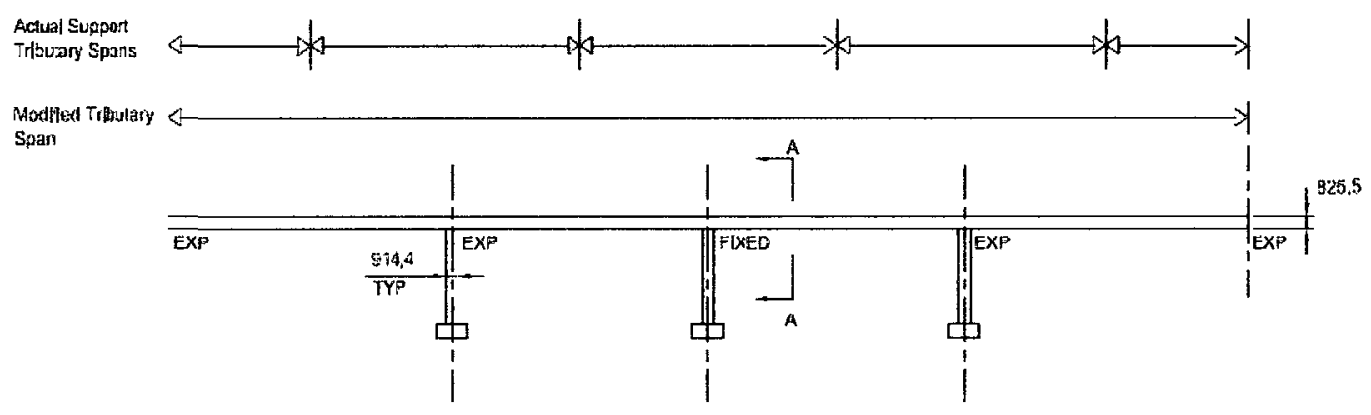

Figure 4.1: Effective tributary span length supported by Pier 2 of the Blair Road Bridge 


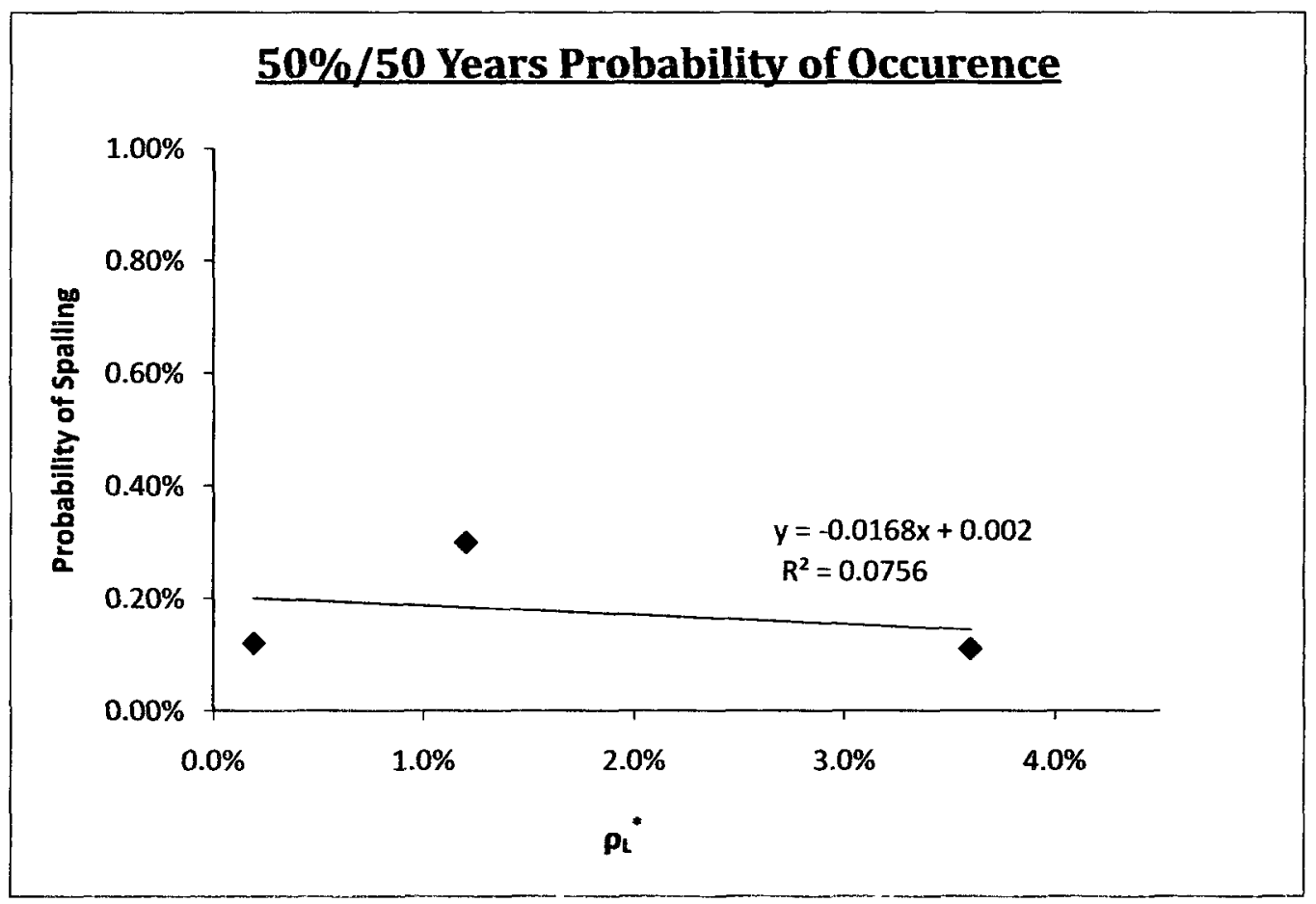

Figure 4.2: Relationship between $\rho_{\mathrm{L}}{ }^{*}$ and probability of spalling for a low seismic event (50\%/50years) 


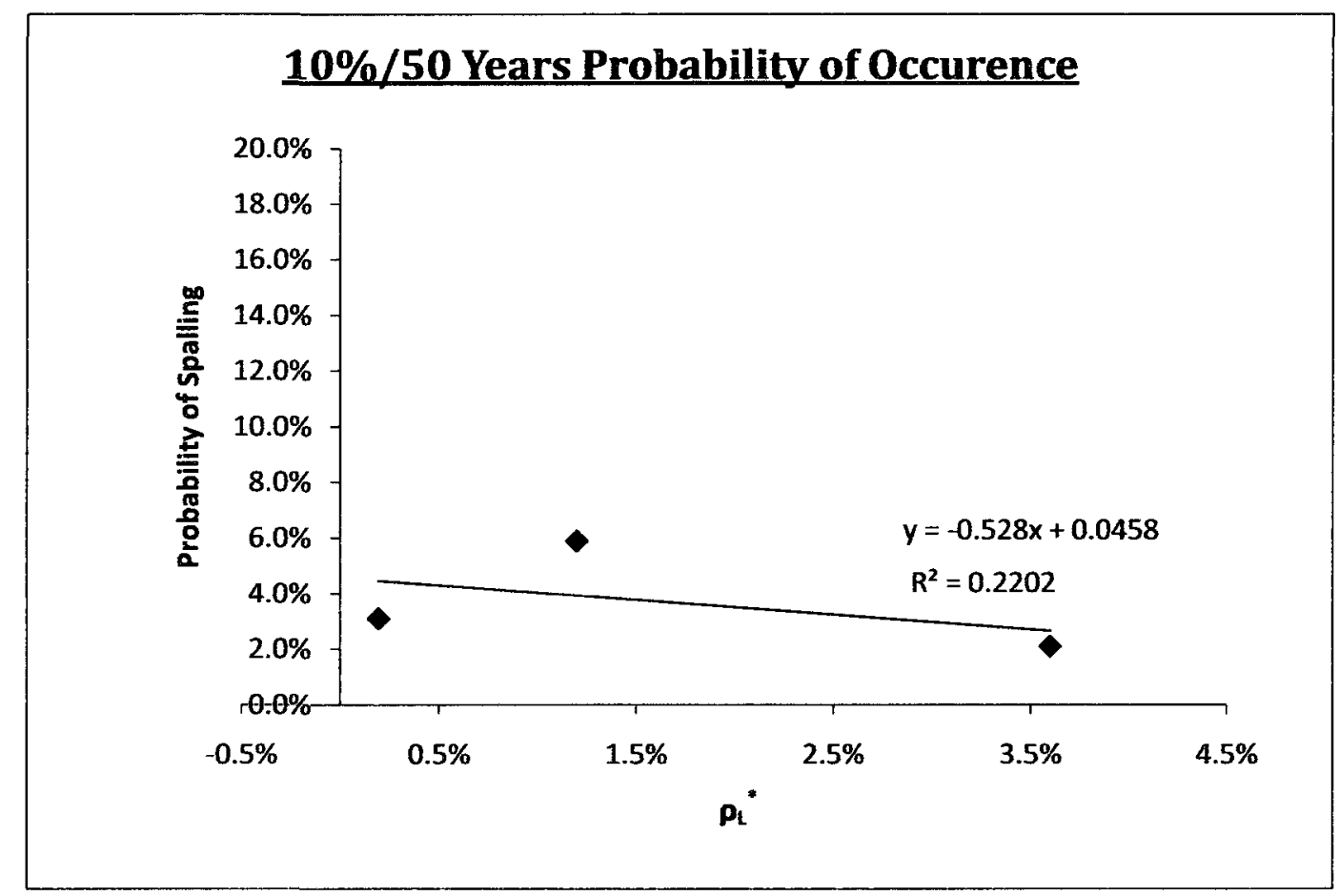

Figure 4.3: Relationship between $\rho_{L}^{*}$ and probability of spalling for a moderate seismic event (10\%/50years) 


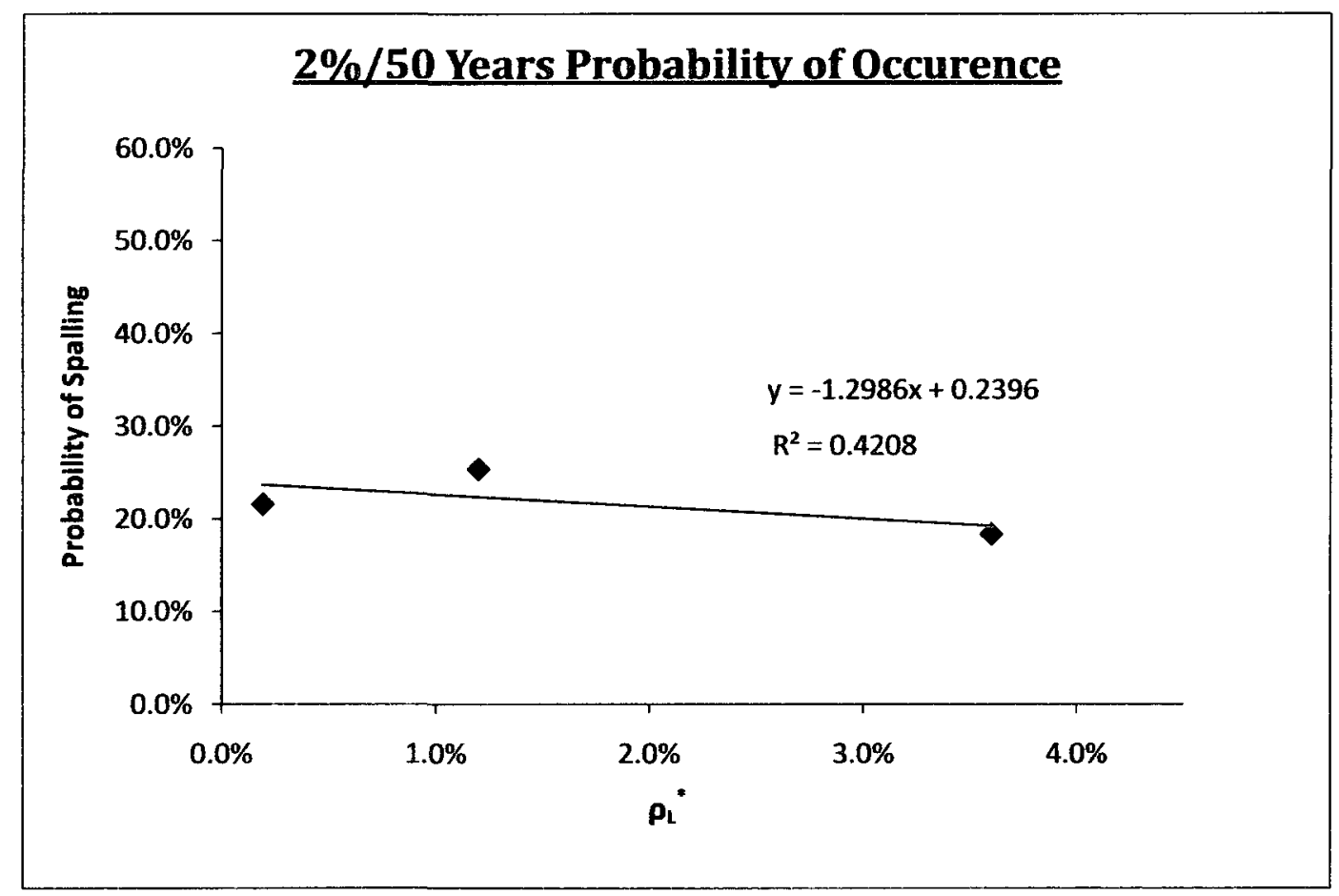

Figure 4.4: Relationship between $\rho_{\mathrm{L}}^{*}$ and probability of spalling for an extreme seismic event ( $2 \% / 50 y e a r s)$ 


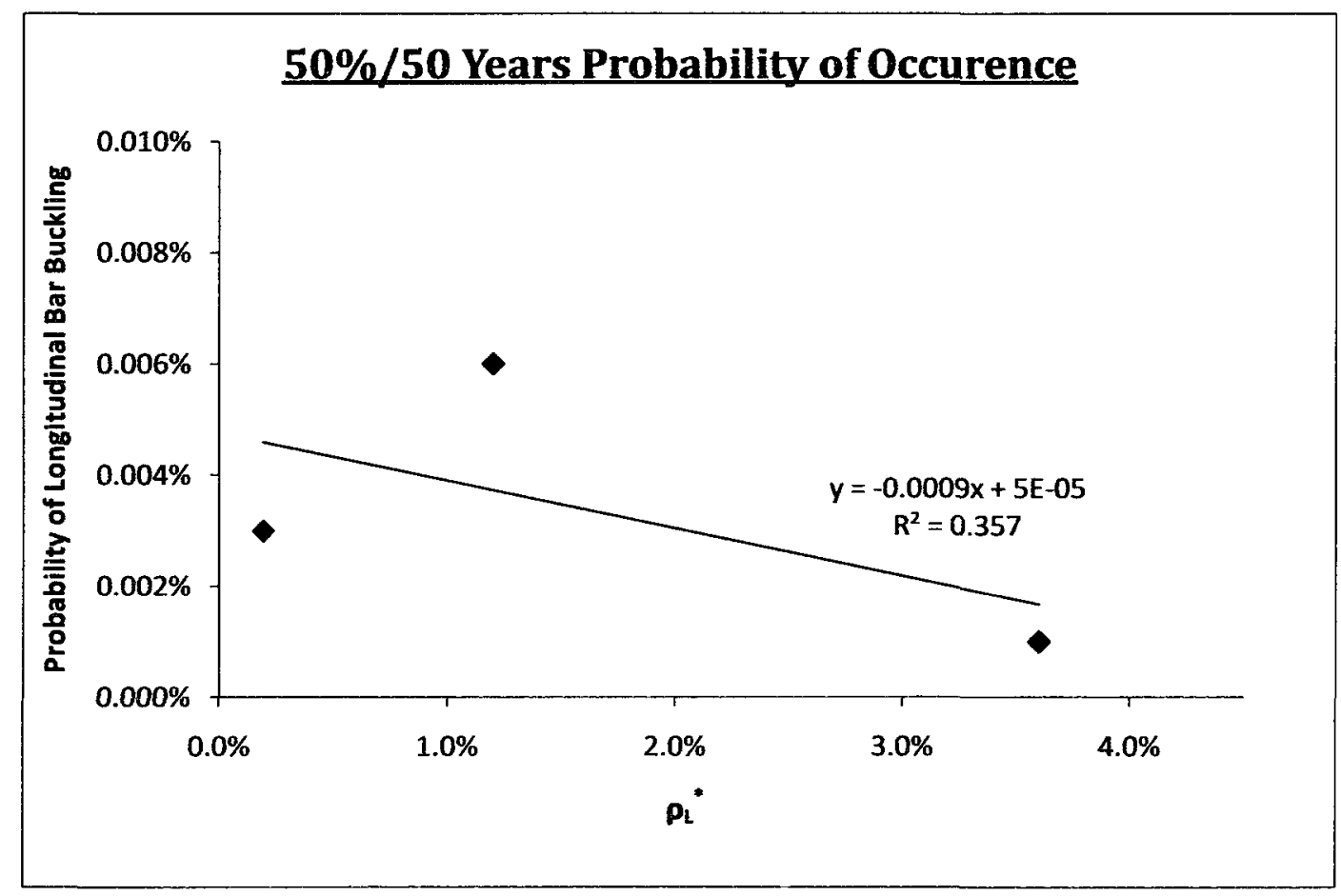

Figure 4.5: Relationship between $\rho_{\mathrm{L}}{ }^{*}$ and probability of longitudinal bar buckling for a low seismic event (50\%/50years) 


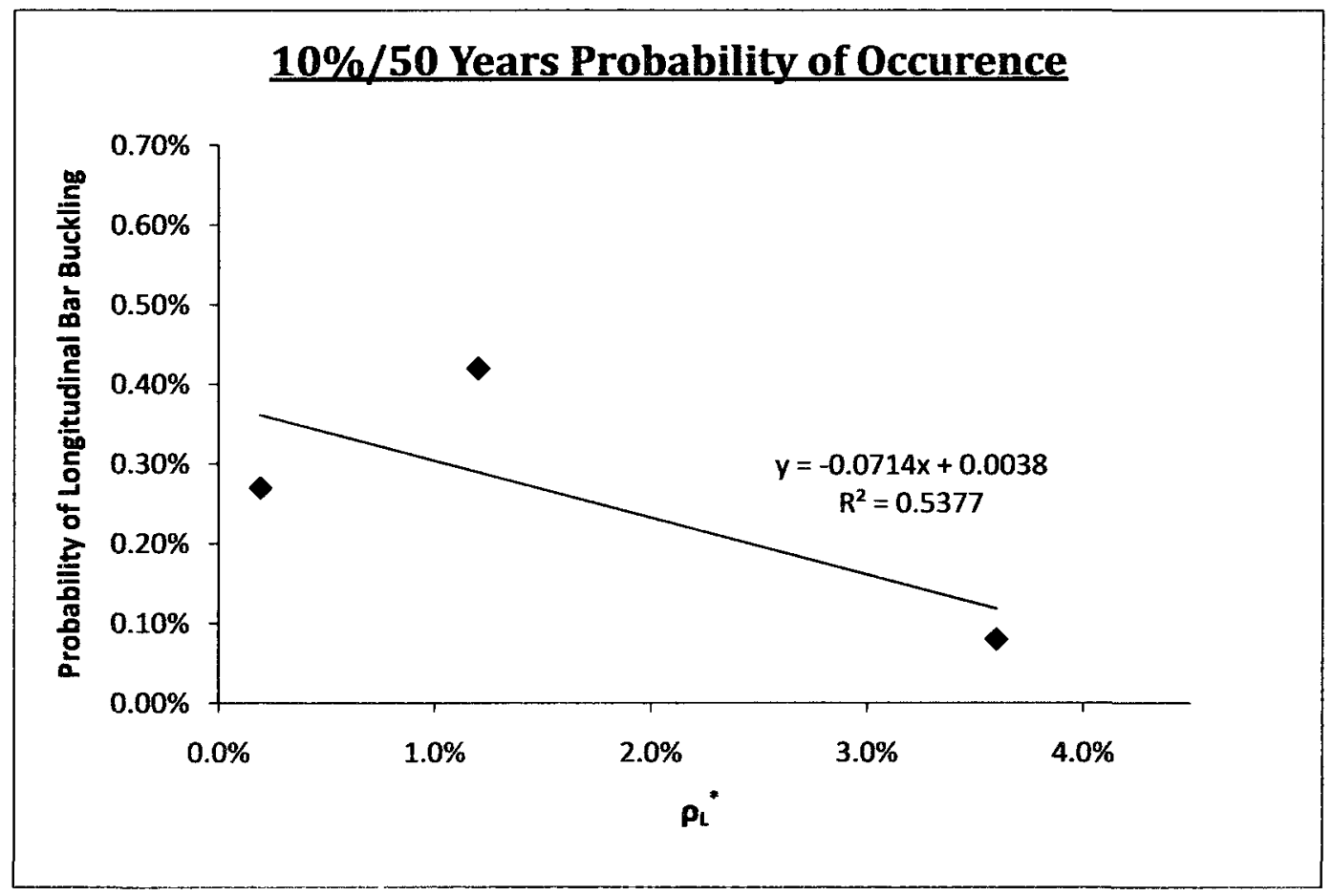

Figure 4.6: Relationship between $\rho_{\mathrm{L}}{ }^{*}$ and probability of longitudinal bar buckling for a moderate seismic event (10\%/50years) 


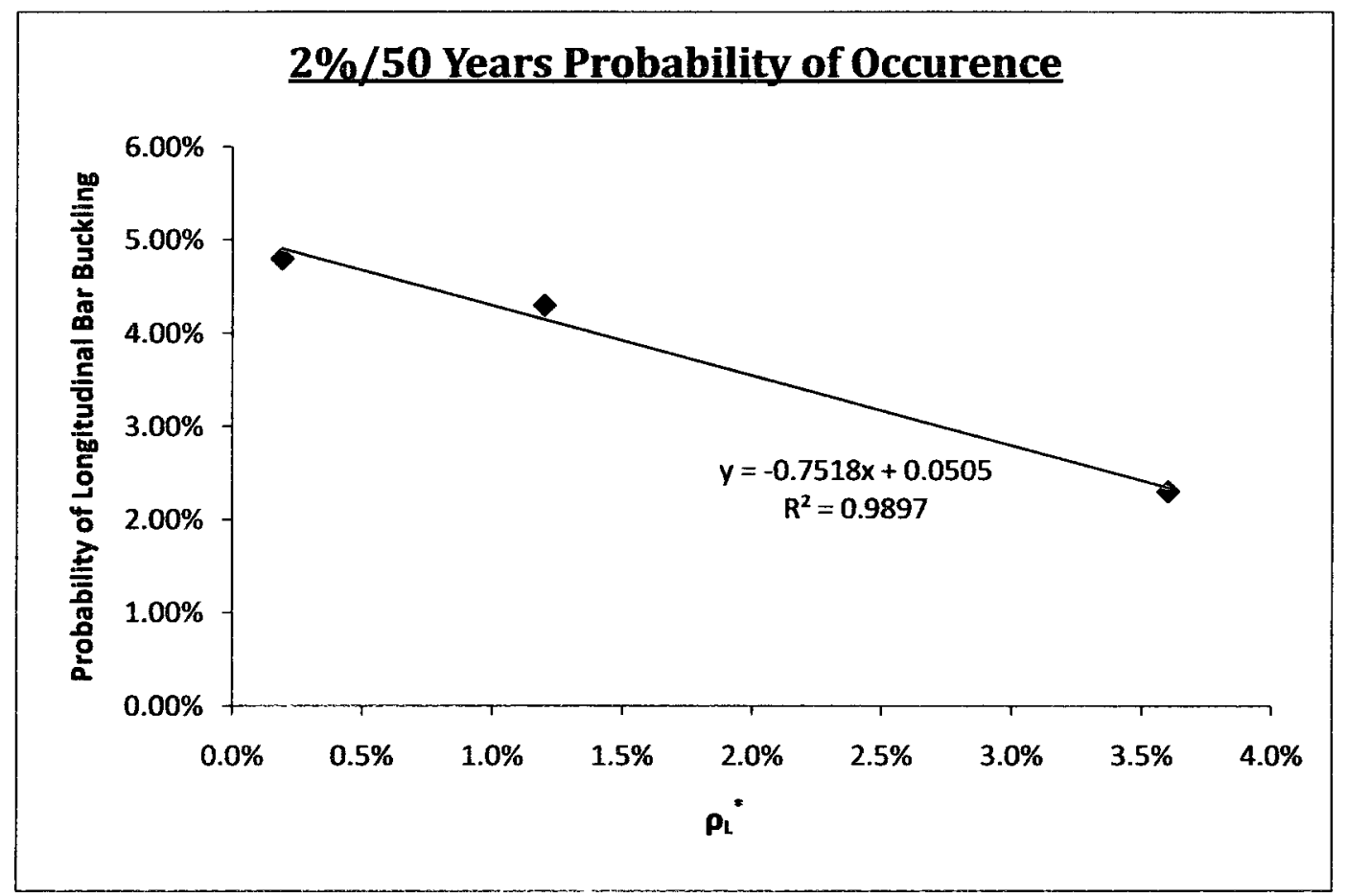

Figure 4.7: Relationship between $\rho_{\mathrm{L}}{ }^{*}$ and probability of longitudinal bar buckling for an extreme seismic event (2\%/50years) 


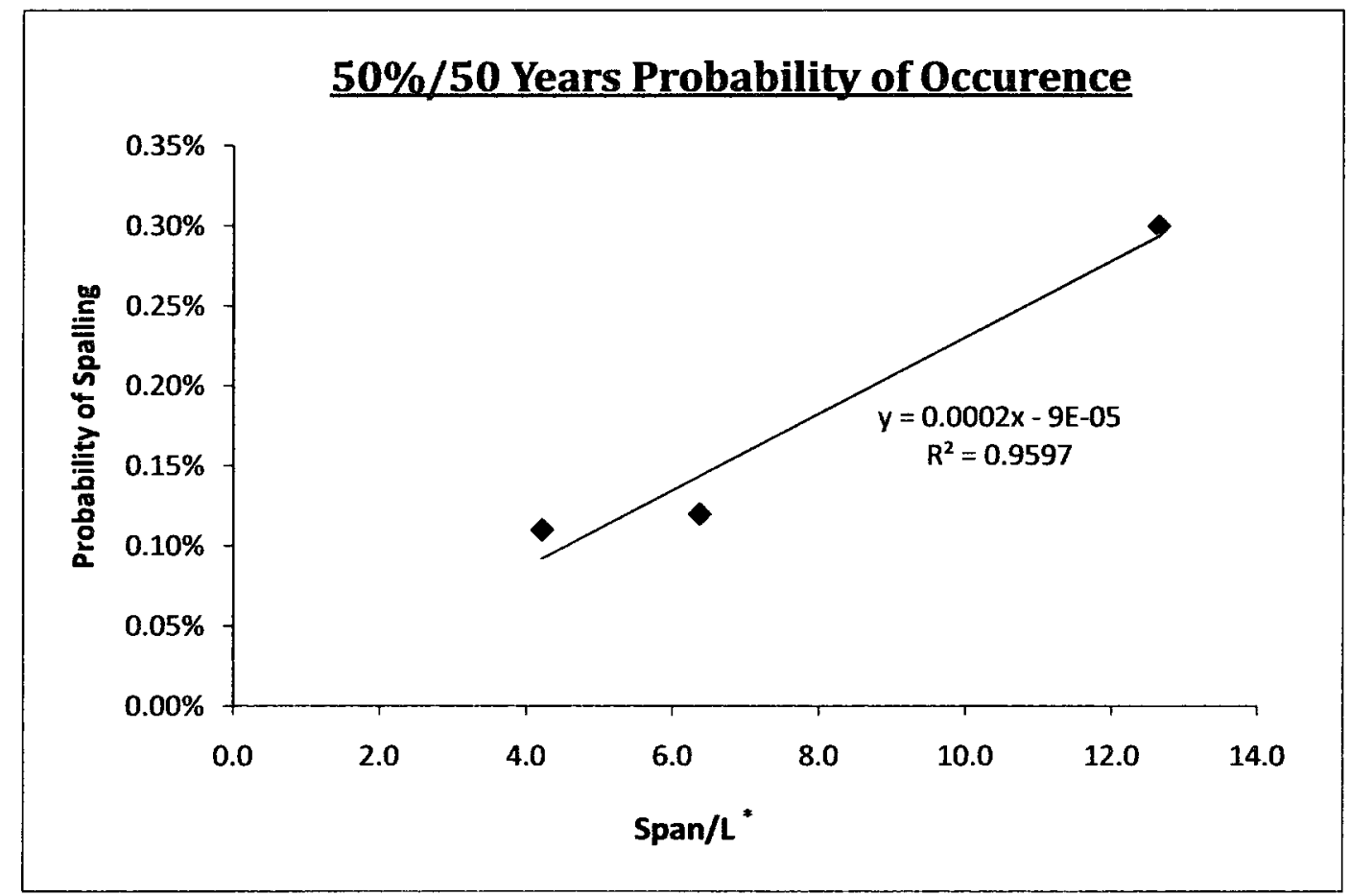

Figure 4.8: Relationship between Span/ $L^{*}$ and probability spalling for a low seismic event $(50 \% / 50 y e a r s)$ 


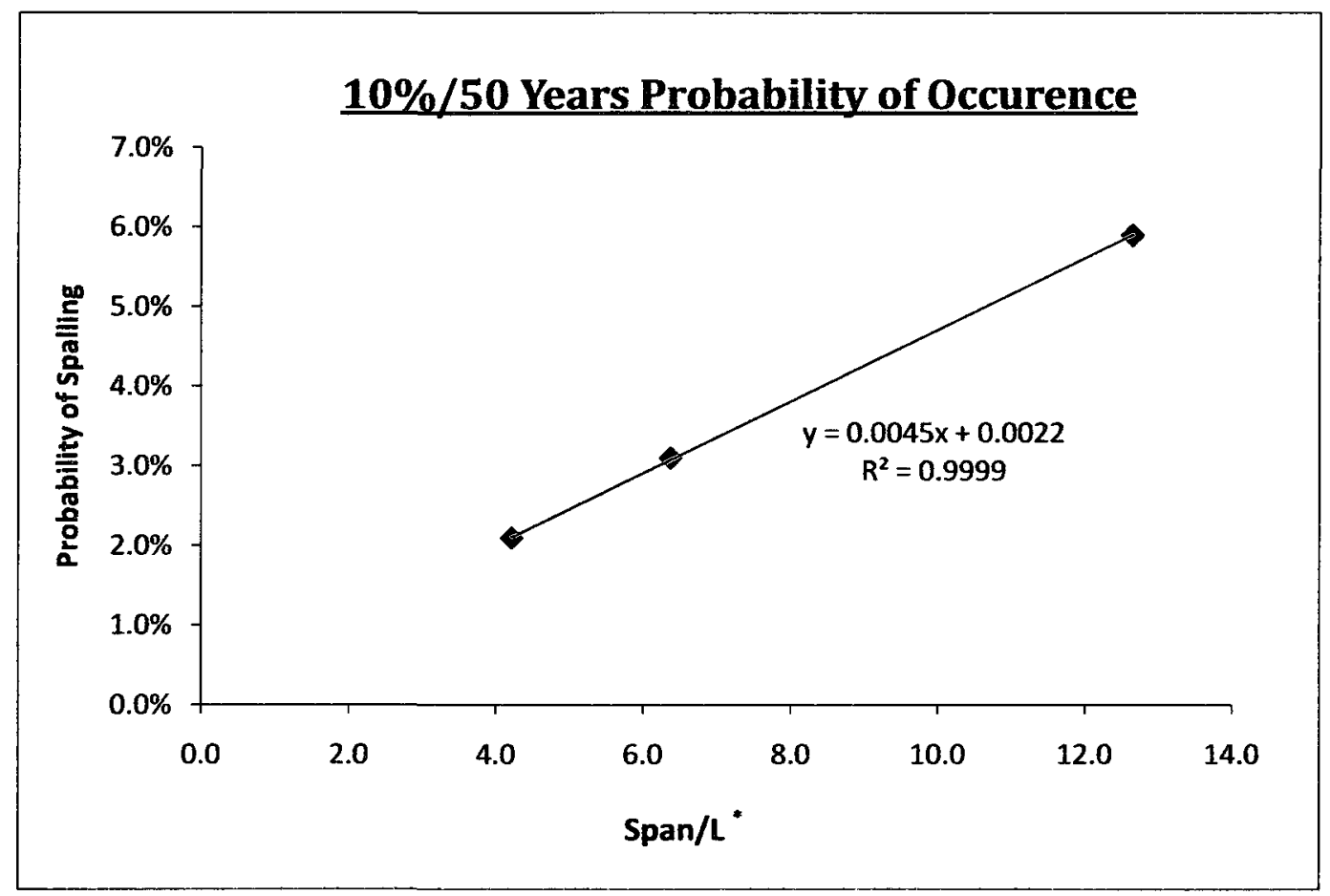

Figure 4.9: Relationship between $S p a n / L^{*}$ and probability spalling for a moderate seismic event (10\%/50years) 


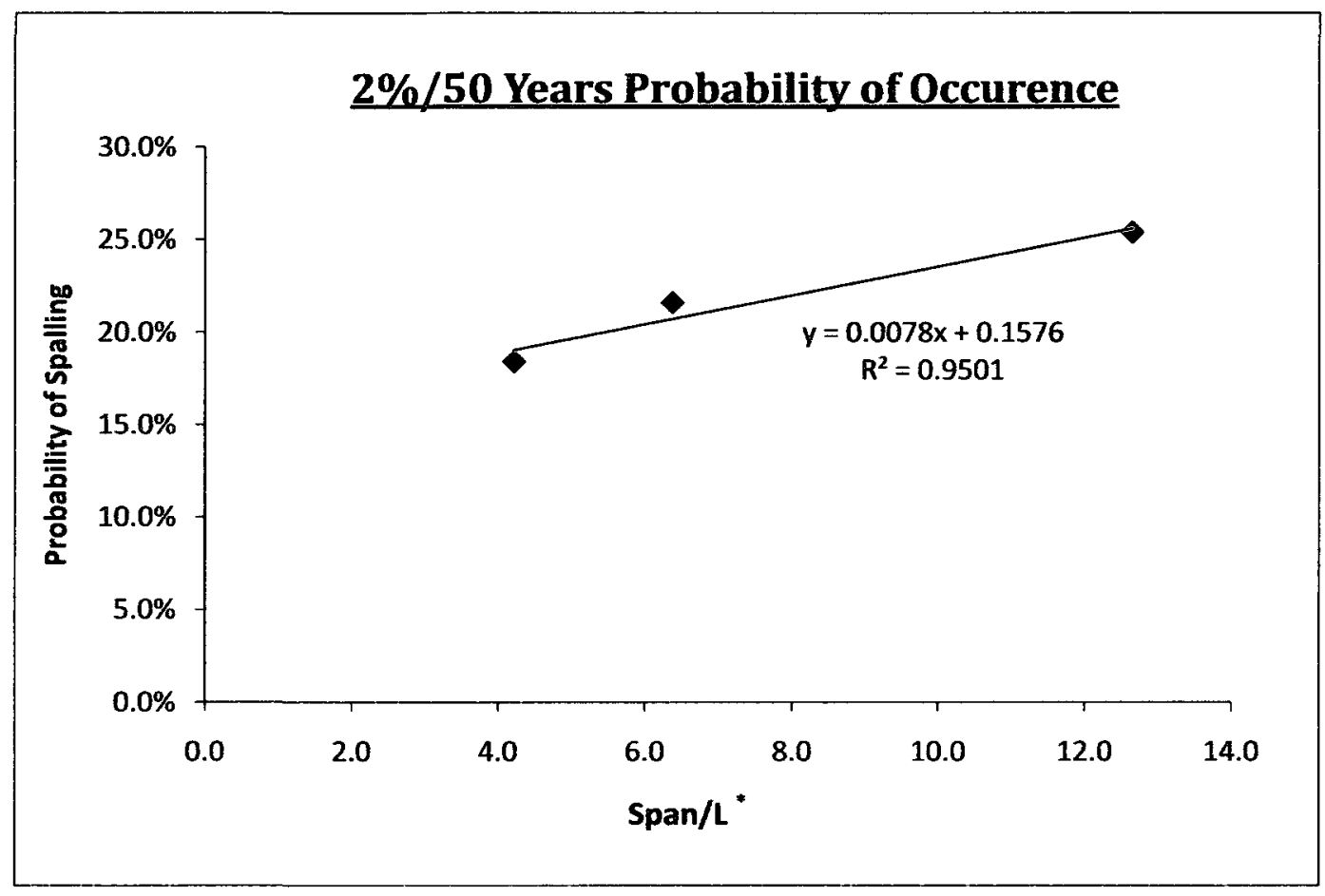

Figure 4.10: Relationship between Span/L * and probability spalling for an extreme seismic event (2\%/50years) 


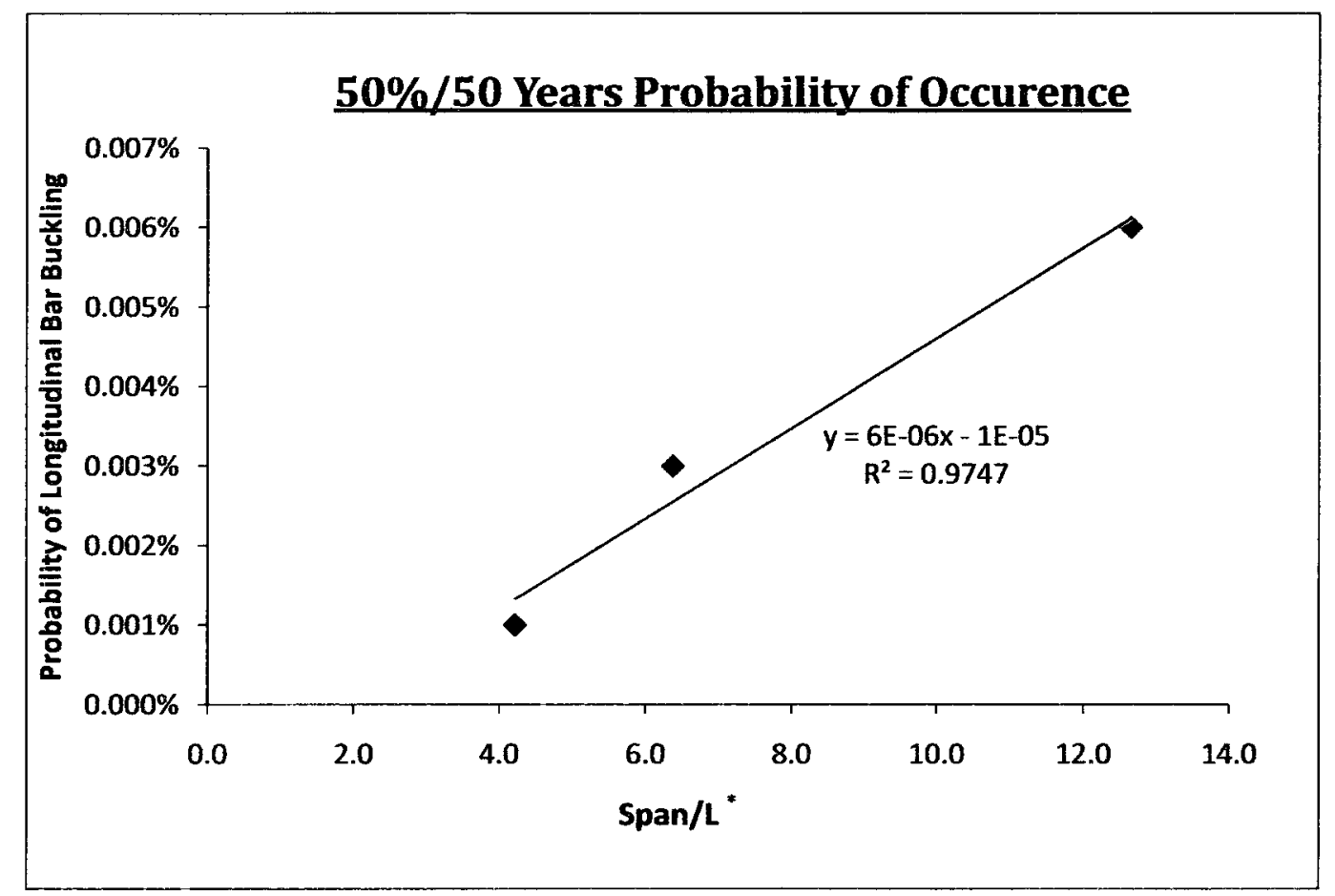

Figure 4.11: Relationship between Span/L* and probability of longitudinal bar buckling for a low seismic event (50\%/50years) 


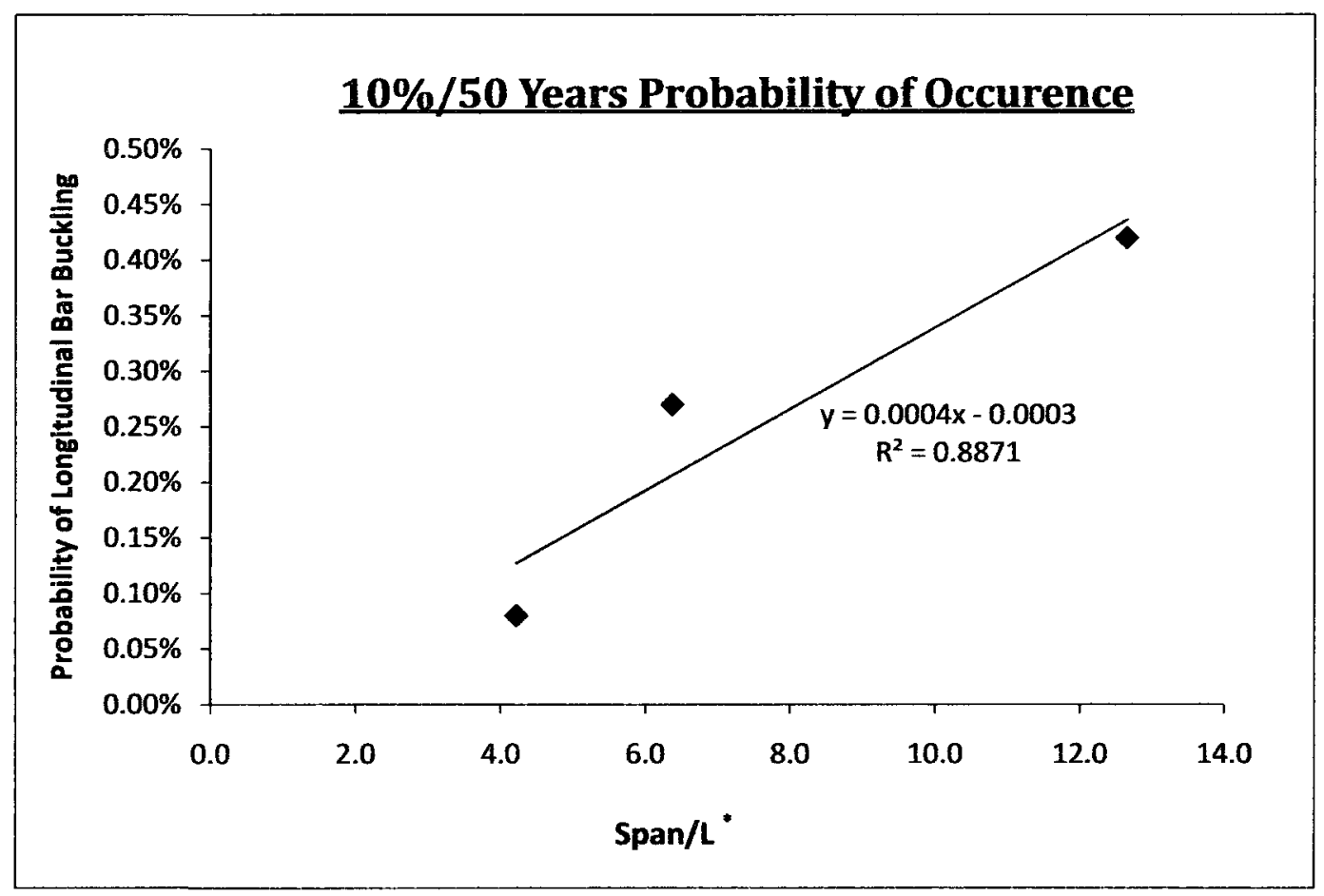

Figure 4.12: Relationship between Span/L ${ }^{*}$ and probability of longitudinal bar buckling for a moderate seismic event (10\%/50years) 


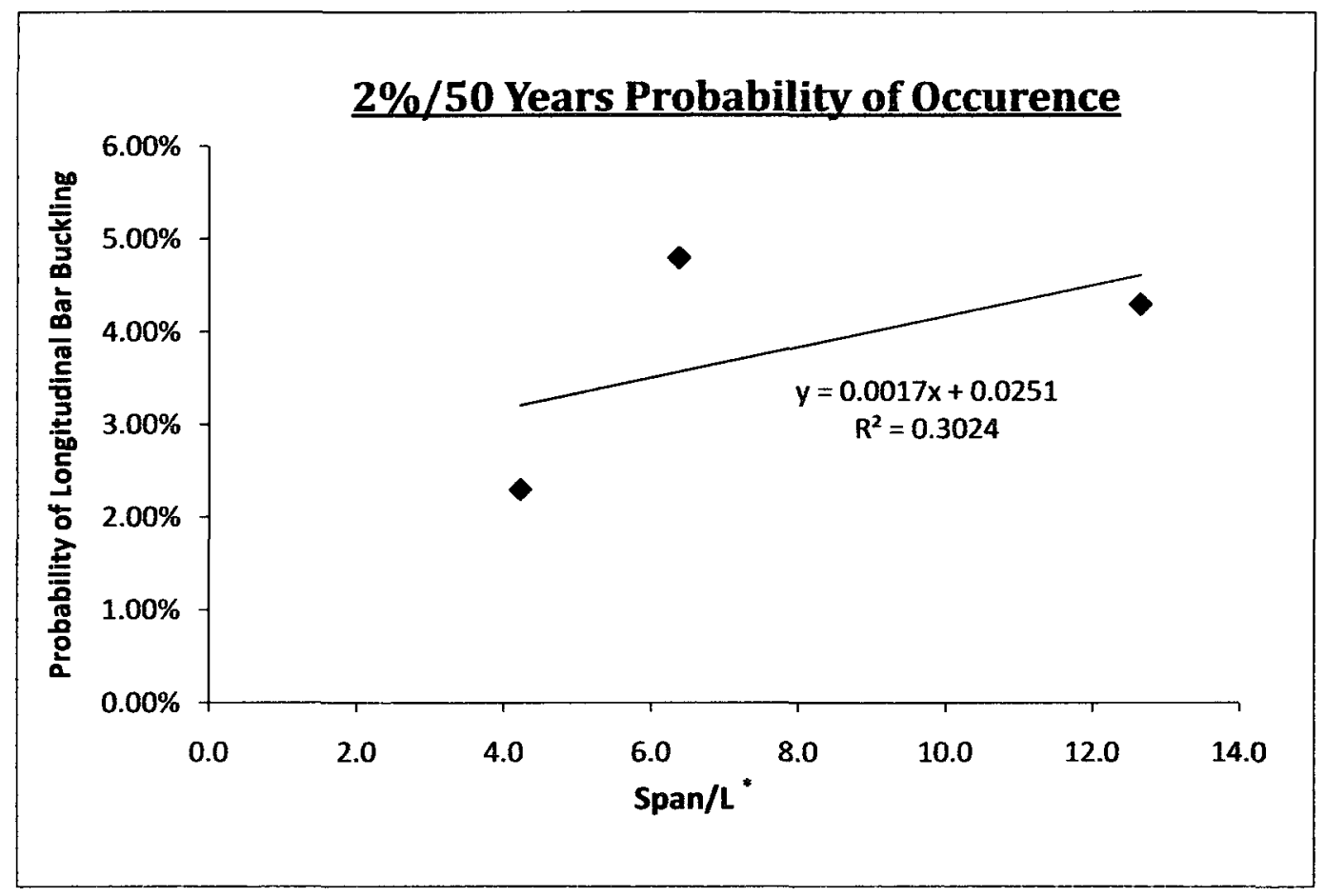

Figure 4.13: Relationship between Span/L and probability of longitudinal bar buckling for an extreme seismic event ( $2 \% / 50 y e a r s)$ 


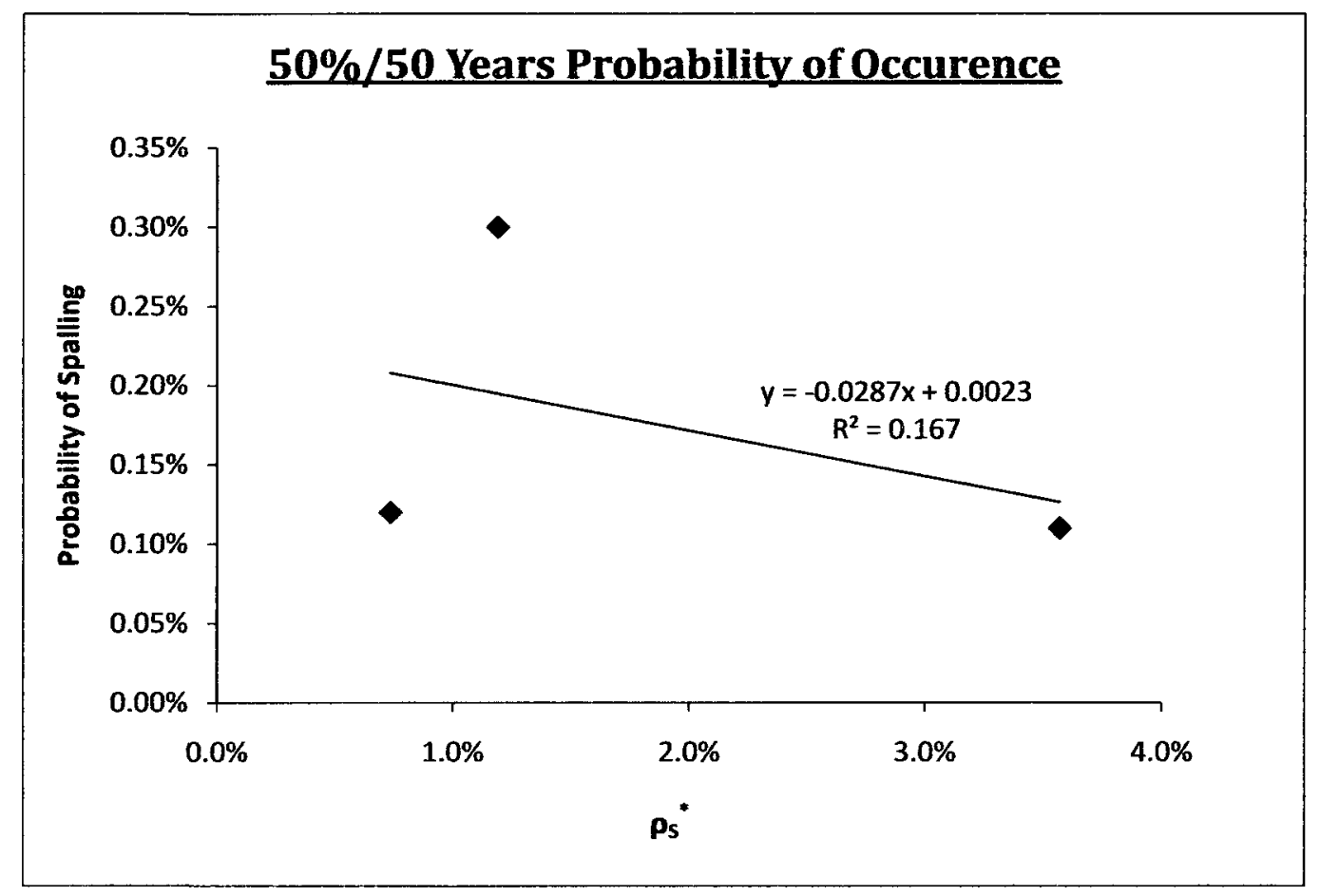

Figure 4.14: Relationship between $\mathrm{s}^{*}$ and probability of spalling for a low seismic event (50\%/50years) 


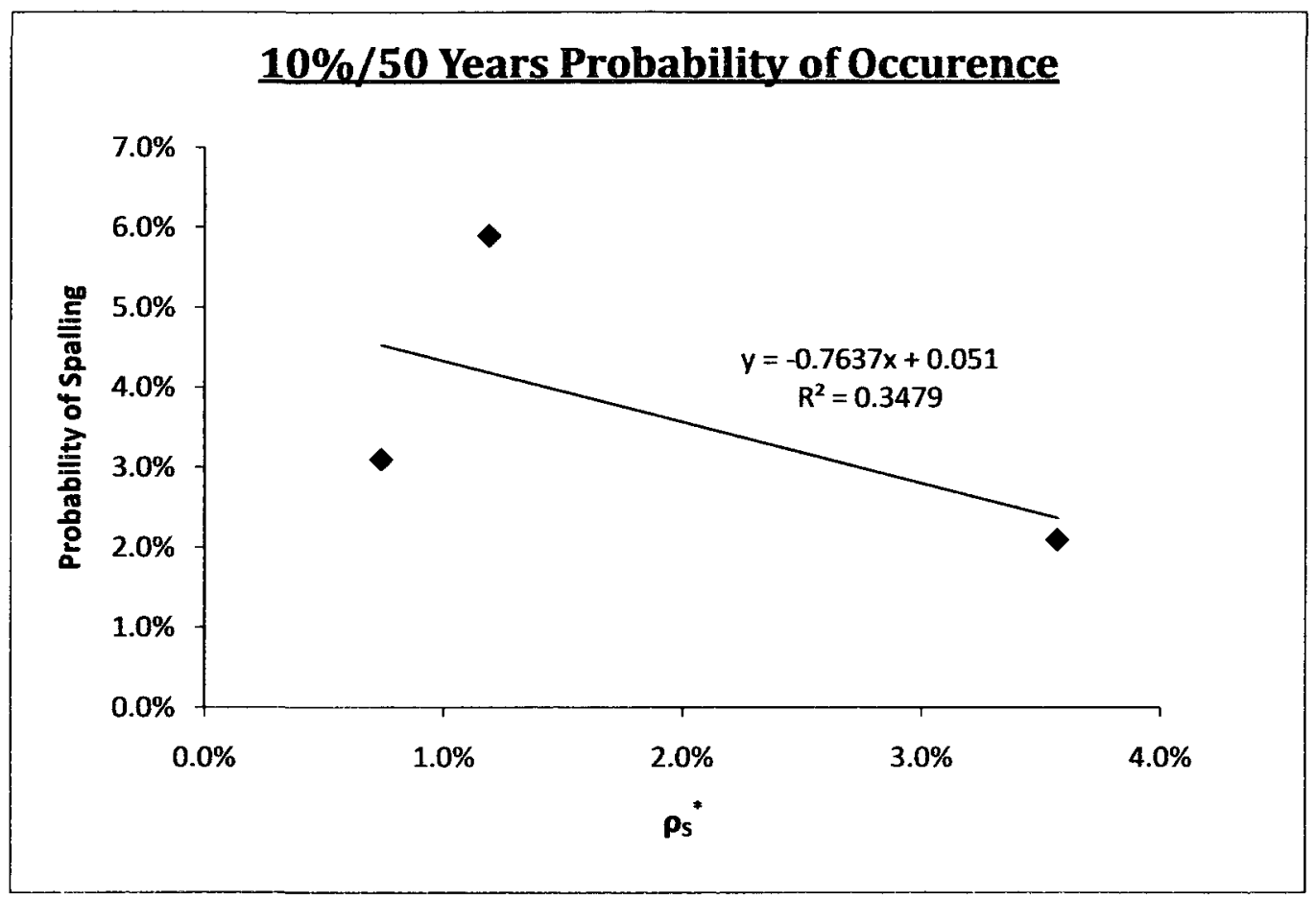

Figure 4.15: Relationship between $\rho{ }^{*}$ and probability of spalling for a moderate seismic event (10\%/50years) 


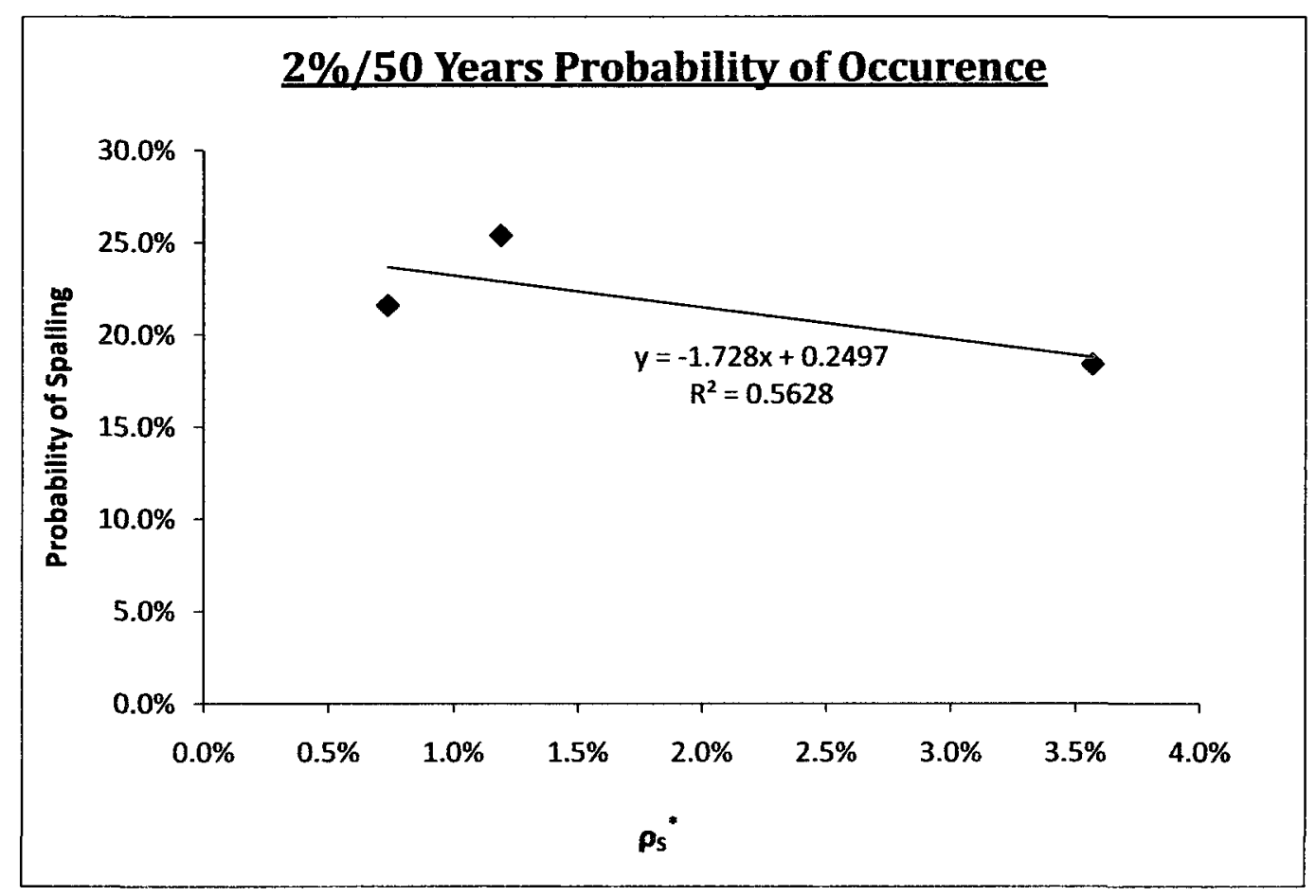

Figure 4.16: Relationship between $\rho{ }^{*}$ and probability of spalling for an extreme seismic event ( $2 \% / 50 y e a r s)$ 


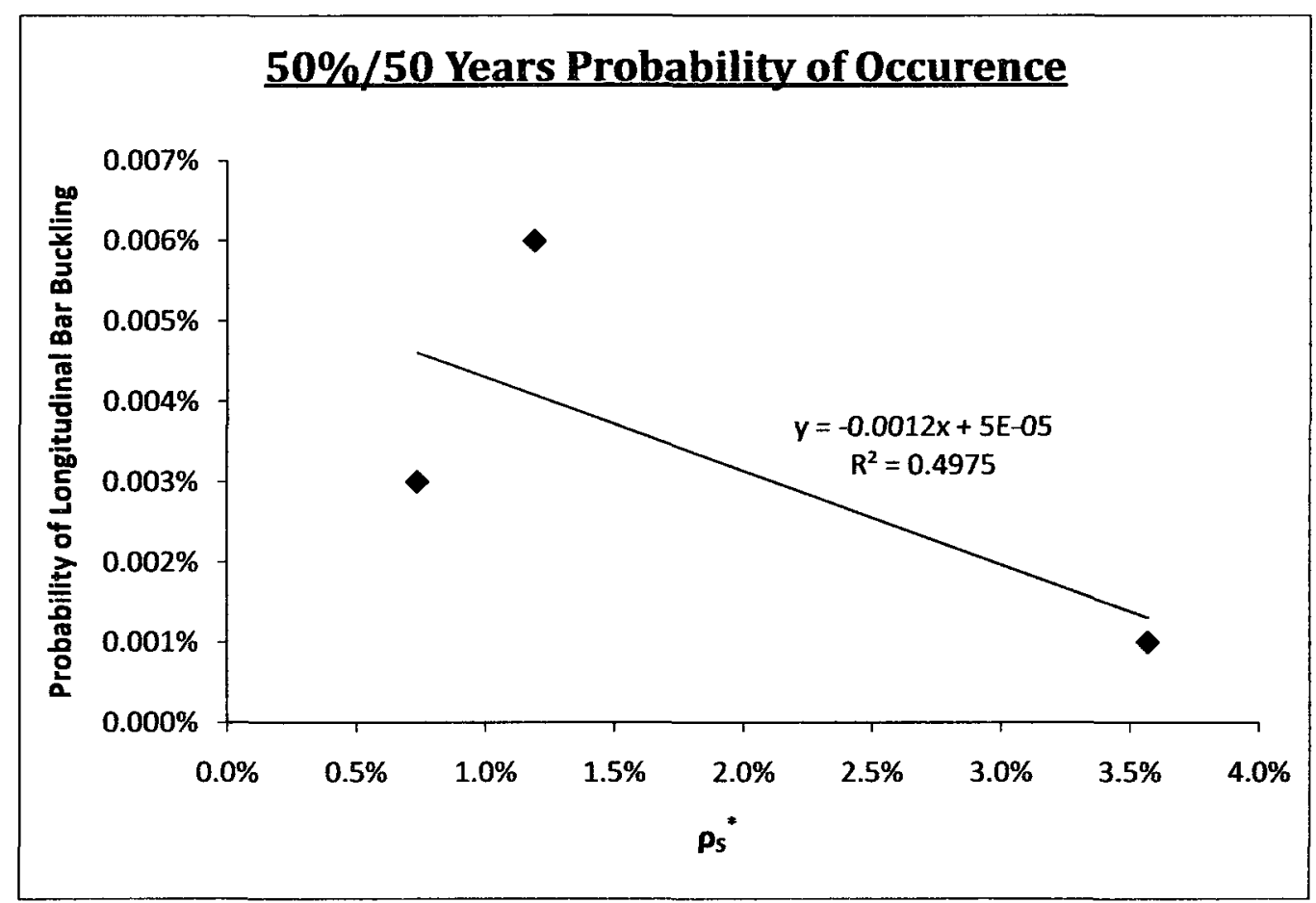

Figure 4.17: Relationship between $\rho s^{*}$ and probability of longitudinal bar buckling for a low seismic event (50\%/50years) 


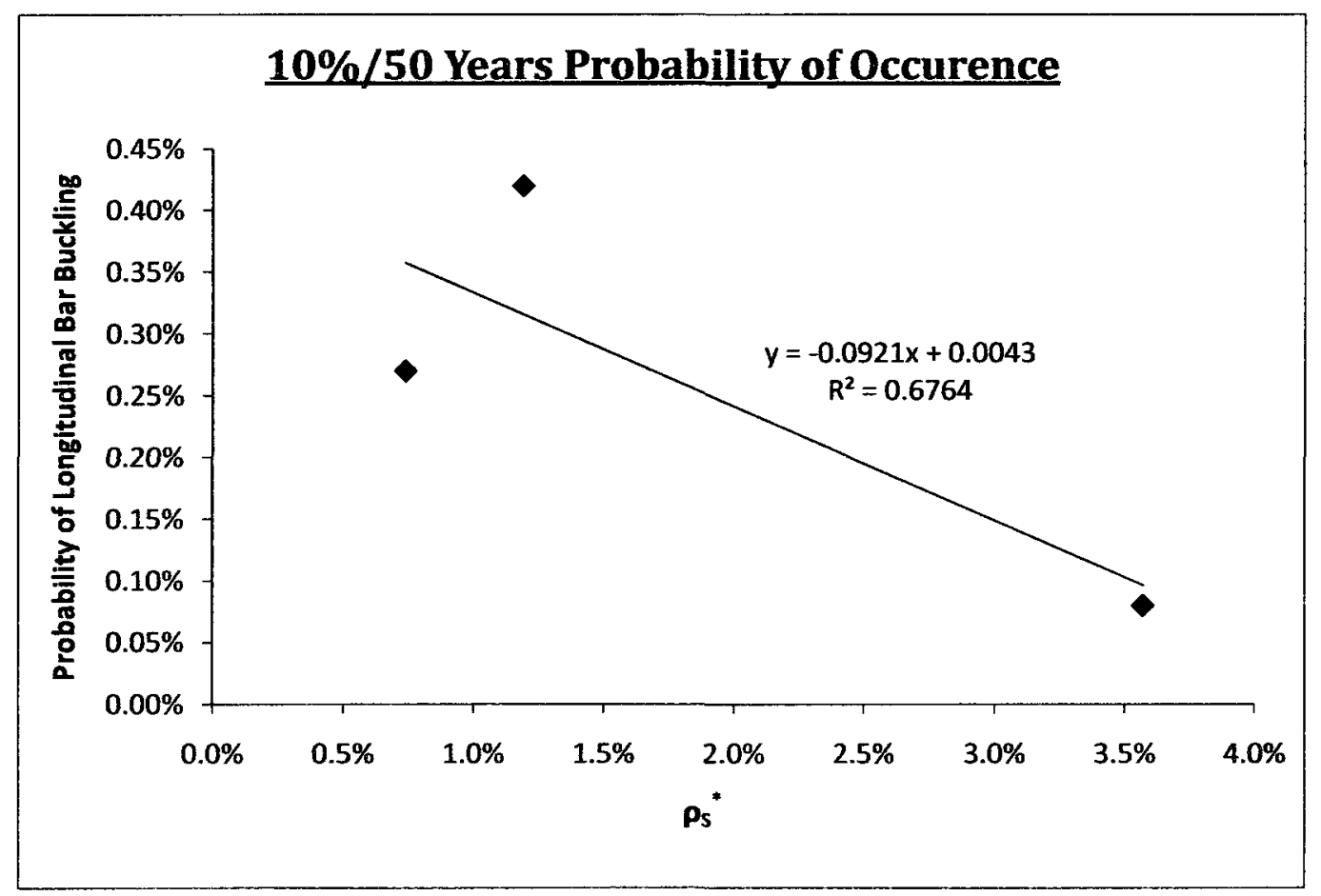

Figure 4.18: Relationship between $\rho s^{*}$ and probability of longitudinal bar buckling for a moderate seismic event (10\%/50years) 


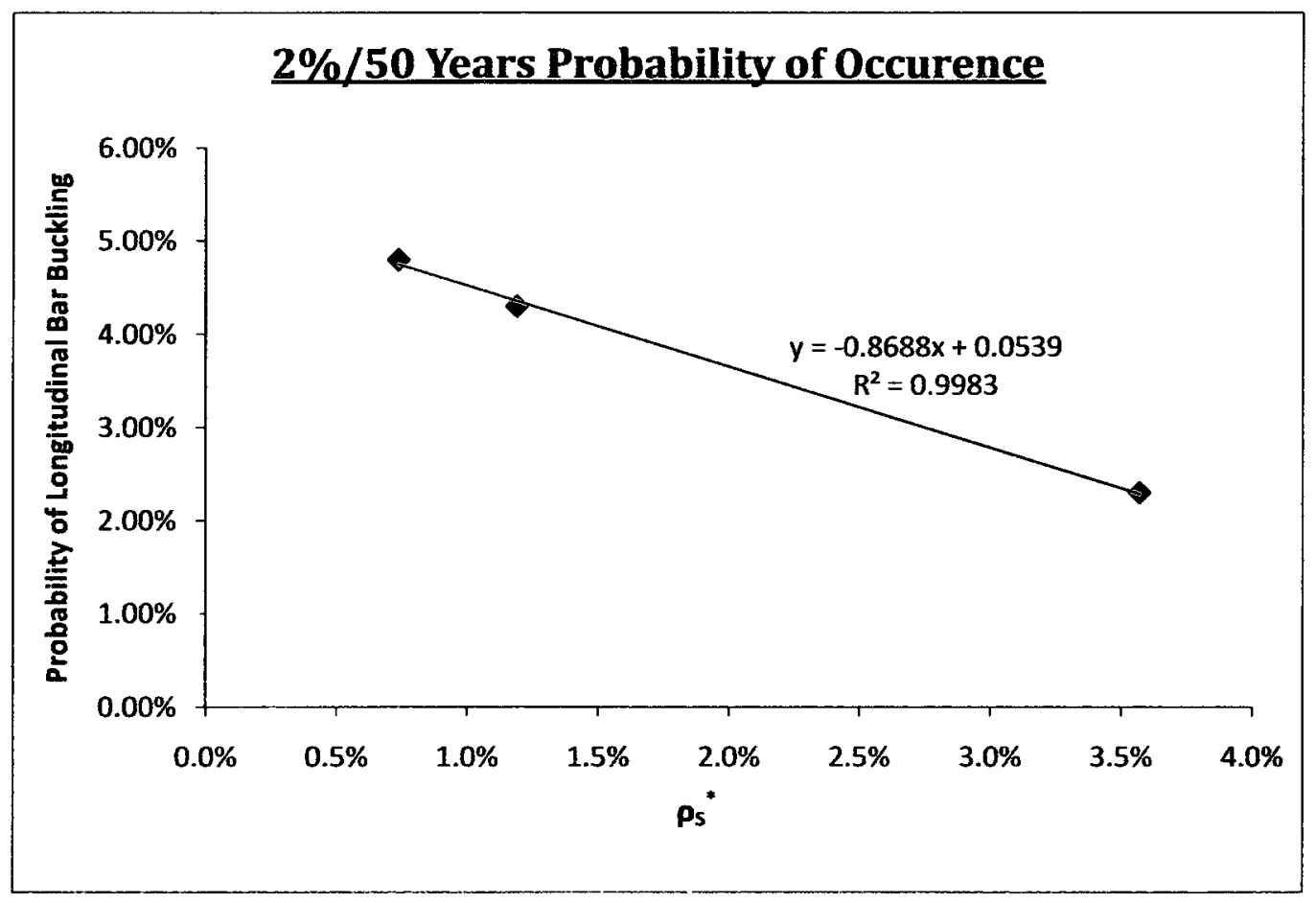

Figure 4.19: Relationship between $\mathrm{s}^{*}$ and probability of longitudinal bar buckling for an extreme seismic event $[2 \% / 50$ years] 


\section{Chapter 5 \\ Summary \& \\ Recommendations}

\subsection{Summary}

The objective of this research is to develop and apply a probabilistic performancebased seismic risk methodology based on easily identified structural characteristic parameters suitable for quick assessment of groups of bridges typically found in the inventory of Canadian cities. This process would allow for relatively inexpensive and fast evaluation of the bridge inventory in a region or network without the need of detailed evaluations of every bridge by non-linear time history analysis. Based on this process bridges most at risk could be identified and prioritized for detailed engineer evaluations. This process could also be used to red flag bridges most likely 
to experience damage should significant seismic activity occur. This would allow for better allocation of limited resources. Based on extensive literature review, there has not been similar research in the past on development of quick assessment methodologies for seismic risk assessment of large group of bridges.

In collaboration with the Bridge Infrastructure Division of the City of Ottawa, a sample representative group of bridges from the bridge structure inventory in the City have been selected for the present study. These bridges are selected as representative types of bridges in the area. Probabilistic performance-based seismic risk assessment methodologies developed in past research have been adapted to formulate and develop a new probabilistic assessment approach suitable for quick assessment of a large number of bridges without the need of carrying out detailed non-linear time-history dynamic analysis of the evaluated bridges. Two typical failure modes in reinforced concrete bridges are considered in the assessment. Probability of concrete spalling and longitudinal bar buckling of the piers are estimated for low, moderate and extreme seismic hazard events which represent the continual operational level seismic event, design level seismic event and collapse prevention seismic hazard event.

Nonlinear time history analyses of selected bridges have been carried out for the purpose of obtaining results to calibrate the quick assessment methodology. Fragility relationships relating potential or probability of damage to easily identified or determined structural performance characteristic parameters of the evaluated bridges have been developed. Three separate structural performance characteristic 
parameters have been selected in the present study. These are the effective longitudinal reinforcement ratio $\left(\rho_{L}{ }^{*}\right)$, effective transverse reinforcement ratio $\left(\rho_{S}^{*}\right)$ and effective span over height ratio (span/L*) of the bridge piers. The results show that structural performance characteristic parameters $\rho_{L}{ }^{*}$ and $\rho_{S}{ }^{*}$ both act as good performance parameters for developing fragility relationships for determining the probability of longitudinal bar buckling for the extreme seismic event and that Span/L works well for determining the probability of spalling for all seismic events levels and for the low and moderate seismic event levels for probability of longitudinal bar buckling.

Based on the fragility relationships developed based on calibrations of the nonlinear time-history analysis results of selected bridges the seismic risk of the remaining bridges in the sample inventory are evaluated. From the assessment results obtained using the developed fragility relationships, an order or priority list of the bridges can be established based on the evaluated vulnerability to seismic damage of the bridges.

\subsection{Recommendations}

The present research has developed a new quick assessment approach for probabilistic-based seismic risk assessment of large groups or inventories of bridges. It has demonstrated the process by which detailed nonlinear dynamic time history analysis results can be used to develop and calibrate general fragility 
relationships which then can be used to establish a priority list of vulnerable bridges for further detailed evaluation. The purpose herein is to demonstrate the framework and steps in the new probabilistic performance-based seismic risk assessment methodology based on easily determined structural characteristic parameters. The accuracy and reliability of the established fragility relationships between potential or probability of failure or damage with the selected structural characteristic parameters could be improved by more extensive nonlinear time history bridge analysis results in their calibration. To improve the robustness of the quick assessment methodology developed here, it is important that a database of more variety of bridges be considered in the development of the generalized fragility relationship. Separating bridges in the inventory into different classes and sub-classes based on geometric details, such as number of columns per bent, horizontal curves, skew, span numbers, etc, would improve the accuracy of the fragility relationships. Once a large sample of bridges has been evaluated, inventories could be grouped into similar classes and sub-classes and compared to the evaluated bridges of the same class. This would allow for more representative projections.

This research is a first attempt of its kind for developing a quick assessment methodology suitable for estimating the seismic risk and vulnerability of large groups or inventories of bridges. The primary objective here is to demonstrate the advantages and benefits of the proposed quick assessment methodology. There are areas which can be improved in future investigations. The quick assessment methodology can be improved by incorporating seismic microzonation hazard 
information (Motazedian, 2010) in the seismic hazard assessment stage to account for the soil-structure interaction and influence of the local site condition on the seismic behavior and performance of bridges.

In addition, only two common bridge damage and failure mechanisms have been considered in this research: concrete column spalling and longitudinal bar buckling. There are other modes of damage and failure that may also have significant impact on the progressive damage and collapse behavior of bridges. Future research should look at other probable failure mechanisms such as shear failure of columns or loss of span. 


\section{References}

Adams, J. and S. Halchuk. Fourth generation seismic hazard maps of Canada: Maps and grid values to be used with the 2005 National Building Code of Canada; Geological Survey of Canada, Open File 5813, 2008; 32 pages. Available from http://earthquakescanada.nrcan.gc.ca/ ca as of June 12, 2009

Atkinson, $\mathrm{G}$ and Beresnev, I. Compatible Ground-Motion Time Histories for New National Seismic Hazard Maps. Canadian Journal of Civil Engineering. April 1998. pg.305

Aviram. A, K. Mackie and B. Stojadinovic. Guidelines for Nonlinear Analysis of Bridge Structures in California. PEER Report 2008/03, Pacific Earthquake Engineering Research Center, University of California, Berkeley, August 2008.

Berry, M. P., and M. 0. Eberhard. Performance models for flexural damage in reinforced concrete columns. PEER Report 2003/18, University of California, Berkeley, California; 2003.

Berry, M. P., M. Parrish, and M. O. Eberhard. 2004. PEER structural performance database user's manual. Pacific Earthquake Engineering Research Center. University of California, Berkeley, California.

http://nisee.berkeley.edu/spd/performance database manual 1-0.pdf 
Chai, Y.H., M.J.N. Priestley, and F. Seible. Seismic Retrofit of Circular Bridge Columns for Enhanced Flexural Performance, ACI Structural Journal, Vol. 88, No.5, September/October 1991, pp. 572-584

Cornell C. A. Calculating building seismic performance reliability; a basis for multilevel design norms. Proc. Eleventh Conf. on Earthquake Engineering, Acapulco, Mexico; 1996

Dutta, A. and J.B. Mander. Seismic Fragility Analysis of Highway Bridges. Proc., INCEDE-MCEER Centre-to-Centre Workshop on Earthquake Engineering Frontiers in Transportation Systems, Tokyo, Japan, 311-325., 1998.

Fung, G.G., R.J. Lebeau, E.D, Klein, J. Belvedere and A.F. Goldschmidt. Field Investigation of Bridge Damage in the San Fernando Earthquake. Technical Report, Bridge Department, Sacramento: California Department of Transportation, 1971.

Gasparini, D. and E. Vanmarcke. Evaluation of Seismic Safety of Buildings Report No.2: Simulated Earthquake Motions Compatible with Prescribed Response Spectra. Publication No.R76-4, January 1976.

Jalayer, F. and C. Cornell. A Technical Framework for Probability-Based Demand and Capacity Factor Design (DCFD) Seismic Formats. PEER Report 2003/08 Pacific Earthquake Engineering Center College of Engineering University of California Berkeley, November 2003 
Kennedy, R. P., S. A. Short. Basis for seismic provisions of DOE-STD-1020 1994.

UCRLCR-111478, Prepared for U.S. Department of Energy, Washington, D.C.;1994.

Kunnath, Sashi K. Application of the PEER PBEE Methodology to the I-880 Viaduct. PEER Report 2006/10, Pacific Earthquake Engineering Research Center, College of Engineering, University of California, Berkeley; February 2007

Lin, Lan and John Adams. Strong Motion Records of the Val-des-Bois, Quebec, Earthquake of June 23, 2010. Canadian Hazard Information Service Internal Report 2010-1.1

Mackie, K., and Božidar Stojadinović. Fragility Basis for California Highway Overpass Bridge Seismic Decision Making. PEER Report 2005/02 Pacific Earthquake Engineering Research Center College of Engineering University of California, Berkeley June 2005

Mackie, K., John-Michael Wong, and Bozidar Stojadinovic. Integrated Probabilistic Performance-Based Evaluation of Benchmark Reinforced Concrete Bridges. PEER Report 2007/09. Pacific Earthquake Engineering Research Centre. University of California, Berkeley. January 2008.

Mander, J.B., M.J.N. Priestley, and R. Park 1984. Theoretical Stress-Strain Model for Confined Concrete. Journal of Struc-tural Engineering. ASCE. 114(3). 1804-1826.

Medina, R., Seismic demands for non-deteriorating frame structures and their dependence on ground motions, Ph.D. Thesis, Department of Civil and Environmental 
Engineering, Stanford, CA., 2002

Motazedian D, J.A. Hunter, A. Pugin, K. Khaheshi Banab, and H. Crow. "Near Surface Geophysical Methods for Microzonation Studies in the City of Ottawa, Canada", Canadian Geotechnical Engineering Journal, 2010

Panagiotakos, T. and Michael Fardis. Deformation of Reinforced Concrete Members at Yielding and Ultimate. ACI Structural Journal. V.98, No.2. March-April 2001

Priestley, M.J.N., F. Seible and G.M. Calvi. Seismic Design and Retrofit of Bridges. New York: John Wiley \& Sons, 1996.

Priestley, M.J.N., F. Seible and G. MacRae. The Kobe Earthquake of January 17, 1995: Initial Impressions from a Quick Reconnaissance, Structural Systems Research Project, Report SSRP-94/06, University of California, San Diego, August 1992, pp. 226

Sewell R. T., G. R. Toro, and R. K. McGuire. Impact of ground motion characterization on conservatism and variability in seismic risk estimates. Report NUREG/CR-6467, U.S. Nuclear Regulatory Commission, Washington D.C. 1991.

Shinozuka, M., Swagata Banerjee, and Sang-Hoon Kim. Fragility Considerations in Highway Bridge Design. Technical Report MCEER-07-0023. December 14, 2007.

Shinozuka, M., Swagata Banerjee, and Sang-Hoon Kim. Statistical and Mechanistic Fragility Analysis of Concrete Bridges. Technical Report MCEER-07-0015. September $10,2007$. 
Shinozuka, M., M.Q. Feng, H. Kim, T. Uzawa and T. Ueda. Statistical Analysis of Fragility Curves. Technical Report MCEER-03-0002. June 16, 2003.

SIMQKE: A Program for Artificial Motion Generation. User Manual and

Documentation. Department of Civil Engineering. Massachusetts Institute of Technology. November 1976. 